\title{
Quaternized carbon quantum dots with broad- spectrum antibacterial activity for treatment of wounds infected with mixed bacteria
}

\section{Zhao Cheng-fei}

Fujian Medical University

\section{Xuewen Wang}

Fujian Medical University

Luying Yu

Fujian Medical University

\section{Lina Wu}

Fujian Medical University

\section{Xiaoli Hao}

Fujian Medical University

Liu Qicai

Fujian Medical University https://orcid.org/0000-0003-1766-9395

\section{Lin Li-qing}

Fujian Medical University

\section{Zhengjun Huang}

Fujian Medical University

\section{Shaohuang Weng}

Fujian Medical University

Ailin Liu ( $\square$ liuailinlal@163.com )

Fujian Medical University

\section{Xinhua Lin}

Fujian Medical University

\section{Article}

Keywords: Antimicrobial resistance, Quaternized carbon quantum dots, Broad-spectrum antibacterial activity, Quantitative proteomics, Antibacterial mechanism

Posted Date: November 23rd, 2020

DOI: https://doi.org/10.21203/rs.3.rs-103890/v1 
License: (c) (i) This work is licensed under a Creative Commons Attribution 4.0 International License. Read Full License

Version of Record: A version of this preprint was published at Acta Biomaterialia on November 12th, 2021. See the published version at https://doi.org/10.1016/j.actbio.2021.11.010. 


\section{Abstract}

Quaternized carbon quantum dots (qCQDs) with broad-spectrum antibacterial activity were synthesized by a simple green "one-pot" method using dimethyl diallyl ammonium chloride and glucose as reaction precursors. The qCQDs showed satisfactory antibacterial activity against both gram-positive and gramnegative bacteria. In rat models of wounds infected with mixed bacteria, qCQDs obviously restored the weight of rats, significantly reduced the death of rats from severe infection, and promoted the recovery and healing of infected wounds. Biosafety tests confirmed that qCQDs had no obvious toxic and side effects during the testing stage. The analysis of quantitative proteomics revealed that qCQDs mainly acted on the ribosomal proteins of gram-positive bacteria and significantly down-regulated the metabolization-related proteins of gram-negative bacteria. Real-time quantitative PCR verified the expression levels of genes corresponding to the proteins with significant differences expressed by the two species of bacteria after treated with qCQDs. The variation trend of the detected genes was consistent with the results of proteomics, meaning that qCQDs played the antibacterial effect on bacteria with a new antibacterial mechanism.

\section{Introduction}

There is no doubt that bacterial infectious diseases have always posed a serious threat to human health and are always a sever challenge for medical workers. With the widespread and extensive use of antibiotics for the last 70 years or so, antimicrobial resistance (AMR) has become an imminent threat to the effective treatment of bacterial infections. The Review on Antimicrobial Resistance chaired by Jim O'Neill has predicted that the burden of deaths from AMR could balloon to 10 million lives each year by 2050, at a cumulative cost to global economic output of 100 trillion USD ${ }^{1}$. Thus, novel antimicrobial agents against severely resistant bacteria are urgently needed to address the problem. Otherwise, we may be entering a post-antibiotic era where advances in modern medicine would be jeopardized, resulting in an increase in serious infections ${ }^{2}$. In response to increasing antibiotic resistance in bacteria, alternatives different from traditional antibiotics are being investigated, including antibodies, probiotics, bacteriophages and antimicrobial peptides currently undergoing clinical trials, and advancements within artificial intelligence, biotechnology, genetic engineering and synthetic chemistry have opened up new avenues towards the search for therapies that can substitute for antibiotics ${ }^{3,4}$. However, extensive use of these alternatives is limited by the cost of production and limited shelf life, and the potential biotoxicity and the occurrence of new bacterial resistance always puzzle the application of various new technologies in research and development of antimicrobial drug. Thus, the exploitation of novel antimicrobial agents can not only realize the specific antibacteria of strains or species, but also achieve broad-spectrum antibacteria, so as to solve the bottleneck problem. Meanwhile, it is still an urgent task to clarify the molecular mechanism of antibacterial and avoid new bacterial resistance.

In more recent study, various nanomaterials have gradually emerged as excellent substitutes for antimicrobial agents, and have been widely explored for a broad range of bacterial infections via the 
photodynamic effect or/and photothermal ability ${ }^{5-7}$. Compared with reported nanomaterials, carbon nanomaterials (e.g. fullerenes, carbon nanotubes, graphenes, carbon quantum dots) with broad spectral coverage and other superior material properties have attracted wider attention in antibacterial and related applications in recent years ${ }^{8-10}$. Carbon quantum dots (CQDs), especially hetero-element doped CQDs with particle size of less than $10 \mathrm{~nm}$, stand out in the field of antibacterial research due to their advantageous properties including nontoxic nature, photostability, versatility in surface functionality for desired microbial adhesion and interactions, and their production from abundant and inexpensive precursors for extremely broad and low to ultralow cost applications ${ }^{11-16}$. At present, the mechanism of action of CQDs against bacteria mainly focuses on the three aspects of directly producing reactive oxygen species (ROS), such as superoxide $\left(\cdot \mathrm{O}_{2}{ }^{-}\right)$and hydroxyl radical $(\cdot \mathrm{OH}){ }^{17,18}$, producing ROS assisted by photoactivation or other compound ${ }^{6,19-21}$ and damaging the cell membrane caused by the insertion of surface controlled CQDs through electrostatic interaction and/or hydrophobic interaction ${ }^{22-24}$. However, the above mechanism cannot further explain the signaling pathway of antibacterial CQDs against bacteria at the molecular level and there has been a lack of in-depth understanding of the interaction between such CQDs and bacteria. And the understanding of the molecular target of CQDs to bacteria will help the precision design of antibacterial CQDs for overcoming the need of AMR.

Quaternary ammonium compounds (QACs) with cationic groups can predominantly act on cytoplasmic (inner) membrane in bacteria or plasma membrane in yeasts to play antibacterial action ${ }^{25}$. Besides, combination of quaternary ammonium groups (QAGs) and nanomaterials can introduce new effects for improving antibacterial properties and safety ${ }^{26-28}$. In the other hand, quaternary ammonium carbon nanomaterials have become an important way to develop carbon nanomaterials with antibacterial activity 22, 29,30. For example, lauryl betaine (QACs) modified carbon dots prepared from 3-[2-(2aminoethylamino)ethylamino]propyl-trimethoxysilane and glycerol as the precursors could selectively kill gram-positive bacteria ${ }^{29}$; a kind of quaternized carbon dots prepared from glycerol and quaternary ammonium-carrying organosilane could effectively disrupt the cell walls of gram-positive bacteria through the synergistic action of both electrostatic and hydrophobic interactions ${ }^{22}$; and graphene oxidequaternary ammonium salt nanocomposite exhibited the synergistic antibacterial activity on Staphylococcus aureus and Escherichia coli on the basis of the combined action of mechanical membrane perturbation and oxidative stress induction ${ }^{30}$. The above antibacterial mechanisms of CQDs functionalized with QAGs mainly focused on electrostatic interaction, hydrophobic interaction and oxidative stress. However, the mechanism of QAGs functionalized carbon nanomaterials on bacteria has not been elucidated at the molecular level. Revealing and exploring the molecular antibacterial mechanism of carbon nanomaterial will promote the development of new antibacterial agents.

In this work, dimethyl diallyl ammonium chloride (DDA) and glucose as precursors were used to directly synthesize quaternized carbon quantum dots (qCQDs) with broad-spectrum antibacterial activity by a simple green "one-pot" method (Scheme 1). The qCQDs had the antibacterial activity against both grampositive and gram-negative bacteria, including Staphylococcus aureus, methicillin-resistant 
Staphylococcus aureus, Staphylococcus epidermidis, Escherichia coli, Pseudomonas aeruginosa and Enterococcus faecalis. In addition to the advantages of simple preparation, convenient synthesis and low cost, qCQDs had different antibacterial mechanisms from traditional quaternary ammonium compounds and other carbon quantum dots with antibacterial activities. The quantitative proteomics based tandem mass tags revealed that the targets of qCQDs on gram-positive and gram-negative bacteria were different. The qCQDs mainly interfered with the ribosomal proteins of gram-positive bacteria, but downregulated a variety of metabolized-related proteins for gram-negative bacteria, among which the citrate cycle was the most significant. At the same time, the effects of qCQDs on the corresponding genes of related proteins of gram-positive and gram-negative bacteria were verified by real-time quantitative PCR (RT-qPCR). The qCQDs were used to treat the wounds infected with mixed bacteria (Staphylococcus aureus and Pseudomonas aeruginosa), showing the similar therapeutic effect as positive control antibiotic and the promising prospect of qCQDs for the cure of complex bacterial infection.

\section{Results}

\section{Characterization of qCQDs.}

The size distribution of carbon nanomaterials is not only the simple physical change, but also is able to affect their antibacterial activity ${ }^{31}$. Transmission electron microscope (TEM) image showed that the average diameter of qCQDs was about $3 \mathrm{~nm}$ with homogeneous size distribution (Fig. 1a). Highresolution TEM (HRTEM) showed that the well-resolved lattice fringe with intercrystalline spacings of qCQDs was $0.22 \mathrm{~nm}$ (Fig. 1b), corresponding to the (100) facets of graphitic carbon ${ }^{18,32}$. The particle size of qCQDs measured by dynamic light scattering (DLS) was centered at $4.5 \mathrm{~nm}$ with relatively concentrated distribution, suggesting the consistent and uniform morphology of qCQDs confirmed from TEM.

The optical property of qCQDs was evaluated. UV-vis absorption spectrum (Fig. 1d) of qCQDs showed $\pi \rightarrow \pi^{*}$ transition of $\mathrm{C}=\mathrm{C}$ (aromatic sp ${ }^{2}$ domains) at $225 \mathrm{~nm}$ and $\mathrm{n} \rightarrow \pi^{*}$ transition of $\mathrm{C}=0$ and $\mathrm{C}-\mathrm{O}$ at 283 $\mathrm{nm}^{33}$. The maximum emission wavelength of qCQDs fluorescence increased with the red shift of excitation wavelength (Fig. 1e), suggesting the excitation-dependent luminescence behavior ${ }^{32}$. And qCQDs generated a fluorescence spectrum with the maximum emission wavelength at $455 \mathrm{~nm}$ under the excitation wavelength of $355 \mathrm{~nm}$ (red arrows in Fig. 1e). Furthermore, Fig. $1 \mathrm{f}$ showed the typical mirror symmetry of maximum emission spectrum (black) and the maximum excitation spectrum (red). Using quinine sulfate in $0.5 \mathrm{~mol} / \mathrm{L} \mathrm{H}_{2} \mathrm{SO}_{4}$ as standard reference ${ }^{34}$, the fluorescent quantum yield of qCQDs was calculated to be $4.61 \%$ when the excitation wavelength was at $355 \mathrm{~nm}$, suggesting the acceptable luminescence property.

The molecular functional groups of qCQDs was investigated by fourier transform infrared spectroscopy (FTIR) and nuclear magnetic resonance spectroscopy (NMR), as shown in Fig. 2. The FTIR absorption peaks of DDA at $3027 \mathrm{~cm}^{-1}$ and $2983 \mathrm{~cm}^{-1}$ and glucose at $2944 \mathrm{~cm}^{-1}$ and $2913 \mathrm{~cm}^{-1}$, were attributed to 
asymmetric telescopic vibration and symmetric telescopic vibration of C-H bond, respectively ${ }^{29}$. The qCQDs formed by DDA reacting with glucose still exhibited the absorption peaks of asymmetric telescopic vibration and symmetric telescopic vibration of $\mathrm{C}-\mathrm{H}$ bond at $3029 \mathrm{~cm}^{-1}$ and $2933 \mathrm{~cm}^{-1}$, while the characteristic absorption peaks attributing to the aldehyde group in glucose at $2796 \mathrm{~cm}^{-1}$ and 2694 $\mathrm{cm}^{-1}$ disappeared in qCQDs, suggesting that the aldehyde group was destroyed in the synthetic process of qCQDs. The absorption peaks of qCQDs at $1646 \mathrm{~cm}^{-1}$ and DDA at $1643 \mathrm{~cm}^{-1}$ were attributed to the contraction vibration generated by the $\mathrm{C}=\mathrm{C}$ double bond, indicating the new formation of $\mathrm{C}=\mathrm{C}$ double bond in qCQDs or the retaining of $\mathrm{C}=\mathrm{C}$ double bond of DDA in qCQDs. The absorption peaks of qCQDs at $1473 \mathrm{~cm}^{-1}$ was attributed to the shear plane bending vibration of $\mathrm{C}-\mathrm{H}$ in $-\mathrm{N}^{+}\left(\mathrm{CH}_{3}\right)_{2}$, which was consistent with the absorption peak of $-\mathrm{N}^{+}\left(\mathrm{CH}_{3}\right)_{2}$ - in DDA at $1479 \mathrm{~cm}^{-1}$, confirming that qCQDs was functionalized with quaternary ammonium groups ${ }^{27}$. The absorption peaks at $1380 \mathrm{~cm}^{-1}$ and $1340 \mathrm{~cm}^{-1}$ caused by inplane bending vibration of $\mathrm{O}-\mathrm{H}$ single bond in glucose, and a series of absorption peak at $1295 \mathrm{~cm}^{-1}$, $1224 \mathrm{~cm}^{-1}, 1203 \mathrm{~cm}^{-1} 1149 \mathrm{~cm}^{-1}$ and $1110 \mathrm{~cm}^{-1}$ (yellow area in Fig. 2a) generated by the C-O-H bond in glucose, disappeared in qCQDs. The absorption peaks of symmetric telescopic vibration at $1078 \mathrm{~cm}^{-1}$ and $1035 \mathrm{~cm}^{-1}$ in qCQDs were ascribed to alkyl aromatic ether, indicating that aromatic ether structure existed in qCQDs. The absorption peaks of qCQDs at $962 \mathrm{~cm}^{-1}$ and $879 \mathrm{~cm}^{-1} \mathrm{might}$ be generated by the telescopic vibration of $\mathrm{C}-\mathrm{C}$ and $\mathrm{C}-\mathrm{O}$, respectively. NMR was further applied to investigate glucose, DDA and qCQDs using $\mathrm{D}_{2} \mathrm{O}$ as solvent ${ }^{27}$. The ${ }^{1} \mathrm{H}$ NMR spectra in Fig. $2 \mathrm{~b}$ revealed that the peaks of the proton signals of glucose at green area almost disappeared in qCQDs. Nevertheless, the proton peaks of $\mathrm{C}=\mathrm{C}$ (6.21 and $5.89 \mathrm{ppm}),-\mathrm{CH}_{2}-(4.07 \mathrm{ppm})$ and $-\mathrm{N}^{+}\left(\mathrm{CH}_{3}\right)_{2}-(3.18 \mathrm{ppm})$ in DDA remained in qCQDs with a chemical shift of about $0.13 \mathrm{ppm}$. The results of ${ }^{1} \mathrm{H}$ NMR spectra signified that glucose dehydroxylated and deprotonated to form $\mathrm{C}=\mathrm{C}$ double bonds and polymerized with DDA to obtain carbon quantum dots modified by quaternary ammonium groups. Compared with DDA, the chemical shift of the proton peaks of $\mathrm{C}=\mathrm{C}(6.08$ and $5.75 \mathrm{ppm}),-\mathrm{CH}_{2}-(3.93 \mathrm{ppm})$ and $-\mathrm{N}^{+}\left(\mathrm{CH}_{3}\right)_{2}-(3.05 \mathrm{ppm})$ in qCQDs to high field may be due to the effect that the qCQDs contained more quaternary ammonium groups and formed more conjugated systems, which weakened the electronegativity in their structures and generated shielding effect, causing the proton peaks to shift toward high field ${ }^{35}$.

The percentage content, chemical state and chemical bond of elements in qCQDs were further analyzed by X-ray photoelectron spectroscopy (XPS), as shown in Fig. 2. The XPS spectrum of qCQDs (Fig. 2c) showed the three main elements, i.e. C, $\mathrm{N}$ and $\mathrm{O}$, with the corresponding percentages of $72.45 \%, 6.21 \%$ and $21.23 \%$, respectively. Fig. $2 \mathrm{~d}$ showed that the high resolution peaks of $\mathrm{C} 1 \mathrm{~s}$ at the positions of 284.2 and $284.8 \mathrm{eV}$ corresponded to $\mathrm{C}-\mathrm{C}$ single bond/ $\mathrm{C}=\mathrm{C}$ double bond of graphene carbon ${ }^{32}$. And the peaks at the positions of $285.6,286.1$ and $286.8 \mathrm{eV}$ corresponded to $\mathrm{C}-\mathrm{N}$ single bond ( $\mathrm{sp}^{3}$ hybrid carbon), C-O single bond ( $\mathrm{sp}^{3}$ hybrid carbon) and $\mathrm{C}=0$ double bond, respectively ${ }^{36}, 37$. Fig. 2e showed that the peaks of $\mathrm{N} 1 \mathrm{~s}$ at $399.6 \mathrm{eV}$ and $401.3 \mathrm{eV}$ were attributed to $\mathrm{C}-\mathrm{N}-\mathrm{C}$ structure like pyridine type, and the peaks at 401.9 $\mathrm{eV}$ and $402.6 \mathrm{eV}$ were assigned to the positively charged quaternary ammonium group $\left(-\mathrm{N}^{+}\left(\mathrm{CH}_{3}\right)_{2}{ }^{-}\right)$, indicating the doping effect of $\mathrm{N}$ element and quaternary ammonium group in qCQDs ${ }^{26,38,39}$. The high- 
resolution results of $01 \mathrm{~s}$ (Fig. 2f) showed the peak of $\mathrm{C}=0$ double bond (carbonyl oxygen) at the binding energy of $531.3 \mathrm{eV}$ and the peaks $\mathrm{C}-\mathrm{O}$ single bond ( $\mathrm{sp}^{2}$ hybrid oxygen) at the position of $531.9 \mathrm{eV}$ and $532.5 \mathrm{eV}$. According to the results of TEM, FTIR, NMR and XPS, it was deduced that qCQDs contained carbon core and functional groups including quaternary ammonium group $\left(-\mathrm{N}^{+}\left(\mathrm{CH}_{3}\right)_{2}-\right)$, carbonyl group $(\mathrm{C}=\mathrm{O})$ and typical graphene carbon $(\mathrm{C}-\mathrm{C} / \mathrm{C}=\mathrm{C})$.

\section{In vitro antibacterial activity of qCQDs.}

The antibacterial activity of qCQDs on different species of bacteria was investigated (Fig. 3). Disk a, b and c on MHA plates contained $0.2 \mathrm{mg}$ of qCQDs, $0.2 \mathrm{mg}$ of glucose and $0.2 \mathrm{mg}$ of DDA, respectively. Four species of gram-positive bacteria (S. aureus, MRSA, S. epidermidis and E. faecalis) and two species of gram-negative bacteria ( $E$. coli and $P$. aeruginosa) were used as model bacteria to evaluate the antibacterial activity of qCQDs. Obvious inhibition zones appeared around disk a (qCQDs) on all the MHA plates with incubated bacteria, and the diameters of inhibition zones were more than $10 \mathrm{~mm}$. In contrast, there was no inhibition zone around disk $b$ (glucose) or c (DDA), indicating no antibacterial activity of two reaction substrates. Moreover, the minimum inhibitory concentration (MIC) of qCQDs on the above six species of bacteria was determined by broth dilution method, as shown in Supplementary Table 1. The MIC of qCQDs was $12.5 \mu \mathrm{g} / \mathrm{mL}$ for $S$. epidermidis, $25 \mu \mathrm{g} / \mathrm{mL}$ for $S$. aureus, MRSA and E. faecalis, and 50 $\mu \mathrm{g} / \mathrm{mL}$ for both $E$. coli and $P$. aeruginosa. The above results confirmed that qCQDs exhibited antibacterial action on both gram-positive and gram-negative bacteria, implying the broad-spectrum antibacterial properties.

In order to better understand bactericidal and bacteriostatic effect of qCQDs, we investigated the number of colonies on nutrient agar plates after the six species of bacteria were exposed to different concentrations of qCQDs in different periods, as shown in Supplementary Fig. 1. When the concentration was up to $200 \mu \mathrm{g} / \mathrm{mL}$, the changing tendency of the six species of bacteria was similar to that of 100 $\mu \mathrm{g} / \mathrm{mL}$, indicating that qCQDs can effectively inhibit and kill the gram-positive and gram-negative bacteria at $100 \mu \mathrm{g} / \mathrm{mL}$. The detailed description for Supplementary Fig. 1 was provided in Supplementary Information.

\section{Antimicrobial mechanism of qCQDs against gram-positive bacteria and gram-negative bacteria.}

The morphological changes of the six species of bacteria before and after the treatment of qCQDs were characterized by TEM, as shown in Fig. 4. Without the treatment of qCQDs, all of the bacteria exhibited normal cell structure, complete cell walls, and uniform density of substance inside the cells (Fig. 4a, 4c, $4 \mathrm{e}, 4 \mathrm{~g}, 4 \mathrm{i}$ and $4 \mathrm{k}$ ). In comparison, after the treatment of $100 \mu \mathrm{g} / \mathrm{mL}$ qCQDs for $12 \mathrm{~h}$, bacterial cells were significantly changed with obviously broken cell wall and cell membrane (Fig. 4b, 4d, 4f, 4h, 4j and 4l). More specifically, the bacterial cells treated with qCQDs were disintegrated to different degrees, the cytoplasmic density of bacterial cells obviously decreased, and even the phenomenon of cavities and substance agglomeration occurred in the bacterial cells. And bacterial cells lost their integrity, causing irreversible damage to bacteria cells and resulting in death of bacteria 40,41 , which was completely 
different from the untreated bacteria. The morphology of the treated bacteria indicated that qCQDs had the significant destructive effects on the above six species of bacterial cells, confirming the killing effect of qCQDs on both gram-positive and gram-negative bacteria. Furthermore, using $S$. aureus and $E$. coli as the representative bacteria, flow nanoanalyzer was applied to measure the changes of particle size of bacteria before and after the treatment of qCQDs, as shown in Supplementary Fig. 2. For untreated $S$. aureus and E. coli, particles larger than $1000 \mathrm{~nm}$ accounted for $78.3 \%$ and $92.2 \%$ of the total particles, respectively. After $S$. aureus and E. coli were treated with qCQDs, particles larger than $1000 \mathrm{~nm}$ were significantly reduced in both bacteria. In addition, with the increase of qCQDs concentration from 50 to $100 \mu \mathrm{g} / \mathrm{mL}$ and then to $200 \mu \mathrm{g} / \mathrm{mL}$, particles larger than $1000 \mathrm{~nm}$ in the two species of bacteria decreased from $52 \% / 64.2 \%$ to $16.8 \% / 21.1 \%$ and then to $10.3 \% / 1.0 \%$, respectively, showing gradual decreasing trend. It is further confirmed that qCQDs could make bacterial cells lyse or disintegrate, resulting in death of the bacteria, which is consistent with the results observed by TEM.

The 2',7'-dichlorofluorescin-diacetate (DCFH-DA) as ROS probe was used to investigate whether or not ROS was generated in the process of qCQDs interacting with bacteria ${ }^{42}$. As shown in Supplementary Fig. 3 , DCFH-DA had little fluorescence at $520 \mathrm{~nm}$ with the interaction with $S$. aureus or E. coli. After $\mathrm{H}_{2} \mathrm{O}_{2}$ (ROS representative substance) was added, obvious fluorescence at $520 \mathrm{~nm}$ appeared in the both bacterial suspension. However, for the direct interacting system of qCQDs and bacteria, there was hardly any fluorescence at $520 \mathrm{~nm}$ in the both bacterial suspension containing DCFH-DA. Then, the above both bacterial suspension containing DCFH-DA and qCQDs showed obvious fluorescence at $520 \mathrm{~nm}$ with the addition of $\mathrm{H}_{2} \mathrm{O}_{2}$. Therefore, it is preliminarily inferred that almost no ROS generated in the process of qCQDs combating bacteria.

In order to elucidate the antibacterial mechanism of qCQDs against bacteria, S. aureus and E. coli were used as the representative gram-positive and gram-negative bacteria, respectively. And then, tandem mass tag (TMT)-based quantitative proteomics was performed to analyze the protein changes of bacteria before and after the treatment of qCQDs ${ }^{43}, 44$. Control group (C), low concentration group (L) and high concentration group $(\mathrm{H})$ were set up in the test of quantitative proteomics. After $S$. aureus and $E$. coli were treated with qCQDs, the analysis of differential expressed proteins was conducted by comparing $L$ with $\mathrm{C}$ and $\mathrm{H}$ with $\mathrm{C}$. With the increase of qCQDs concentration, the amount of the differential proteins with both up-regulated and down-regulated expression increased in $S$. aureus and $E$. coli, respectively, and the differential expressed proteins in $S$. aureus were significantly more than those in $E$. coli (Supplementary Fig. 4). After S. aureus and E. coli were treated with qCQDs, the identified proteins of the two bacteria were annotated in Cluster of Orthologous Groups of proteins (COG), showing that the functions of the proteins were mainly annotated in energy production and conversion, amino acid transport and metabolism, carbohydrate transport and metabolism, and translation, ribosomal structure and biogenesis (Supplementary Fig. 5). The enrichment analysis of Kyoto Encyclopedia of Genes and Genomes (KEGG) pathway revealed the proteins pathways with significant statistical differences. In the KEGG pathway for $S$. aureus, the differentially expressed proteins were mainly enriched in ribosome, RNA degradation, aminoacyl-tRNA biosynthesis and carbon fixation in photosynthetic organisms by 
comparing $\mathrm{L}$ with $\mathrm{C}$ and $\mathrm{H}$ with $\mathrm{C}$ (Supplementary Fig. 6). Ribosome, RNA degradation and aminoacyltRNA biosynthesis were mainly related to protein synthesis, among which the enrichment of ribosomal proteins showed the most significant difference $\left(\mathrm{p}=3.34 \times 10^{-5}\right)$. The 46 differentially expressed proteins were enriched in ribosomes by further analysis of KEGG chord diagram (Fig. 5a and Supplementary Table 2). The corresponding clustering heat map was drawn, and 33 ribosomal proteins were up-regulated and 13 were down-regulated by comparing $\mathrm{H}$ with $\mathrm{C}$ (Fig. $5 \mathrm{C}$ ). Correspondingly, for $E$. coli, the differentially expressed proteins in the KEGG pathway were mainly enriched in biosynthesis of antibiotics, microbial metabolism in diverse environments, citrate cycle, sulfur metabolism, metabolic pathways, biosynthesis of secondary metabolites, tryptophan metabolism, propanoate metabolism, carbon metabolism, lysine degradation, butanoate metabolism, benzoate degradation and nitrogen metabolism by comparing $L$ with $\mathrm{C}$ and $\mathrm{H}$ with $\mathrm{C}$ (Supplementary Fig. S8). Among them, further analysis of KEGG chord diagram showed that 10 differentially expressed proteins were enriched in the following six pathways (Fig. 5b and Table 3 ), including biosynthesis of antibiotics, microbial metabolism in diverse environments, citrate cycle, metabolic pathways, biosynthesis of secondary metabolites and carbon metabolism. And these 10 proteins are essential enzymes for the citrate cycle $\left(p=3.01 \times 10^{-5}\right)$ (Supplementary Fig. 8). The corresponding clustering heat map showed that the 10 differentially expressed proteins in citrate cycle were down-regulated by comparing $\mathrm{H}$ with $\mathrm{C}$ (Fig. 5d). After the differentially expressed proteins associated with ribosome in S. aureus and citrate cycle in E. coli were annotated in Gene Ontology (GO), the two types of proteins were classified according to cellular component, molecular function and biological processes, respectively. All the 46 ribosomal proteins belonged to intracellular cellular component which were mainly related to ribosomes, including large and small subunit, and involved in the biological process of protein translation, and their molecular functions were mainly focused on structural constituent of ribosome and RNA/rRNA binding (Supplementary Fig. 9). In contrast, the molecular function of the 8 proteins associated with citrate cycle were mainly concentrated in the activity of various enzymes, including aconitate hydratase, isocitrate dehydrogenase (NADP ${ }^{+}$), oxoglutarate dehydrogenase (succinyl-transferring), oxidoreductase and electron carrier, and the binding of thiamine pyrophosphate, metalion, cofactor and iron-sulfur cluster, and involved in the biological process including tricarboxylic acid cycle, metabolic process and oxidation-reduction process (Supplementary Fig. 10). Meanwhile, interaction analysis of differentially expressed proteins showed that 22 of the 46 ribosomal proteins were in the three protein functional interaction networks (Fig. 5e) and all the 10 proteins associated with citrate cycle were at the hub positions of the one protein functional interaction networks (Fig. 5f).

In order to gain insight into the contributions of ribosome and citrate cycle to the antibacterial action of qCQDs against $S$. aureus and E. coli, gene set enrichment analysis (GSEA) was conducted to further analyze the genes of differentially expressed proteins in KEGG pathways, and real-time quantitative PCR (RT-qPCR) was used to verify the expression of related protein genes. GSEA showed that there were positive and negative correlations in the function set of ribosomal proteins (Fig. 6a), but all the proteins in the function set of citrate cycle were negatively correlated (Fig. 6b), which were consistent with the differentially expressed proteins in Fig. $5 c$ and 5 d, respectively. At the same time, GSEA gave the 
sequence of the corresponding genes of the proteins in the function set. According to the rank in gene list, six proteins in $S$. aureus and $E$. coli were selected from the corresponding differentially expressed proteins, respectively, and the information of selected proteins was shown in Supplementary Table 5. The proteomics analysis showed that three ribosomal proteins were down-regulated and the other three were up-regulated after $S$. aureus was treated with qCQDs (Supplementary Fig. 11A). Fig. 6c showed the RTqPCR results of the corresponding genes of six ribosomal proteins in S. aureus. The gene expression of the six ribosomal proteins had no significant difference at the low-concentration of qCQDs. When $S$. aureus was treated with high-concentration of qCQDs, the gene expression of down-regulated and upregulated ribosomal proteins changed significantly, which was consistent with the variation trend in the proteomics. The proteomics analysis showed that all six proteins associated with citrate cycle in $E$. coli were down-regulated (Supplementary Fig. 11B). The RT-qPCR results in Fig. 6d showed that the gene expression of these six proteins had no significant difference at the low-concentration of qCQDs, while the gene expression of these six proteins significantly down-regulated at the high-concentration of qCQDs, corresponding to the variation trend of the six proteins in the proteomics.

\section{In vivo antibacterial activity of qCQDs.}

When the skin is compromised, bacteria from environment and skin surface are able to infiltrate into the subcutaneous tissue that is physiologically optimum for colonization and growth, eventually leading to wound infection. The impact of wound infections on health care is enormous, including burns, surgicalsite infections, and nonhealing diabetic foot ulcers. $S$. aureus and $P$. aeruginosa among the most common organisms isolated from both acute and chronic wounds of various etiologies have been attributed to causing infections of penetrating trauma and burn wounds in surgical site infections as well as in the military setting ${ }^{45}$. Double infections with $S$. aureus and $P$. aeruginosa is more virulent and/or results in worse patient outcomes than single infections, and both species are notorious for their resistance to antimicrobials ${ }^{46}$. Therefore, we established the rat trauma model with mixed infection of $S$. aureus and $P$. aeruginosa to evaluate the in vivo antibacterial activity of qCQDs. The experimental process was shown in Fig. 7a.

Fig. $7 \mathrm{~b}$ and Supplementary Fig. 12 showed the healing process of infected wounds and the bacterial culture of wound exudate at different times, respectively. A full-layer skin with a diameter of about $18 \mathrm{~mm}$ was resected with a scalpel on the back of the clean grade Sprague-Dawley (SD) rats to form the round wounds. After that, the application containing $2 \mathrm{~mL}$ of mixed bacterial suspension was adhered to the wound surface and fixed with mesh elastic bandage. The concentrations of both $S$. aureus and $P$. aeruginosa were about $3.0 \times 10^{8} \mathrm{CFU} / \mathrm{mL}$ in the mixed bacterial suspension. After $48 \mathrm{~h}$, the massive abscess appeared on the wounds. The qCQDs in the experimental group, levofloxacin in the positive control group, and normal saline in the negative control group were employed to treat the infected skin wounds, respectively, investigating the in vivo antibacterial activity of qCQDs. After treatment for 3 days, compared with the negative control group, the obvious scab was observed on the infected skin wounds with decreased exudate in the experimental group and the positive control group. After treatment for 5 days, although exudate appeared in all three groups, purulent lesions and the number of bacteria in the 
experimental group and the positive control group were significantly lower than that in the negative control group. After treatment for 7 days, exudate, purulent lesions and the number of bacteria significantly reduced in both the experimental group and the positive control group. After treatment for 10 days, the wound area in the experimental group and the positive control group significantly decreased, but the wound size in the negative control group was similar to that of the other two groups on the seventh day and there was still a large amount of exudate and numerous bacteria. After treatment for 14 days, the wounds in the two treated groups completely had no exudate and basically healed without detectable bacteria, but the wound size of the negative control group was the same as that of the two treated groups on the tenth days with the still present bacteria colonies. The above results indicated that qCQDs could promote the recovery of the wound infected with mixed bacteria, which had the same therapeutic effect as levofloxacin at a certain concentration.

Fig. 8a showed that three groups of SD rats lost weight after the wounds were infected with mixed bacteria for 48 hours, and the weight of the rats in the experimental group and the positive control group increased gradually after intervention. The increasing trend continued within 14 days. Meanwhile, the weight of the negative control group increased slowly in the first 6 days intervention, and always were lower than that of the experimental group and the positive control group. Within the whole course of intervention, the dead rats appeared in the negative control group on $2^{\text {nd }}, 3^{\text {rd }}, 5^{\text {th }}, 6^{\text {th }}$ and $9^{\text {th }}$ day, as shown in Fig. 8b, with a final survival rate of $56.4 \%$. All the rats of experimental group and positive control group survived in the treating process. The above results indicated that qCQDs could effectively combat the infection with mixed bacteria of $S$. aureus and $P$. aeruginosa, greatly contribute to the weight recovery of experimental rats, and significantly reduce the death rate of the rats.

H\&E staining was carried out on the pathological sections of the wound tissues after 48 hours infection and 14 days treatment to evaluate the recovery of the infected wounds in different groups, as shown in Fig. 8c. For the infected wounds, a large number of neutrophils appeared in the wound tissues, with enlarged blood vessels and increased blood cells (black arrow in Fig. 8c), which confirmed the successfully infected wounds with $S$. aureus and $P$. aeruginosa. After intervention for 14 days, capillaries in the wound tissues of the experimental group and the positive control group were significantly reduced, neutrophils basically disappeared, and obvious connective tissue formed on the surface of the wound (red arrow in Fig. 8c). In the negative control group, there were still a large number of neutrophils in wound tissues and many blood cells in the enlarged capillaries accompanying with the uncontrolled inflammation in the wounds after intervention for 14 days. The above results indicated that qCQDs were beneficial for the abatement of inflammation in the infected wound tissues and had similar therapeutic effect to levofloxacin in the wounds infected with mixed bacteria.

\section{Biosafety evaluation of qCQDs.}

At first, the possible induced drug resistance of qCQDs to bacteria was evaluated to assess the biosafety ascribed to the serious and common problem of bacterial antibiotic resistance. Supplementary Fig. 13 showed that $S$. aureus, E. coli and MRSA did not develop resistance to qCQDs after induced resistance for 
30 days at sub-MIC level, meaning that bacteria could not easily develop new or secondary resistance to qCQDs. It may be due to the fact that the qCQDs can play an antimicrobial role via new signaling pathways or effect targets that is different from the acting targets of traditional antibiotics. In vitro cytotoxicity of qCQDs was further investigated by MTT test based on the effects of qCQDs at different concentrations on macrophages and HepG2 cells at different times. As shown in Supplementary Fig. 14, when the concentration of qCQDs was $150 \mu \mathrm{g} / \mathrm{mL}$, the survival rates of macrophages (Supplementary Fig. 14a) and HepG2 (Supplementary Fig. 14b) were above $80 \%$ within 6 to 12 hours, and $67.3 \%$ and $70.7 \%$ after exposed for $24 \mathrm{~h}$, respectively. When the concentration reached $200 \mu \mathrm{g} / \mathrm{mL}$, the survival rates of the two kinds of cells were somewhat reduced with $63.2 \%$ and $42.9 \%$ after exposed for $24 \mathrm{~h}$. The above results showed that certain cytotoxic effects of qCQDs on eukaryotic cells would also occur in vitro when the concentration reached a high level. The reason might be the poor selectivity of qCQDs for target ascribed to the broad-spectrum antibacterial activity. In vitro hemolysis test was also conducted to verify whether qCQD s could cause erythrolysis. As can be seen from Supplementary Fig. 14c, when red blood cells were added to the sterilized water, the solution changed from colorless to red after centrifugation, meaning that red blood cells were ruptured due to different osmotic pressures inside and outside the cells. Red blood cells were added to normal saline containing different concentrations of qCQDs, and subjected to centrifugation. Red blood cells were deposited at the bottom of the centrifuge tube, and the solutions were still transparent and colorless. Even if the concentration of qCQDs reached $400 \mu \mathrm{g} / \mathrm{mL}$, compared with the negative control, the hemolysis rate is only $1.9 \%(<5 \%)$, as shown in Supplementary Fig. 14d, indicating that qCQDs would not cause red blood cells rupture and hemolysis in physiological conditions and has good blood compatibility.

The in vivo toxicity of qCQDs to the main organs (including heart, liver, spleen, lung and kidney) of rats was evaluated by pathomorphology, as shown in Supplementary Fig. 15. Rats in the experimental group were given with $4 \mathrm{mg} / \mathrm{mL}$ of qCQDs solution by continuous gavage at the dose of $5 \mathrm{~mL} /$ day for 7 days, and the control group was given with the same dose of sterilized normal saline by gavage. Within 7 days, the rats in the two groups showed normal activity, diet and mental state. H\&E-stained pathological sections of heart, liver, spleen, lung and kidney showed no significant difference in the tissue structure between the two groups, meaning that qCQDs would not cause pathological damage to main organs of rats by intragastric administration for 7 days. It may be the reason that qCQDs does not generate toxicity and side effects on the main organs of the body, or qCQDs can be converted into non-toxic substances for the main organs in the body. Thus, it is preliminarily concluded that qCQDs may be a kind of carbon nanomaterial without detectable in vivo toxicity for in vivo antibacterial applications.

\section{Discussion}

The qCQDs with the particle size of $3 \sim 4.5 \mathrm{~nm}$ showed the broad-spectrum antibacterial activity against gram-positive and gram-negative bacteria. It was confirmed by TEM that qCQDs could destroy the integrity of bacterial structure, make the substances inside the cell agglomerate and leak, and result in the death of bacteria. It is well known that the generation of ROS is the main combating mechanism of 
antibacterial nanomaterials with broad-spectrum antibacterial activity ${ }^{47}$. According to the results of ROS detection, we could clearly know that QCQDs did not generate ROS in the process of interaction with bacteria. Proteomics is an attractive omics technique that allows the identification of secreted active compounds, the selection of drug-targets and the elucidation of action mechanisms of drug candidates ${ }^{48}$. According to the comprehensive analysis of the quantitative proteomics, we further confirmed that qCQDs had different targets and pathways for generating antibacterial activity against $S$. aureus (gram-positive) and E. coli (gram-negative). The qCQDs mainly acted on ribosomal proteins in gram-positive bacteria to interfere with and disrupt the synthesis of bacterial protein, thus playing an antibacterial effects (Fig. 9a). For gram-negative bacteria, qCQDs mainly interfered with its cellular respiration by down-regulating the essential proteins in citrate cycle to further disrupt multiple relevant metabolic pathways in bacterial cells, thus producing antibacterial effects (Fig. 9b). RT-qPCR successfully verified the gene expression of six representative differentially expressed proteins screened from $S$. aureus and E. coli by interaction analysis of proteins and GSEA, respectively. Therefore, it is further confirmed that qCQDs against gram-positive and gram-negative bacteria had different target pathways and different antibacterial mechanisms to produce irreversible damage to bacteria and make bacteria rupture or lyse, leading to the death of bacteria. The antibacterial mechanisms of qCQDs on bacteria is obviously different from the common mechanism of ROS generation, electrostatic interaction, surface adsorption or peroxidase-like activity of antibacterial agents reported in the literature $23,30,33,42,49-51$. Compared with the reported representative antibacterial carbon nanomaterials (Supplementary Table 6) ${ }^{6}$ $24,30,33,42,52-55$, the mechanism of antibacterial action of the as-synthesized CQDs in this work provided a new way of thinking for studying the antibacterial mechanism of CQDs with broad-spectrum antibacterial activities. This study provides a feasible basis for the research and development of new antibiotics and the application of CQDs in the field of antibiotics. In addition, the application of quantitative proteomics combined with RT-qPCR in this study provides a feasible strategy for studying the antibacterial mechanism of antimicrobial CQDs at molecular level. The proved pathway of qCQDs on bacteria may also be extended as the new medicinal targets for the development of bactericidal agents.

In this work, biocompatible qCQDs functionalized by quaternary ammonium group without detectable resistance evolution was synthesized with DDA and glucose by a simple "one-pot" method. According to the analysis of quantitative proteomics, it was found that qCQDs exerted the antibacterial effect against gram-positive and gram-negative bacteria through different targets. The qCQDs exhibited effective therapeutic effects on the wounds infected with mixed bacteria in SD rats, and significantly reduced the death of rats caused by infection. This work provides a new feasible way to prepare carbon quantum dots with broad-spectrum antibacterial activity and study the antibacterial mechanism of carbon quantum dots on bacteria, and expends a new development direction for the preparation of novel carbon quantum dots with low risk of AMR evolution.

\section{Methods}

\section{Materials and reagents.}


$\mathrm{D}(+)$-glucose anhydrous (glucose), sodium chloride, acetone and chloral hydrate were purchased from Sinopharm Chemical Reagent Co., Ltd (Shanghai China). Dimethyl diallyl ammonium chloride (DDA) were purchased from Aladdin Biochemical Technology Co., Ltd (Shanghai China). Needle cartridge filter ( $\Phi$ 13, $0.22 \mu \mathrm{m}$ ) was purchased from Jinteng (Tianjin China). The Amicon Ultra $4 \mathrm{~mL}$ centrifugal filter with a membrane NMWL of $3 \mathrm{kDa}$ was purchased from Millipore (USA). Mueller-Hinton (MH) broth, Luria-Bertani (LB) broth and Mueller-Hinton (MH) agar were purchased from Qingdao Hope Bio-Technology Co., Ltd (Qingdao China). Columbia blood agar medium was from Jiangmen Caring Trading Co., Ltd (Jiangmen China). Sterile wound dressing $(6 \mathrm{~cm} \times 7 \mathrm{~cm})$ was purchased from Qingdao Hainuo Biological Engineering Co., Ltd (Qingdao China). Medical reticular elastic bandage (5 \#) was purchased from Healthy Sanitation Kingdom Medical Apparatus Co., Ltd (Foshan China). Polystyrene round-bottom tube $(5 \mathrm{~mL})$ was purchased from Corning Science México S.A. de C.V. (México). Levofloxacin hydrochloride capsules was from Jiangsu Fubang Pharmaceutical Co., Ltd (Lianyungang China). Staphylococcus aureus (S. aureus) (ATCC6538), S. aureus (ATCC43300), Staphylococcus epidermidis (S. epidermidis) (ATCC12228), Escherichia coli (E. coli) (ATCC25922), Pseudomonas aeruginosa (P. aeruginosa) (CMCC(B)10104), and Enterococcus faecalis (E. faecalis) (ATCC29212) were purchased from Shanghai Luwei Microbial Sci. \& Tech. Co. Ltd (Shanghai China). The standard strain of methicillin-resistant Staphylococcus aureus (MRSA) is S. aureus (ATCC43300). Milli-Q ultrapure water (18.2 M $\Omega \cdot \mathrm{cm}$; EMD Millipore, Billerica, MA, USA) was used in all experiments.

\section{Synthesis of qCQDs.}

Glucose and DDA were used as the reaction precursor to synthesize qCQDs. At first, glucose $(0.5 \mathrm{~g})$ was placed and heated at $150^{\circ} \mathrm{C}$ for $20 \mathrm{~min}$ in a $50 \mathrm{~mL}$ of round-bottomed flask, and then $1 \mathrm{~mL}$ of DDA was added into the flask and continually stirred for $150 \mathrm{~min}$ at $150{ }^{\circ} \mathrm{C}$. After that, it was cooled to room temperature to get the dark brown solid substance. After the addition of $10 \mathrm{~mL}$ of deionized water dissolved the solid substance, the solution was filtered with needle cartridge filter, and then was dialyzed in a cellulose dialysis bag with deionized water for $24 \mathrm{~h}$. After dialysis, the solid qCQDs were obtained via freeze-drying. A stock solution of qCQDs with accurately controlled concentration by deionized water was prepared for the subsequent experiments.

\section{In vitro antibacterial activity test of qCQDs.}

Bacterial culture and preparation of bacterial suspension were shown in Supplementary Information S1.1.

Disk diffusion test: the bacterial suspension with a concentration of $1.5 \times 10^{8} \mathrm{CFU} / \mathrm{mL}$ was smeared evenly with sterile medical swabs on the $\mathrm{MH}$ agar medium, and then the disks containing the tested substances (including qCQDs (a), glucose (b) and DDA (c)) were placed onto the above medium. The diameter of $\mathrm{MH}$ agar medium was $90 \mathrm{~mm}$. The center distance of all the disks was at least $24 \mathrm{~mm}$. After incubation at $35^{\circ} \mathrm{C}$ for $18 \mathrm{~h}$, the diameter of inhibition zone around each disk was measured. Each disk diffusion test was carried out three times independently. 
Broth dilution test: thirteen sterile test tubes $(12 \times 75 \mathrm{~mm})$ were placed in a row and numbered successively, $1.6 \mathrm{~mL}$ of $\mathrm{MH}$ broth was added into Tube No. 1, and $1.0 \mathrm{~mL}$ of $\mathrm{MH}$ broth was added into the remaining test tubes. After $0.4 \mathrm{~mL}$ of qCQDs solution with a concentration of $5.12 \mathrm{mg} / \mathrm{mL}$ was added into Tube No. 1 and mixed well, $1 \mathrm{~mL}$ in Tube No. 1 was taken out and added into Tube No. 2. After mixed fully, $1 \mathrm{~mL}$ in Tube No. 2 was taken out and added into Tube No. 3, and it was like this until Tube No. 11. The $1 \mathrm{~mL}$ in Tube No. 11 was taken out and discarded. Tube No. 12 without qCQDs was used as the blank growth control. At this time, the concentrations of qCQDs in each tube from No. 1 to No. 11 were successively $1024,512,256,128,64,32,16,8,4,2$ and $1 \mu \mathrm{g} / \mathrm{mL}$, and then $1 \mathrm{~mL}$ of bacterial suspension $\left(1.5 \times 10^{6} \mathrm{CFU} / \mathrm{mL}\right)$ was added into the tubes from No. 1 to No. 12 to obtain the bacterial concentration with $7.5 \times 10^{5} \mathrm{CFU} / \mathrm{mL}$ in each tube. The final concentrations of qCQDs in tubes from No. 1 to No. 12 were successively $512,256,128,64,32,16,8,4,2,1$ and $0.5 \mu \mathrm{g} / \mathrm{mL}$. After the above test tubes were incubated at $35^{\circ} \mathrm{C}$ for $16 \sim 20 \mathrm{~h}$, the lowest concentration of bacteria-free tube was the minimum inhibitory concentration (MIC) of qCQDs for the tested bacteria.

\section{Preparation of animal models with wounds of mixed bacterial infection.}

The animal experiments were performed in accordance with the Guidelines for Animal Experimentation and were approved by the Experimental Animal Ethics Committee of Fujian Medical University (No. FJMU IACUC 2019-0041). All the clean grade Sprague-Dawley (SD) rats in the experiments were purchased from the Experimental Animal Center of Fujian Medical University. The body weight of the SD rats were $250 \pm 20$ $\mathrm{g}$ in the experiment. A total of $18 \mathrm{SD}$ rats were randomly divided into three groups, i.e. experimental group (treated with qCQDs), positive control group (treated with levofloxacin), and negative control group (treated with sterilized saline). After the SD rats were anesthetized with $10 \%$ chloral hydrate solution (3 $\mathrm{mL} / \mathrm{kg}$ ) by intraperitoneal injection, the dorsal hair of the SD rats was shaved with a hair clipper and a nummular full-thickness skin was resected with a scalpel [15]. The diameter of all the wound was about $1.8 \mathrm{~cm}$, about the size of a dime, as shown in Supplementary Fig. 16. The operation was performed under aseptic conditions before the infection. The sterile wound dressing added with $2 \mathrm{~mL}$ of bacterial suspension was adhered to the nummular wound and was fastened with medical reticular elastic bandage. The bacterial suspension contained $S$. aureus and $P$. aeruginosa, both of which had concentrations of $1.5 \times 10^{8} \mathrm{CFU} / \mathrm{mL}$. Then, all the experimental SD rats were separately raised in cages at a standardized temperature. After $48 \mathrm{~h}$, the nummular wounds were infected with $S$. aureus and $P$. aeruginosa and the wound dressing with bacteria was discarded, obtaining the wound model infected with mixed bacteria. The wounds were observed and photographed before and after infection.

\section{Treatment of wounds infected with mixed bacteria.}

The infected wounds were treated with local application in this work. Experimental group and positive control group were treated with sterile wound dressing containing $2 \mathrm{~mL}$ of qCQDs solution $(2.5 \mathrm{mg} / \mathrm{mL})$ and the same volume of levofloxacin $(0.25 \mathrm{mg} / \mathrm{mL})$, respectively. Meanwhile, the negative control group was treated with the sterile wound dressing containing $2 \mathrm{~mL}$ of sterilized normal saline. The wound dressings were changed once a day in each group in the period of 14 days. On the $3^{\text {rd }}, 5^{\text {th }}, 7^{\text {th }}, 10^{\text {th }}$ and 
$14^{\text {th }}$ day from the start of treatment, the infected wounds were compared and photographed. On the $14^{\text {th }}$ day, all the experimental rats were sacrificed by euthanasia, and the tissues of wounds were harvested for bacterial culture of wound tissue and H\&E staining of histopathological sections. Within 14 days of treatment, the weight of rats in each group and the number of rats that died from infection were recorded, and the weight change curve and survival curve were plotted, respectively.

\section{In vitro cytotoxicity test of qCQDs.}

Mouse mononuclear macrophages (macrophages, RAW264.7) and human hepatoma cells (HepG2 cells) were selected to evaluate the toxicity of qCQDs by MTT assay. The $300 \mu \mathrm{L}$ of cell suspension $\left(2 \times 10^{4}\right.$ cells $/ \mathrm{mL}$ ) was added into 96 -well plates, and made the cell counts about 6000 cells/well. After incubation at $37{ }^{\circ} \mathrm{C}$ for $24 \mathrm{~h}$, the cells stuck to wall and the culture medium was discarded. The $300 \mu \mathrm{L}$ of culture medium containing different concentration of qCQDs were added into the preset wells, and the concentrations of qCQDs were $25,50,100,150$ and $200 \mu \mathrm{g} / \mathrm{mL}$, respectively. After incubation at $37^{\circ} \mathrm{C}$ for 6,12 and $24 \mathrm{~h}$, respectively, the culture medium was discarded, and $30 \mu \mathrm{L}$ of $0.5 \% \mathrm{MTT}$ solution and 70 $\mu \mathrm{L}$ of serum-free culture medium were added to each well, and then incubated at $37^{\circ} \mathrm{C}$ for $4 \mathrm{~h}$. After that, the MTT solution in each well was discarded and $300 \mu \mathrm{L}$ of DMSO was added. The absorbance of each well was measured by a microplate analyzer at a wavelength of $490 \mathrm{~nm}$ after the 96 -well plates were shaken at a low speed for 15 min on the oscillator. According to the measured absorbance value, the survival rate of cells was calculated.

\section{Hemolysis test of qCQDs.}

Human blood samples for hemolysis test were obtained from First Affiliated Hospital of Fujian Medical University with the consent of healthy volunteers. Firstly, a certain volume of blood was centrifuged at $1500 \mathrm{rpm}$ for $15 \mathrm{~min}$ to collect red blood cells. And then, the red blood cells were cleaned with normal saline three time with the assist of centrifugation. The $50 \mu \mathrm{L}$ of erythrocyte suspension was dispersed in $1 \mathrm{~mL}$ of normal saline containing different concentration of qCQDs, and the concentrations of qCQDs were $5,10,50,100,200$ and $400 \mu \mathrm{g} / \mathrm{mL}$, respectively. After incubation at $37^{\circ} \mathrm{C}$ for $3 \mathrm{~h}$, the erythrocyte suspension was centrifuged at $12000 \mathrm{rpm}$ for $15 \mathrm{~min}$. The absorbance of the supernatants at $540 \mathrm{~nm}$ was measured, and the hemolysis rate was calculated. Normal saline and sterilized water were used as negative and positive control, respectively.

\section{Preparation of bacteria samples for quantitative proteomics and RT-qPCR.}

S. aureus and E. coli as models were used for the study of quantitative proteomics and RT-qPCR. After $200 \mathrm{~mL}$ of $\mathrm{MH}$ broth was autoclaved, $200 \mu \mathrm{L}$ of bacterial suspension $\left(1.5 \times 10^{8} \mathrm{CFU} / \mathrm{mL}\right)$ was added and incubated at $37^{\circ} \mathrm{C}$ for $12 \mathrm{~h}$. Then, $1 \mathrm{~mL}$ of sterilized normal saline was added into control group (C1, C2, C3), $1 \mathrm{~mL}$ of qCQDs solution with a concentration of $6 \mathrm{mg} / \mathrm{mL}$ was added into low-concentration group $(\mathrm{L} 1, \mathrm{~L} 2, \mathrm{~L} 3)$, and $1 \mathrm{~mL}$ of qCQDs solution with a concentration of $60 \mathrm{mg} / \mathrm{mL}$ was added into highconcentration group $(\mathrm{H} 1, \mathrm{H} 2, \mathrm{H} 3)$. After incubation at $37^{\circ} \mathrm{C}$ for $12 \mathrm{~h}$, the above bacterial solutions were 
centrifuged at $5000 \mathrm{rpm}$ at $4{ }^{\circ} \mathrm{C}$ for $5 \mathrm{~min}$, and the bacterial precipitations were collected. After cleaning with pre-cooled PBS three times, the bacterial precipitates were stored at $-80{ }^{\circ} \mathrm{C}$ when not in use.

Detection of quantitative proteomics labeled with Tandem Mass Tags (TMT) was detailed in Supplementary Information S1.6. Real-time quantitative PCR (RT-qPCR) of bacteria treated with qCQDs was detailed in Supplementary Information S1.7, and primer sequences for RT-qPCR were listed in Supplementary Table 7.

\section{Declarations}

\section{Acknowledgements}

This work was financially supported by National Natural Science Foundation of China (81703477 and 21775023), Joint Funds for the Innovation of Science and Technology in Fujian Province (2017Y9121), Natural Science Foundation of Fujian Province (2019J01308) and University Distinguished Young Scientific Research Talent Training Program of Fujian Province.

\section{References}

1. J. O'Neill, Review on Antimicrobial Resistance: Tackling drug-resistant infections globally, Wellcome Trust and the Department of Health of UK Government (2016).

2. R. Sugden, R. Kelly, S. Davies, Combatting antimicrobial resistance globally. Nat. Microbiol. 1 (10), 16187 (2016).

3. C. Ghosh, P. Sarkar, R. Issa, J. Haldar, Alternatives to conventional antibiotics in the era of antimicrobial resistance. Trends Microbiol. 27 (4), 323-338 (2019).

4. J.M. Stokes, K.Yang, K. Swanson, W.G. Jin, A. Cubillos-Ruiz, N.M. Donghia, C.R. MacNair, S. French, L.A. Carfrae, Z. Bloom-Ackerman, V.M. Tran, A. Chiappino-Pepe, A.H. Badran, I.W. Andrews, E.J. Chory, G.M. Church, E.D. Brown, T.S. Jaakkola, R. Barzilay, J.J. Collins, A deep learning approach to antibiotic discovery. Cell 180 (4), 688-702.e13 (2020).

5. M.J. Meziani, X.L. Dong, L. Zhu, L.P. Jones, G.E. LeCroy, F. Yang, S.Y. Wang, P. Wang, Y.P. Zhao, L.J. Yang, R.A. Tripp, Y.P. Sun, Visible-light-activated bactericidal functions of carbon "Quantum" dots. ACS Appl. Mater. Inter. 8 (17), 10761-10766 (2016).

6. X.L. Nie, C.Y. Jiang, S.L. Wu, W.B.F. Chen, P.F. Lv, Q.Q. Wang, J.Y. Liu, C. Narh, X.M. Cao, R.A. Ghiladi, Q.F. Wei, Carbon quantum dots: A bright future as photosensitizers for in vitro antibacterial photodynamic inactivation. J. Photoch. Photobio. B 206, 111864 (2020).

7. D.I. Abu Rabe, M.M. Al Awak, F. Yang, P.A. Okonjo, X.L. Dong, L.R. Teisl, P. Wang, Y.A. Tang, N.Y. Pan, Y.P. Sun, L.J. Yang, The dominant role of surface functionalization in carbon dots' photo-activated antibacterial activity. Int. J. Nanomed. 14, 2655-2665 (2019).

8. A. Anand, B. Unnikrishnan, S.C.Wei, C.P. Chou, L.Z. Zhang, C.C. Huang, Graphene oxide and carbon dots as broad-spectrum antimicrobial agents-a minireview. Nanoscale Horiz 4 (1), 117-137 (2019). 
9. Q. Xin, H. Shah, A. Nawaz, W.J. Xie, M.Z. Akram, A. Batool, L.Q. Tian, S.U. Jan, R. Boddula, B.D. Guo, Q. Liu, J.R. Gong, Antibacterial carbon-based nanomaterials. Adv. Mater. 31 (45), 1804838 (2019).

10. M. Maas, Carbon nanomaterials as antibacterial colloids. Materials 9 (8), 617 (2016).

11. X.L. Dong, W.X. Liang, M.J. Meziani, Y.P. Sun, L.J. Yang, Carbon dots as potent antimicrobial agents. Theranostics 10 (2), 671-686 (2020).

12. I.A. Baragau, N.P. Power, D.J. Morgan, T. Heil, R.A. Lobo, C.S. Roberts, M.M. Titirici, S. Dunn, S. Kellici, Continuous hydrothermal flow synthesis of blue-luminescent, excitation-independent nitrogen-doped carbon quantum dots as nanosensors. J. Mater. Chem. A 8 (6), 3270-3279 (2020).

13. C.J. Wang, H.X. Shi, M. Yang, Y.J. Yan, E.Z. Liu, Z. Ji, J. Fan, A novel nitrogen-doped carbon quantum dots as effective fluorescent probes for detecting dopamine. J. Photoch. Photobio. A 391, 112374 (2020).

14. M. Kaur, M. Kaur, V.K. Sharma, Nitrogen-doped graphene and graphene quantum dots: A review onsynthesis and applications in energy, sensors and environment. Adv. Colloid. Interfac. 259, 44-64 (2018).

15. C.F. Zhao, X.W. Wang, L.N. Wu, W. Wu, Y.J. Zheng, L.Q. Lin, S.H. Weng, X.H. Lin, Nitrogen-doped carbon quantum dots as an antimicrobial agent against Staphylococcus for the treatment of infected wounds. Colloid. Surface. B 179, 17-27 (2019).

16. C.F. Zhao, L.N.Wu, X.W. Wang, S.H. Weng, Z.P. Ruan, Q.C. Liu, L.Q. Lin, X.H. Lin, Quaternary ammonium carbon quantum dots as an antimicrobial agent against gram-positive bacteria for the treatment of MRSA-infected pneumonia in mice. Carbon 163, 70-84 (2020).

17. N.A. Travlou, D.A. Giannakoudakis, M. Algarra, A.M. Labella, E. Rodriguez-Castellon, T.J. Bandosz, Sand N-doped carbon quantum dots: Surface chemistry dependent antibacterial activity. Carbon 135, 104-111 (2018).

18. P.L. Li, F.X. Han, W.W. Cao, G.K. Zhang, J.Y. Li, J.W. Zhou, X.D. Gong, G. Turnbull, W.M. Shu, L.G. Xia, B. Fang, X.D. Xing, B. Li, Carbon quantum dots derived from lysine and arginine simultaneously scavenge bacteria and promote tissue repair. Appl. Mater. Today 19, 100601 (2020).

19. P. Yadav, S.T. Nishanthi, B. Purohit, A. Shanavas, K. Kailasam, Metal-free visible light photocatalytic carbon nitride quantum dots as efficient antibacterial agents: An insight study. Carbon 152, 587-597 (2019).

20. X.L. Nie, S.L. Wu, A. Mensah, K.Y. Lu, Q.F. Wei, Carbon quantum dots embedded electrospun nanofibers for efficient antibacterial photodynamic inactivation. Mat. Sci. Eng. C-Mater 108, 110377 (2020).

21. O. Moradlou, Z. Rabiei, N. Delavari, Antibacterial effects of carbon quantum dots@hematite nanostructures deposited on titanium against Gram-positive and Gram-negative bacteria. J. Photoch. Photobio. A 379, 144-149 (2019).

22. J.J. Yang, G. Gao, X.D. Zhang, Y.H. Ma, X.K. Chen, F.G. Wu, One-step synthesis of carbon dots with bacterial contact-enhanced fluorescence emission: Fast Gram-type identification and selective Grampositive bacterial inactivation. Carbon 146, 827-839 (2019). 
23. H.H. Ran, X.T. Cheng, Y.W. Bao, X.W. Hua, G. Gao, X.D. Zhang, Y.W. Jiang, Y.X. Zhu, F.G. Wu, Multifunctional quaternized carbon dots with enhanced biofilm penetration and eradication efficiencies. J. Mater. Chem. B 7 (33), 5104-5114 (2019).

24. H.J. Jian, J.T. Yu, Y.J. Li, B. Unnikrishnan, Y.F. Huang, L.J. Luo, D.H.K. Ma, S.G. Harroun, H.T. Chang, H.J. Lin, J.Y. Lai, C.C. Huang, Highly adhesive carbon quantum dots from biogenic amines for prevention of biofilm formation. Chem. Eng. J. 386, 123913 (2020).

25. A.M. Carmona-Ribeiro, L.D.D. Carrasco, Cationic antimicrobial polymers and their assemblies. Int. J. Mol. Sci. 14 (5), 9906-9946 (2013).

26. Y.W. Zhu, C. Xu, N. Zhang, X.K. Ding, B.R. Yu, F.J. Xu, Polycationic synergistic antibacterial agents with multiple functional components for efficient anti-infective therapy. Adv. Funct. Mater. 28 (14), 1706709 (2018).

27. H. Xu, Z.H. Fang, W.Q. Tian, Y.F. Wang, Q.F. Ye, L.N. Zhang, J. Cai, Green fabrication of amphiphilic quaternized beta-chitin derivatives with excellent biocompatibility and antibacterial activities for wound healing. Adv. Mater. 30 (29), 1801100 (2018).

28. Y.J. Pu, Z. Hou, M.M. Khin, R. Zamudio-Vazquez, K.L. Poon, H.W. Duan, M.B. Chan-Park, Synthesis and antibacterial study of sulfobetaine/quaternary ammonium-modified star-shaped poly[2(dimethylamino)ethyl methacrylate]-based copolymers with an inorganic core. Biomacromolecules 18 (1), 44-55 (2017).

29. J.J. Yang, X.D. Zhang, Y.H. Ma, G. Gao, X.K. Chen, H.R. Jia, Y.H. Li, Z. Chen, F.G. Wu, Carbon dot-based platform for simultaneous bacterial distinguishment and antibacterial applications. ACS Appl. Mater. Inter. 8 (47), 32170-32181 (2016).

30. T.F. Liu, Y.Q. Liu, M.L. Liu, Y. Wang, W.F. He, G.Q. Shi, X.H. Hu, R.X. Zhan, G.X. Luo, M. Xing, J. Wu, Synthesis of graphene oxide-quaternary ammonium nanocomposite with synergistic antibacterial activity to promote infected wound healing. Burns Trauma 6 (1), s41038-018-0115-2 (2018).

31. S.B. Liu, M. Hu, T.H. Zeng, R. Wu, R.R. Jiang, J. Wei, L. Wang, J. Kong, Y. Chen, Lateral dimensiondependent antibacterial activity of graphene oxide sheets. Langmuir 28 (33), 12364-12372 (2012).

32. R.B. Guo, B. Chen, F.L. Li, S.H. Weng, Z.F. Zheng, M. Chen, W. Wu, X.H. Lin, C.Y. Yang, Positive carbon dots with dual roles of nanoquencher and reference signal for the ratiometric fluorescence sensing of DNA. Sensor. Actuat. B-Chem. 264, 193-201 (2018).

33. H. Li, J. Huang, Y.X. Song, M.L. Zhang, H.B. Wang, F. Lu, H. Huang, Y. Liu, X. Dai, Z.L. Gu, Z.X. Yang, R.H. Zhou, Z.H. Kang, Degradable carbon dots with broad-spectrum antibacterial activity. ACS Appl. Mater. Inter. 10 (32), 26936-26946 (2018).

34. Z.M. Zhu, X.Y. Lin, L.N. Wu, C.F. Zhao, Y.J. Zheng, A.L. Liu, L.Q. Lin, X.H. Lin, "Switch-On" fluorescent nanosensor based on nitrogen-doped carbon dots-MnO2 nanocomposites for probing the activity of acid phosphatase. Sensor. Actuat. B-Chem. 274, 609-615 (2018).

35. L.J. Wu, Youji Huahewu Bopu Jiexi, third ed., China Medical Science and Technology Press, Beijing (2009). 
36. Y.J. Li, S.G. Harroun, Y.C. Su, C.F. Huang, B. Unnikrishnan, H.J. Lin, C.H. Lin, C.C. Huang, Synthesis of self-assembled spermidine-carbon quantum dots effective against multidrug-resistant bacteria. Adv. Healthc. Mater. 5 (19), 2545-2554 (2016).

37. L. Wang, B. Wu, W.T. Li, S.L. Wang, Z. Li, M. Li, D.Y. Pan, M.H. Wu, Amphiphilic graphene quantum dots as self-targeted fluorescence probes for cell nucleus imaging. Adv. Biosys. 2 (8), 1700191 (2018).

38. Z.Q. Song, F.Y. Quan, Y.H. Xu, M.L. Liu, L. Cui, J.Q. Liu, Multifunctional N,S co-doped carbon quantum dots with $\mathrm{pH}$ - and thermo-dependent switchable fluorescent properties and highly selective detection of glutathione. Carbon 104, 169-178 (2016).

39. Z.T. Fan, K.H.L. Po, K.K. Wong, S. Chen, S.P. Lau, Polyethylenimine-modified graphene oxide as a novel antibacterial agent and its synergistic effect with daptomycin for methicillin-resistant Staphylococcus aureus. ACS Appl. Nano. Mater. 1 (4), 1811-1818 (2018).

40. R.T. Zhao, M. Lv, Y. Li, M.X. Sun, W. Kong, L.H. Wang, S.P. Song, C.H. Fan, L.L. Jia, S.F. Qiu, Y.S. Sun, H.B. Song, R.Z. Hao, Stable nanocomposite based on pegylated and silver nanoparticles loaded graphene oxide for long-term antibacterial activity. ACS Appl. Mater. Inter. 9 (18), 15328-15341 (2017).

41. J. Li, X.M. Liu, L. Tan, Z.D. Cui, X.J. Yang, Y.Q. Liang, Z.Y. Li, S.L. Zhu, Y.F. Zheng, K.W.K. Yeung, X.B. Wang, S.L. Wu, Zinc-doped Prussian blue enhances photothermal clearance of Staphylococcus aureus and promotes tissue repair in infected wounds. Nat. Commun. 10 (1), 4490 (2019).

42. H.J. Jian, R.S. Wu, T.Y. Lin, Y.J. Li, H.J. Lin, S.G. Harroun, J.Y. Lai, C.C. Huang, Super-cationic carbon quantum dots synthesized from spermidine as an eye drop formulation for topical treatment of bacterial keratitis. ACS Nano 11 (7), 6703-6716 (2017).

43. G.F. Du, Y.D. Zheng, J. Chen, Q.Y. He, X.S. Sun, Novel mechanistic insights into bacterial fluoroquinolone resistance. J. Proteome. Res. 18 (11), 3955-3966 (2019).

44. J. Liu, Z. Huang, B. Ruan, H. Wang, M. Chen, S. Rehman, P. Wu, Quantitative proteomic analysis reveals the mechanisms of polymyxin B toxicity to Escherichia coli. Chemosphere 259, 127449 (2020).

45. I. Pastar, A.G. Nusbaum, J. Gil, S.B. Patel, J. Chen, J. Valdes, O. Stojadinovic, L.R. Plano, M. TomicCanic, S.C. Davis, Interactions of methicillin resistant Staphylococcus aureus USA300 and Pseudomonas aeruginosa in polymicrobial wound infection. PIOS ONE 8 (2), e56846 (2013).

46. S. DeLeon, A. Clinton, H. Fowler, J. Everett, A.R. Horswill, K.P. Rumbaugh, Synergistic interactions of Pseudomonas aeruginosa and Staphylococcus aureus in an in vitro wound model. Infect. Immun. 82 (11), 4718-4728 (2014).

47. B.W. Yang, Y. Chen, J.L. Shi, Reactive oxygen species (ROS)-based nanomedicine. Chem. Rev. 119 (8), 4881-4985 (2019).

48. N. Maldonado-Carmona, M. Vázquez-Hernández, O.J.P. Chávez, S.D. Rodríguez-Luna, O.J. Rodríguez, S. Sanchez, C.D. Ceapă, Impact of omics in the detection and validation of potential anti-infective drugs. Curr. Opin. Pharmacol. 48, 1-7 (2019). 
49. H.Z. Zhen, Z.X. Ji, K.R. Roy, M. Gao, Y.X. Pan, X.M. Cai, L.M. Wang, W. Li, C.H. Chang, C. Kaweeteerawat, C.Y. Chen, T. Xia, Y.L. Zhao, R.B. Li, Engineered graphene oxide nanocomposite capable of preventing the evolution of antimicrobial resistance. ACS Nano 13 (10), 11488-11499 (2019).

50. Z.Y. Song, H.J. Wang, Y. Wu, J.J. Gu, S.J. Li, H.Y. Han, Fabrication of bis-quaternary ammonium salt as an efficient bactericidal weapon against Escherichia coli and Staphylococcus aureus. ACS Omega 3 (10), 14517-14525 (2018).

51. Y. Li, W.S. Ma, J. Sun, M. Lin, Y.S. Niu, X.C. Yang, Y.H. Xu, Electrochemical generation of $\mathrm{Fe}_{3} \mathrm{C} / \mathrm{N}-$ doped graphitic carbon nanozyme for efficient wound healing in vivo. Carbon 159, 149-160 (2020).

52. Y.W. Jiang, G. Gao, X.D. Zhang, H.R. Jia, F.G. Wu, Antimicrobial carbon nanospheres. Nanoscale 9 (41), 15786-15795 (2017).

53. G. Otis, S. Bhattacharya, O. Malka, S. Kolusheya, P. Bolel, A. Porgador, R. Jelinek, Selective labeling and growth inhibition of pseudomonas aeruginosa by aminoguanidine carbon dots. ACS Infect. Dis. 5 (2), 292-302 (2019).

54. S. Walia, A.K. Shukla, C. Sharma, A. Acharya, Engineered bright blue- and red-emitting carbon dots facilitate synchronous imaging and inhibition of bacterial and cancer cell progression via ${ }^{1} \mathrm{O}_{2}{ }^{-}$ mediated dna damage under photoirradiation. ACS Biomater. Sci. Eng. 5 (4), 1987-2000 (2019).

55. Z.M. Marković, M. Kováčová, P. Humpolíček, M.D. Budimir, J. Vajd’ák, P. Kubát, M. Mičušík, H. Švajdlenková, M. Danko, Z. Capáková, M. Lehocký, B.M.T. Marković, Z. Špitalský, Antibacterial photodynamic activity of carbon quantum dots/polydimethylsiloxane nanocomposites against Staphylococcus aureus, Escherichia coli and Klebsiella pneumoniae. Photodiagn Photodyn 26, 342349 (2019).

\section{Figures}



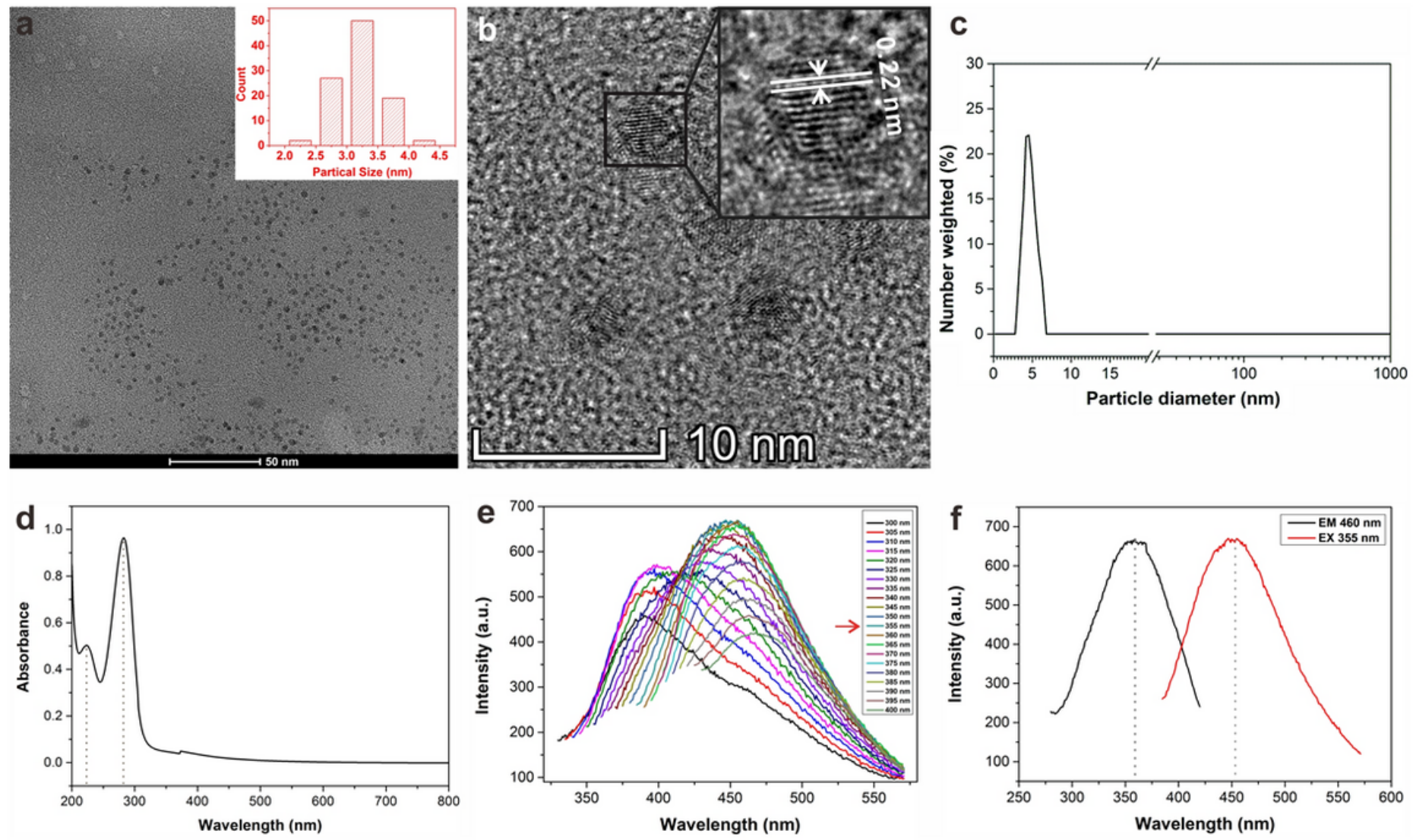

Figure 1

Characterization results of representative sample. TEM image (a), typical HRTEM image (b), DLS measurement (c), UV-vis absorption spectrum (d), fluorescence spectra under different excitation wavelength (e), and emission and excitation spectra (f) of qCQDs. The inset in (a) is a histogram of the particle size distribution of qCQDs. 

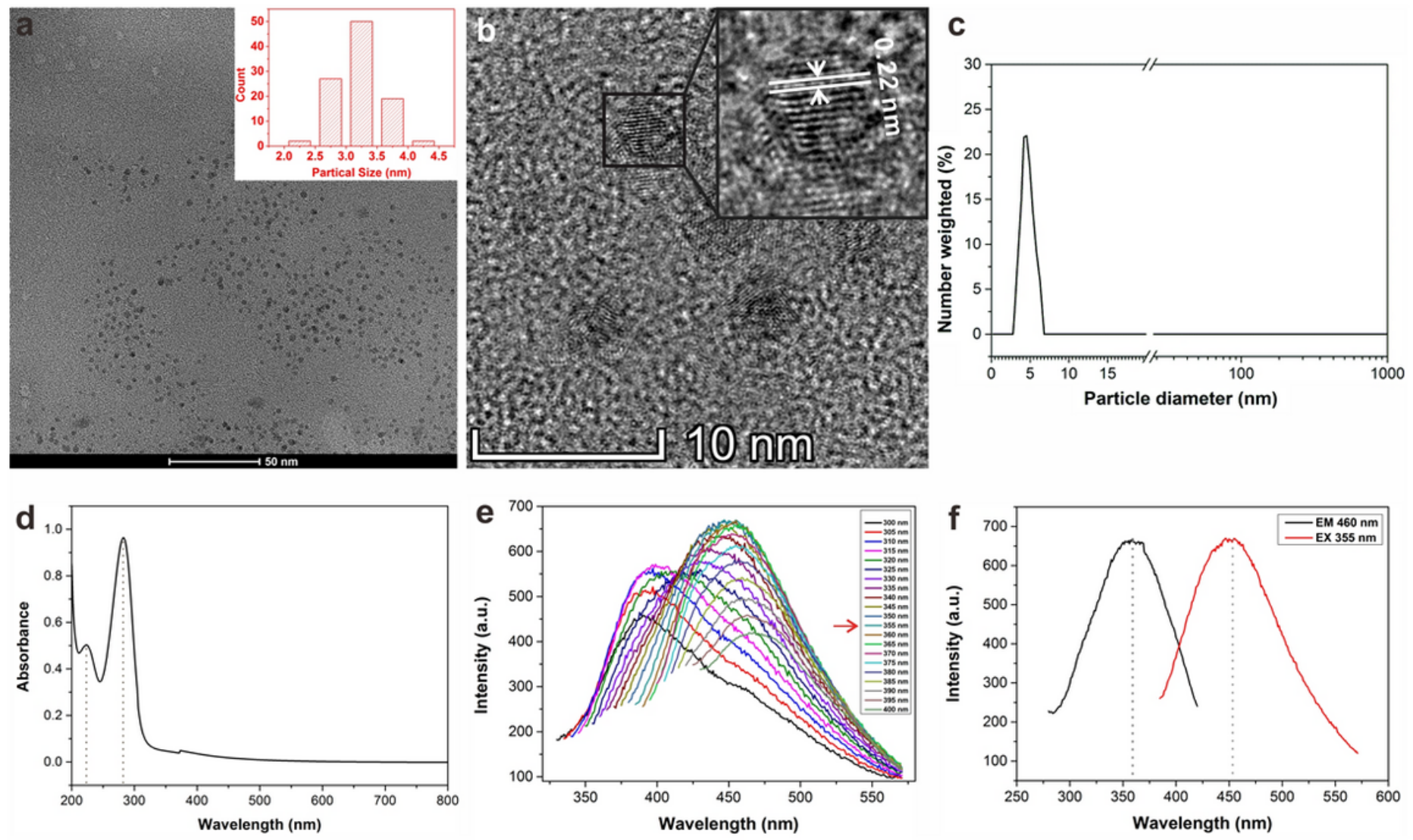

\section{Figure 1}

Characterization results of representative sample. TEM image (a), typical HRTEM image (b), DLS measurement (c), UV-vis absorption spectrum (d), fluorescence spectra under different excitation wavelength (e), and emission and excitation spectra (f) of qCQDs. The inset in (a) is a histogram of the particle size distribution of qCQDs. 

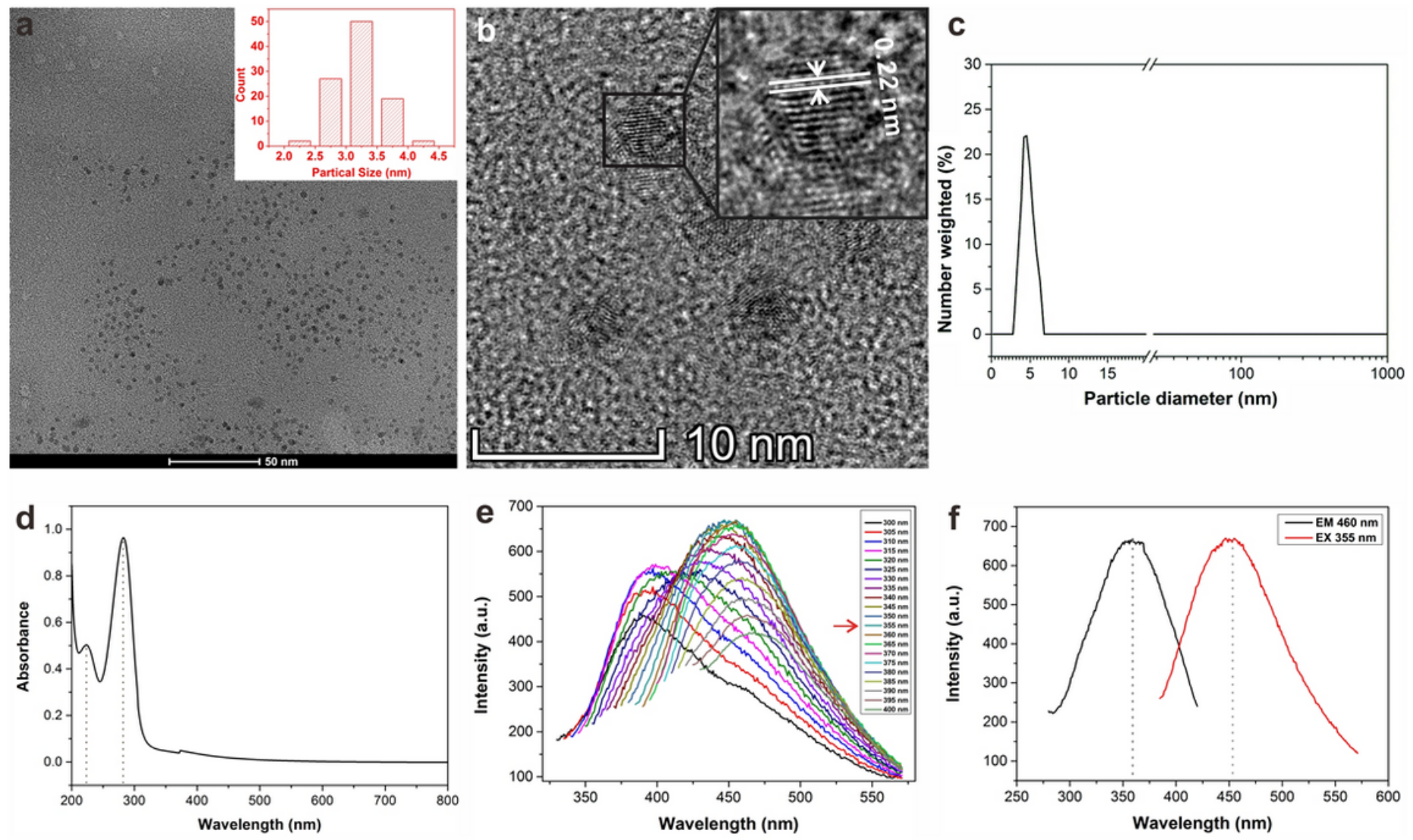

\section{Figure 1}

Characterization results of representative sample. TEM image (a), typical HRTEM image (b), DLS measurement (c), UV-vis absorption spectrum (d), fluorescence spectra under different excitation wavelength (e), and emission and excitation spectra (f) of qCQDs. The inset in (a) is a histogram of the particle size distribution of qCQDs. 

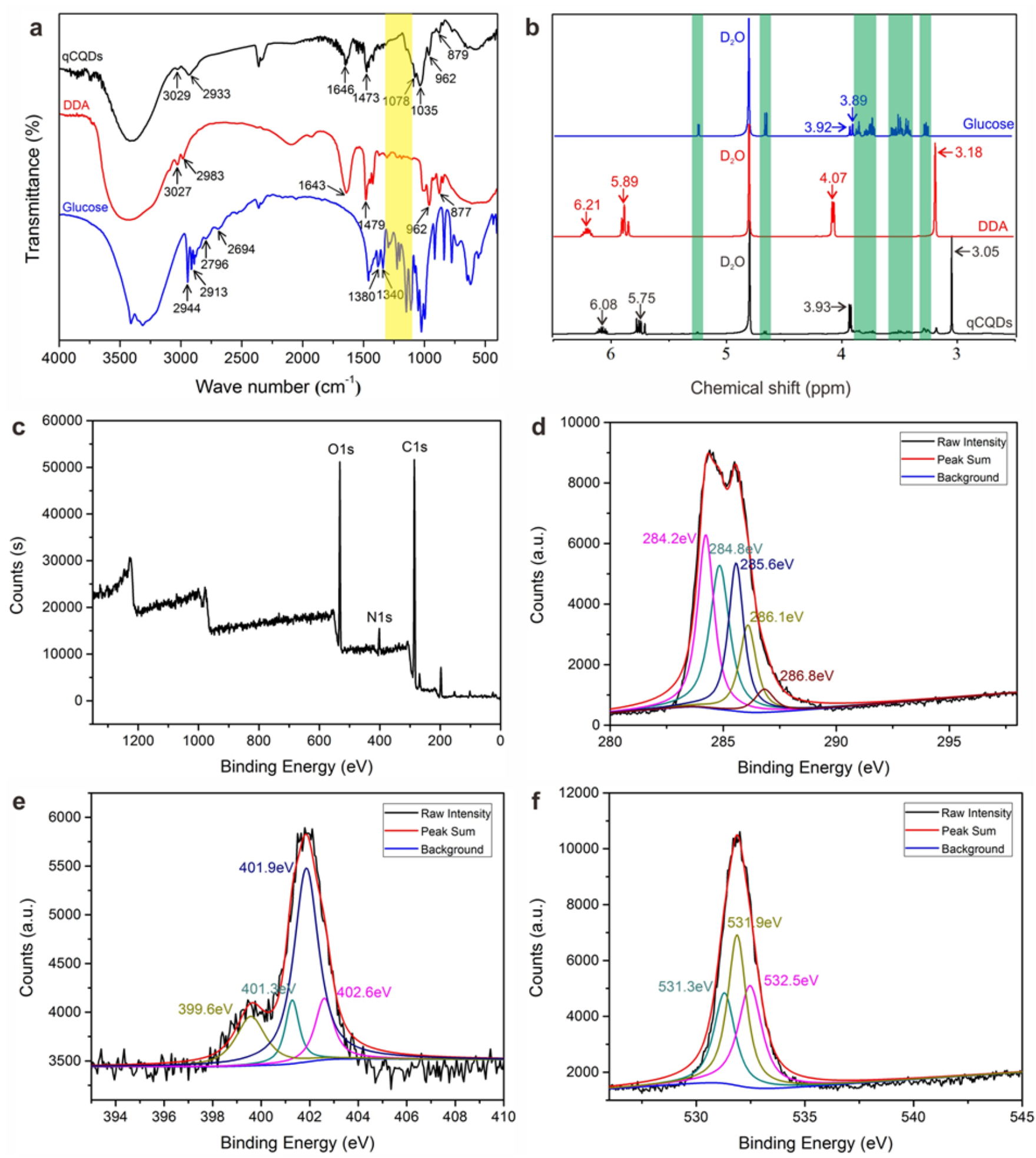

\section{Figure 2}

Characterization of molecular structure. FTIR (a) and 1H NMR (b) of qCQDs (black), DDA (red) and glucose (blue); XPS survey spectrum (c) of qCQDs, and deconvolution of high-resolution XPS spectra of C1s (d), N1s (e) and 01s (f). 

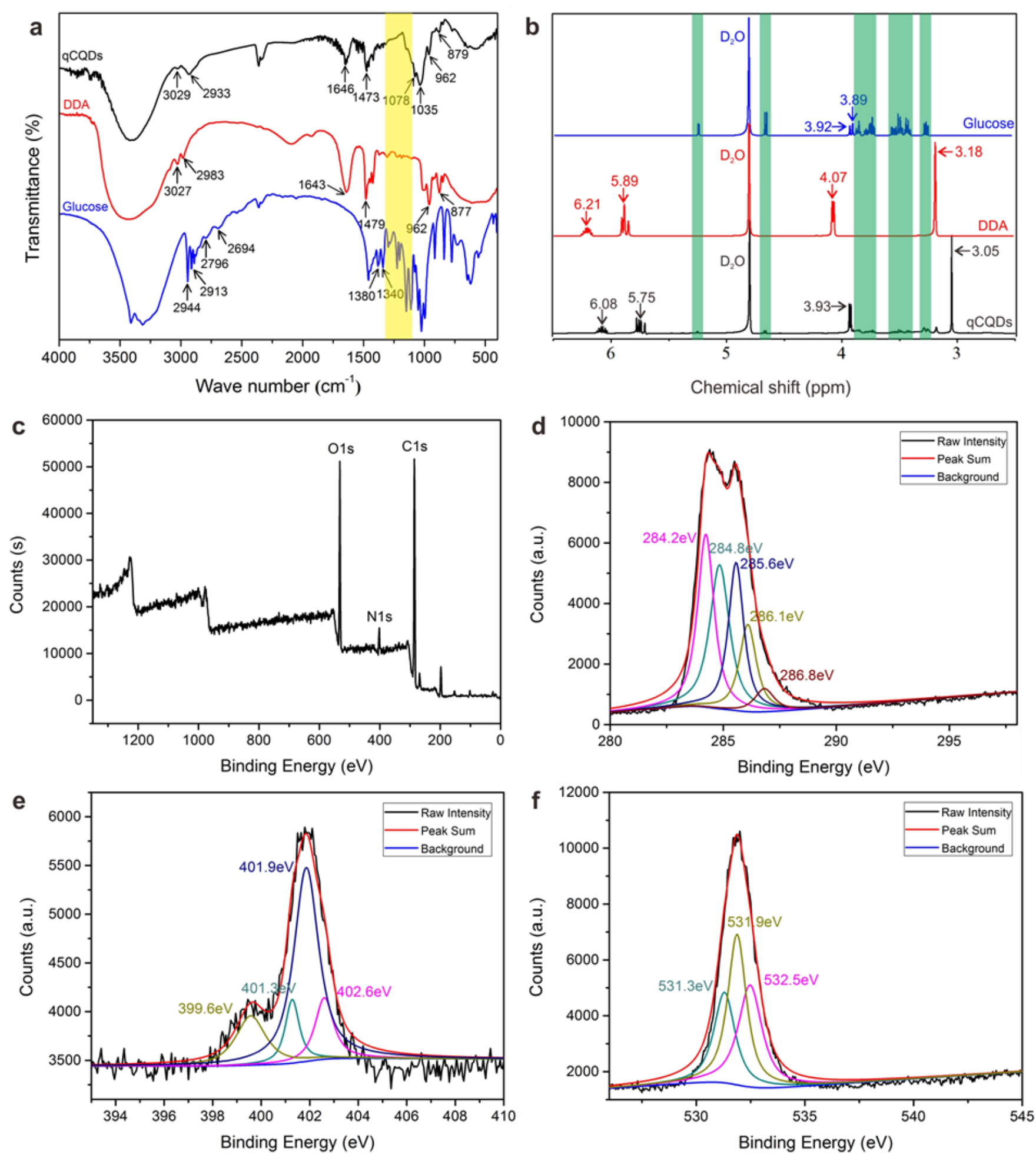

\section{Figure 2}

Characterization of molecular structure. FTIR (a) and 1H NMR (b) of qCQDs (black), DDA (red) and glucose (blue); XPS survey spectrum (c) of qCQDs, and deconvolution of high-resolution XPS spectra of C1s (d), N1s (e) and 01s (f). 

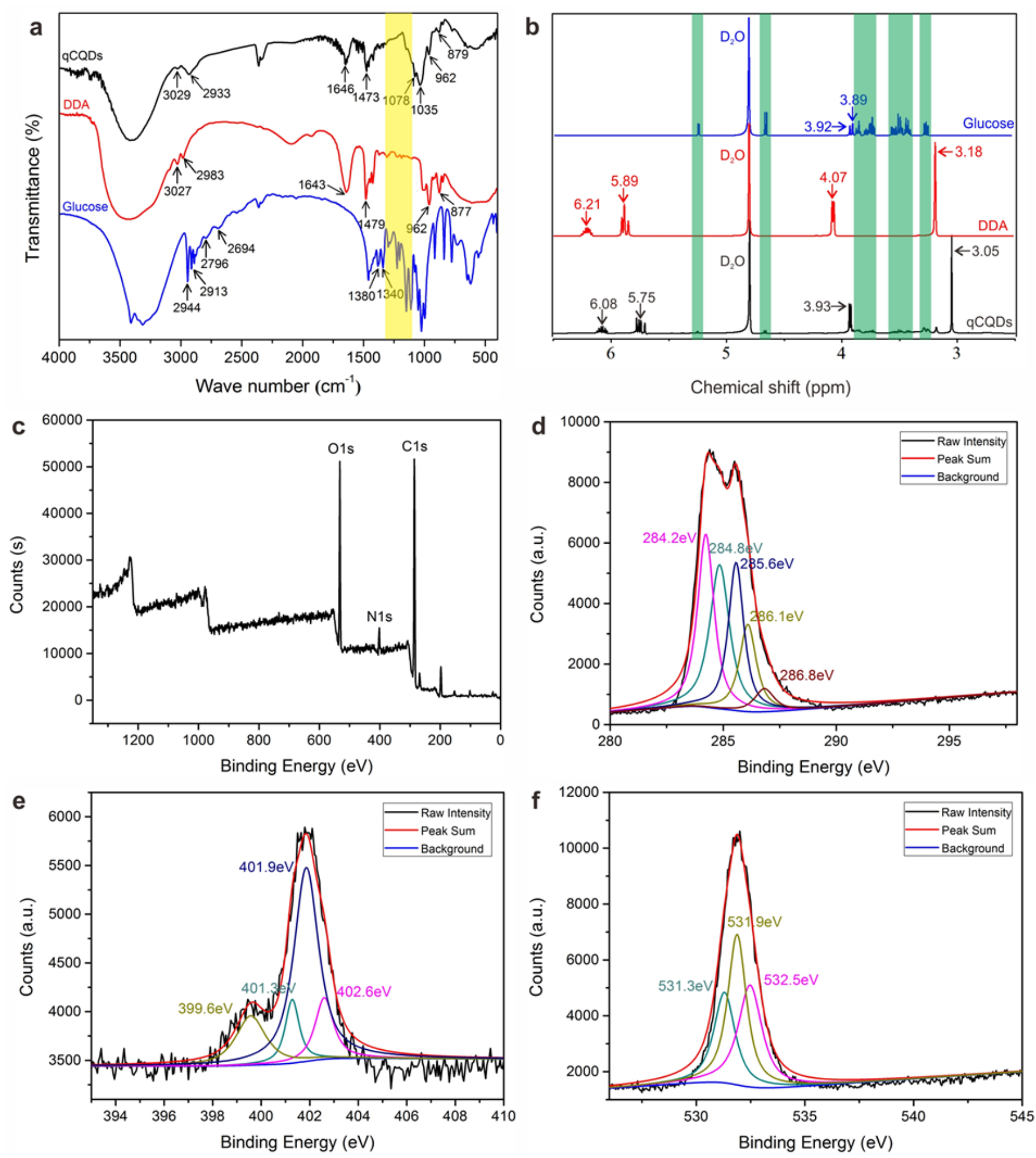

\section{Figure 2}

Characterization of molecular structure. FTIR (a) and 1H NMR (b) of qCQDs (black), DDA (red) and glucose (blue); XPS survey spectrum (c) of qCQDs, and deconvolution of high-resolution XPS spectra of C1s (d), N1s (e) and 01s (f). 


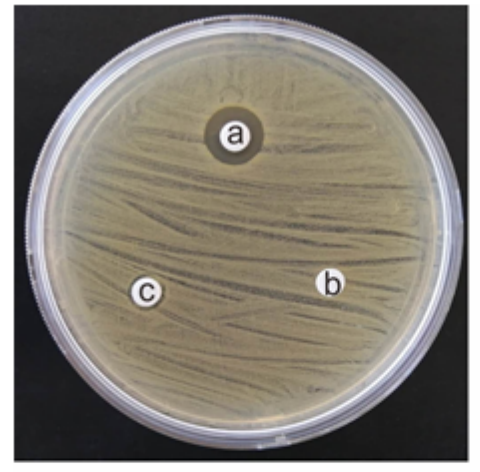

S.aureus

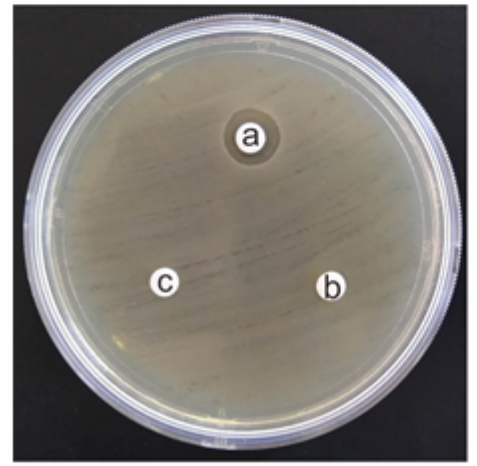

E.coil

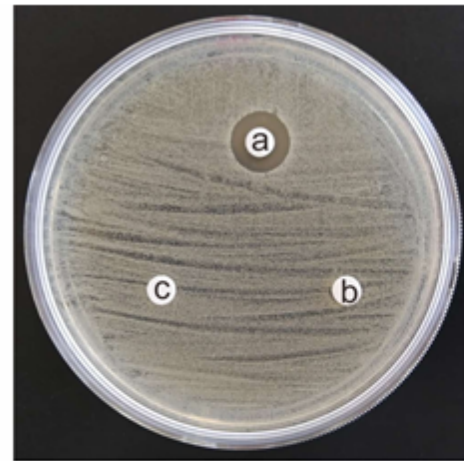

MRSA

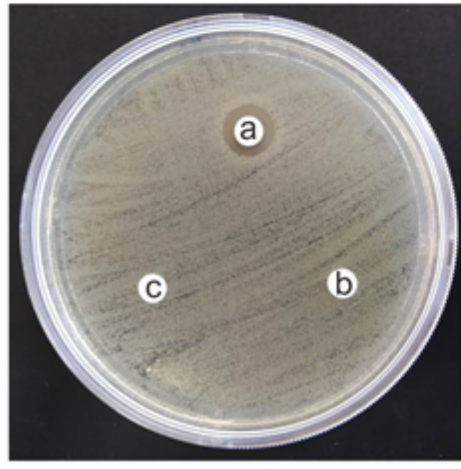

$P$. aeruginosa

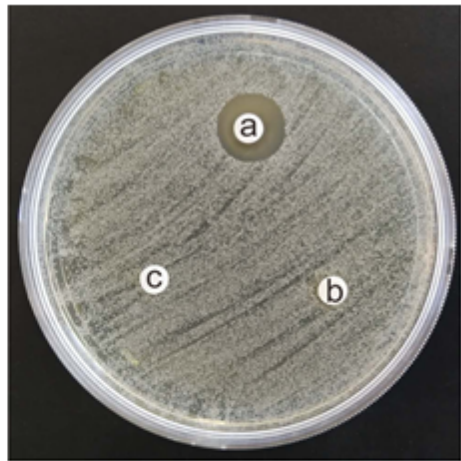

S.epidermidis

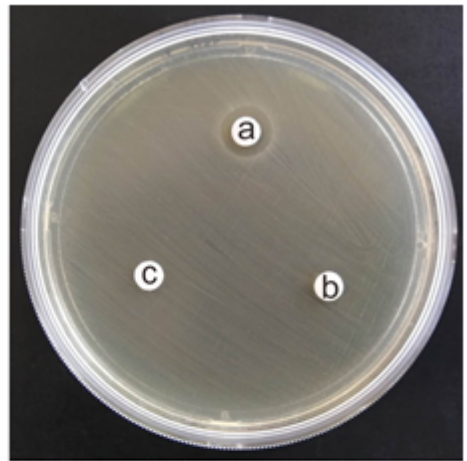

E.faecalis
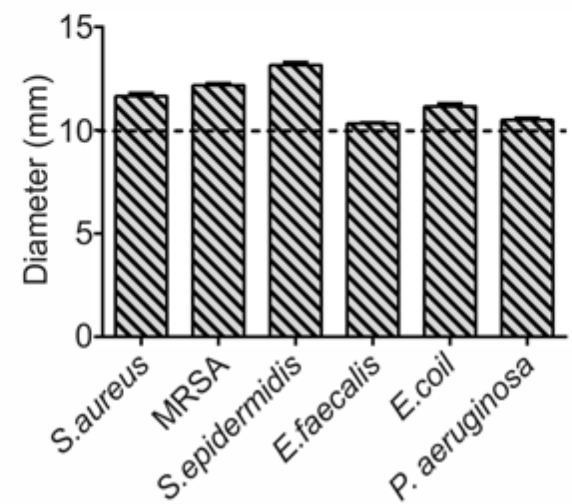

Figure 3

Antibacterial activity on MHA plates. qCQDs (a), glucose (b) and DDA (c). Six species of bacteria is S. aureus, MRSA, S. epidermidis, E. faecalis, E. coli and P. aeruginosa, respectively. The histogram is derived from the diameter of the inhibition zone around disk a.

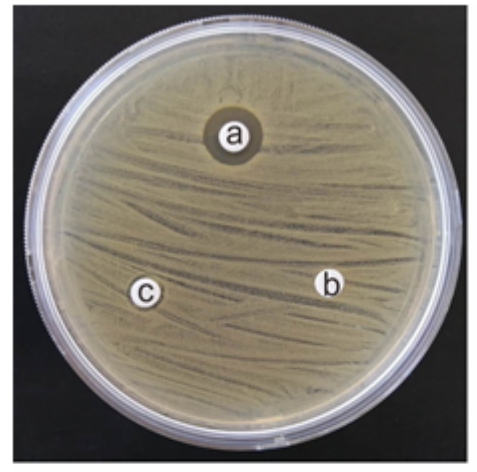

S.aureus

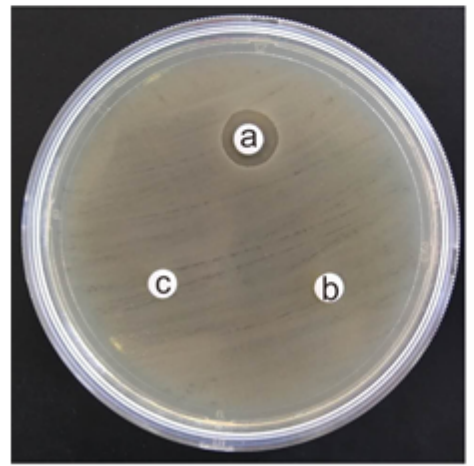

E.coil

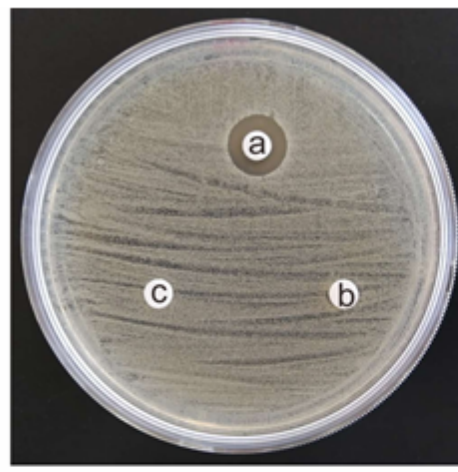

MRSA

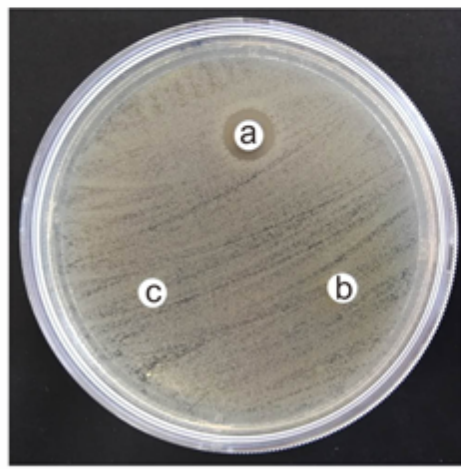

$P$. aeruginosa

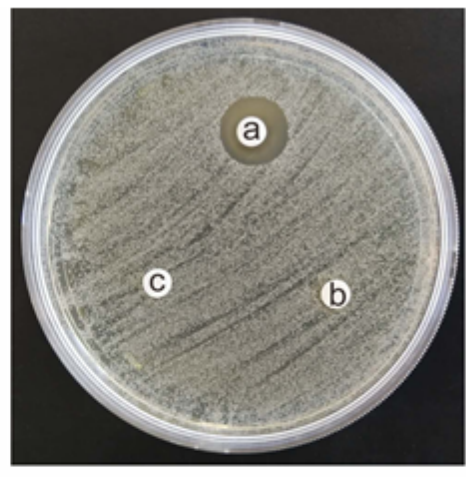

S.epidermidis

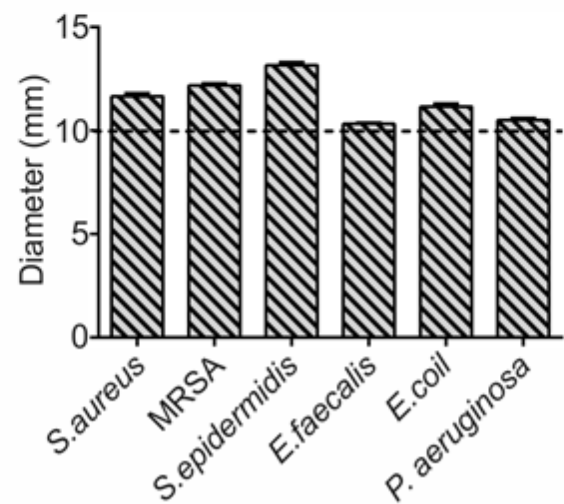

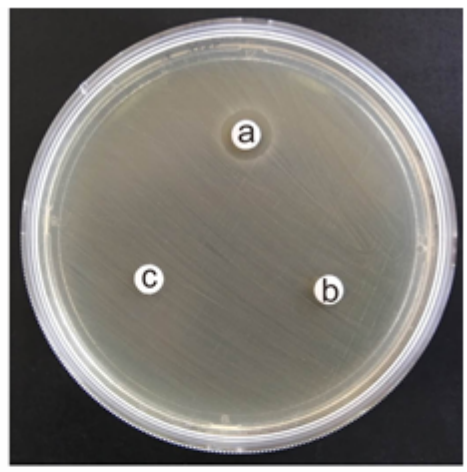

E.faecalis 


\section{Figure 3}

Antibacterial activity on MHA plates. qCQDs (a), glucose (b) and DDA (c). Six species of bacteria is S. aureus, MRSA, S. epidermidis, E. faecalis, E. coli and P. aeruginosa, respectively. The histogram is derived from the diameter of the inhibition zone around disk a.

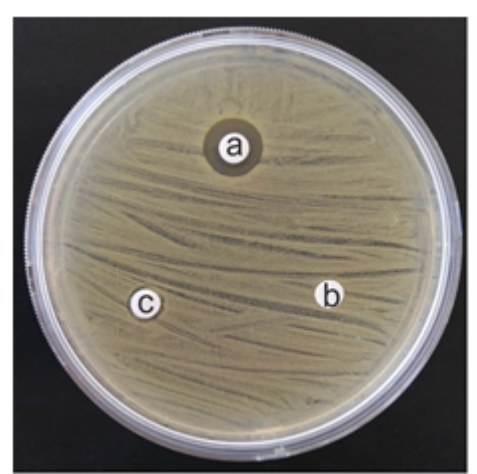

S.aureus

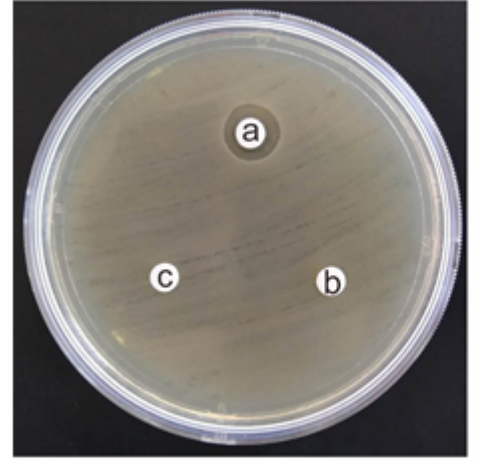

E.coil

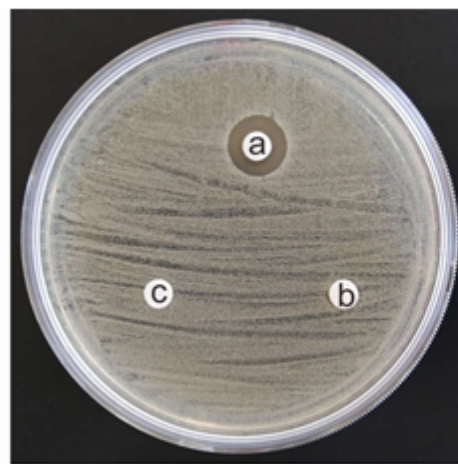

MRSA

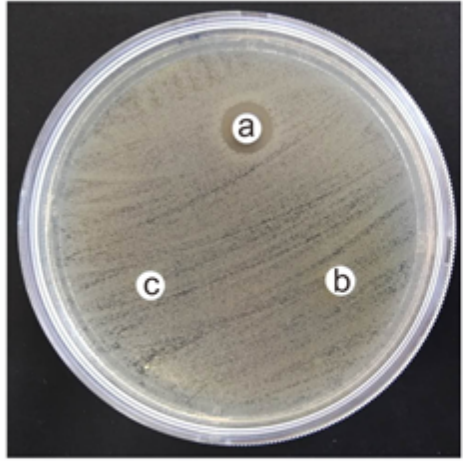

$P$. aeruginosa

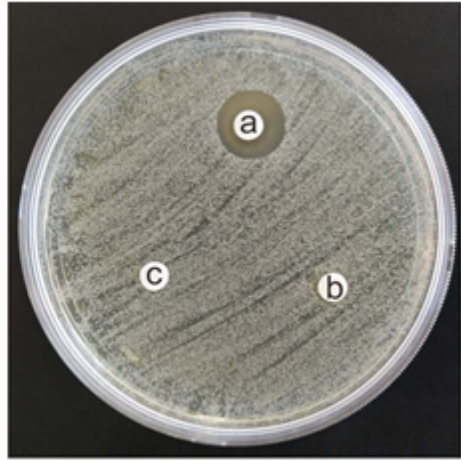

S.epidermidis

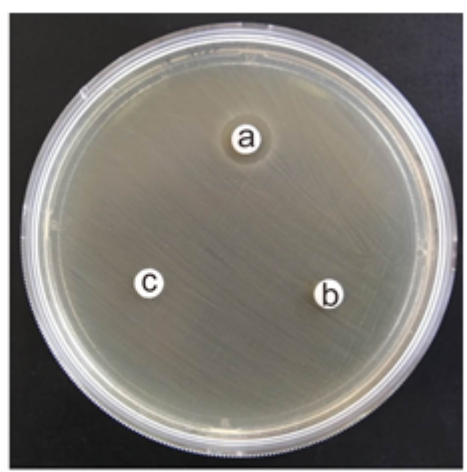

E.faecalis

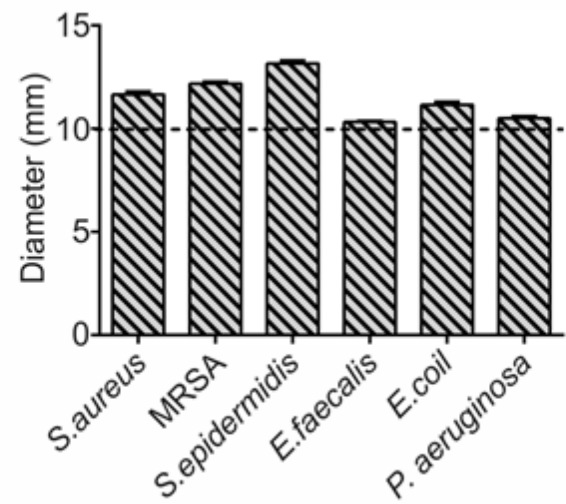

\section{Figure 3}

Antibacterial activity on MHA plates. qCQDs (a), glucose (b) and DDA (c). Six species of bacteria is S. aureus, MRSA, S. epidermidis, E. faecalis, E. coli and P. aeruginosa, respectively. The histogram is derived from the diameter of the inhibition zone around disk a. 

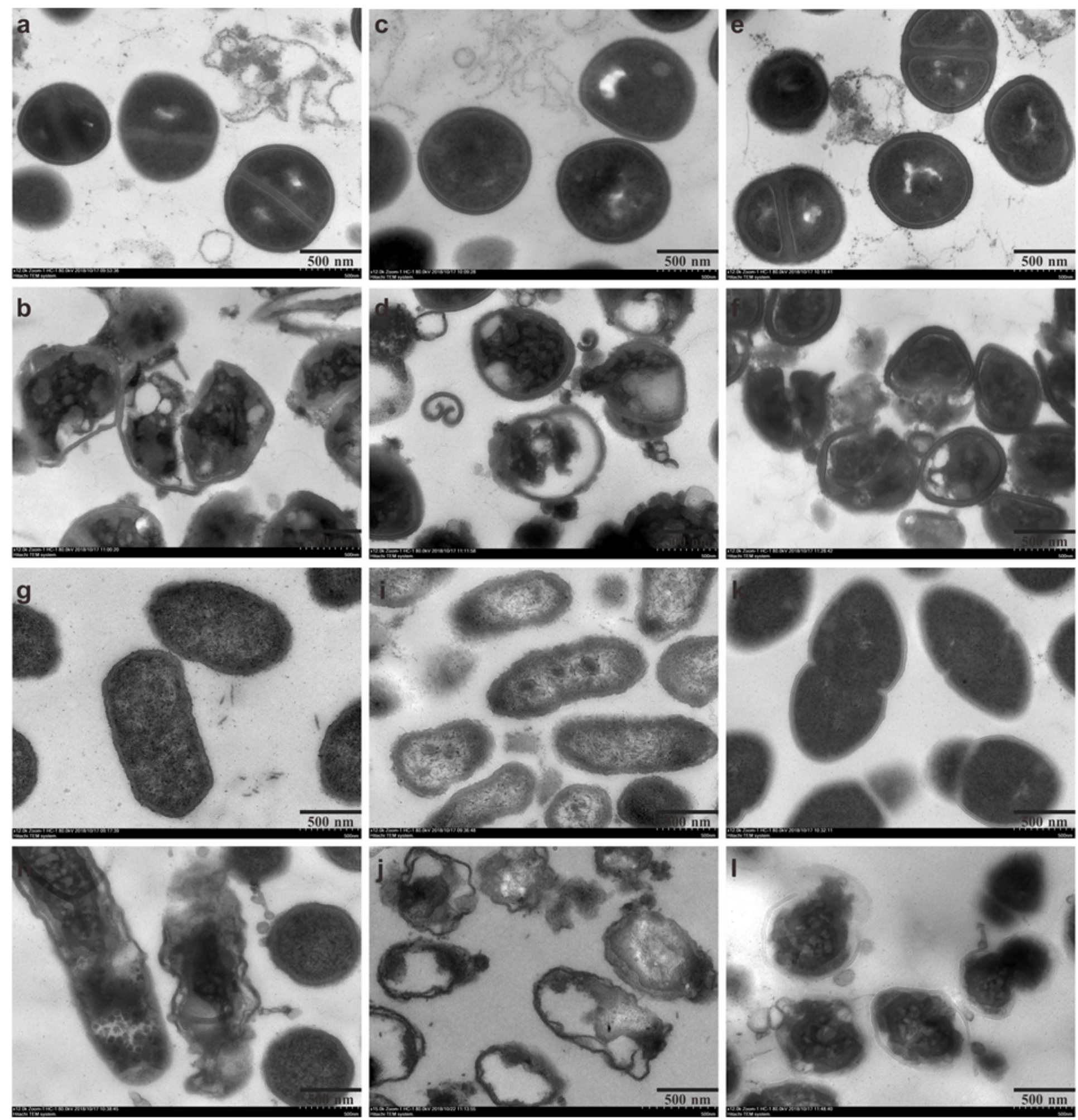

\section{Figure 4}

Morphological changes of bacteria treated without or with qCQDs. TEM images of $S$. aureus ( $a$ and $b$ ), MRSA (c and d), S. epidermidis (e and f), E. coli ( $g$ and $h$ ), P. aeruginosa ( $i$ and $j$ ) and E. faecalis ( $k$ and $I$ ) with the treatment of normal saline (a, c, e, g, i and k) and $100 \mu \mathrm{g} / \mathrm{mL}$ of qCQDs (b, d, f, h, j and I), respectively. 

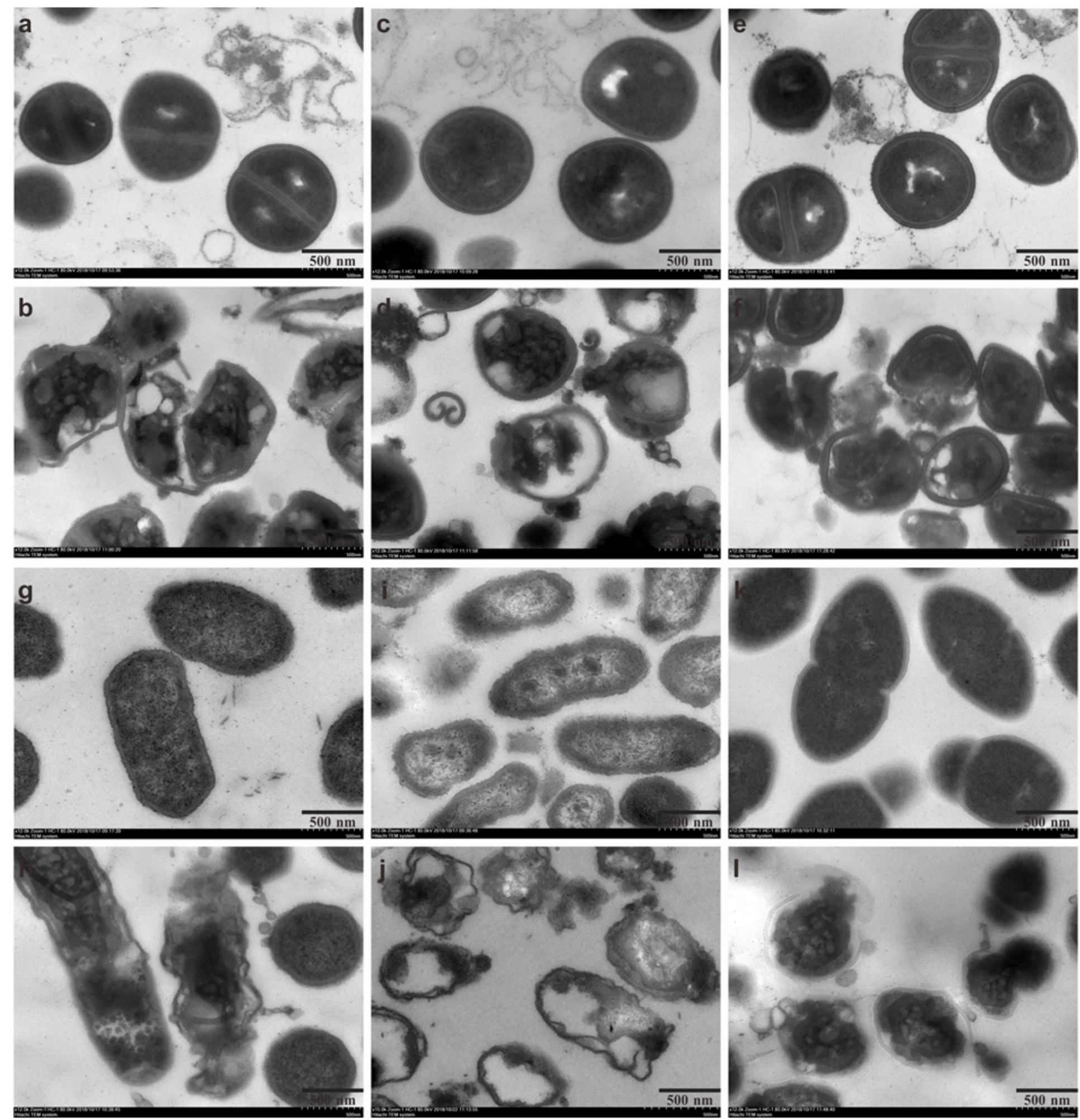

\section{Figure 4}

Morphological changes of bacteria treated without or with qCQDs. TEM images of $S$. aureus ( $a$ and $b$ ), MRSA (c and d), S. epidermidis (e and f), E. coli ( $g$ and $h$ ), P. aeruginosa ( $i$ and $j$ ) and E. faecalis ( $k$ and $I$ ) with the treatment of normal saline (a, c, e, g, i and k) and $100 \mu \mathrm{g} / \mathrm{mL}$ of qCQDs (b, d, f, h, j and I), respectively. 

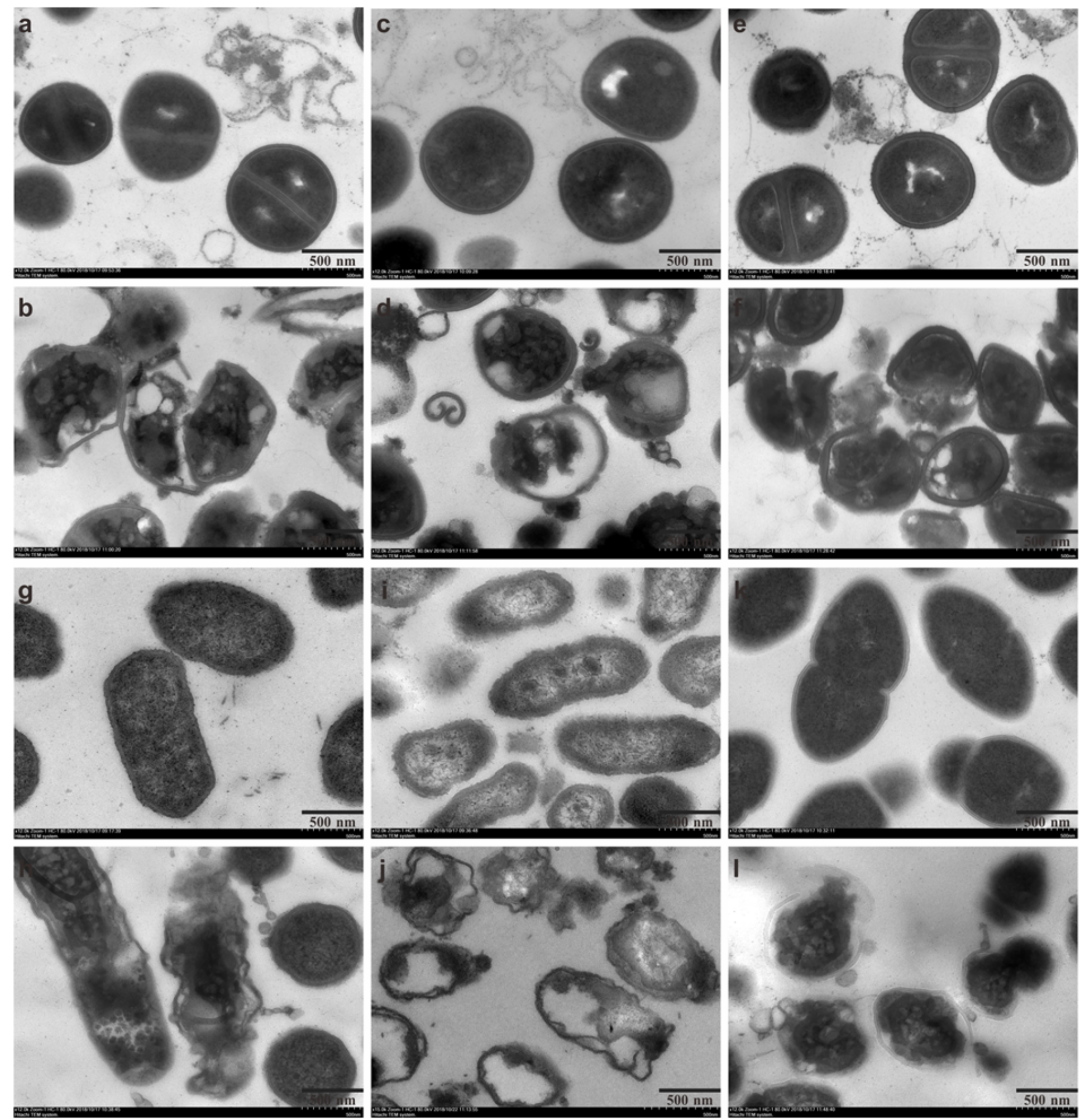

\section{Figure 4}

Morphological changes of bacteria treated without or with qCQDs. TEM images of $S$. aureus ( $a$ and $b$ ), MRSA (c and d), S. epidermidis (e and f), E. coli ( $g$ and $h$ ), P. aeruginosa ( $i$ and $j$ ) and E. faecalis ( $k$ and $I$ ) with the treatment of normal saline (a, c, e, g, i and k) and $100 \mu \mathrm{g} / \mathrm{mL}$ of qCQDs (b, d, f, h, j and I), respectively. 

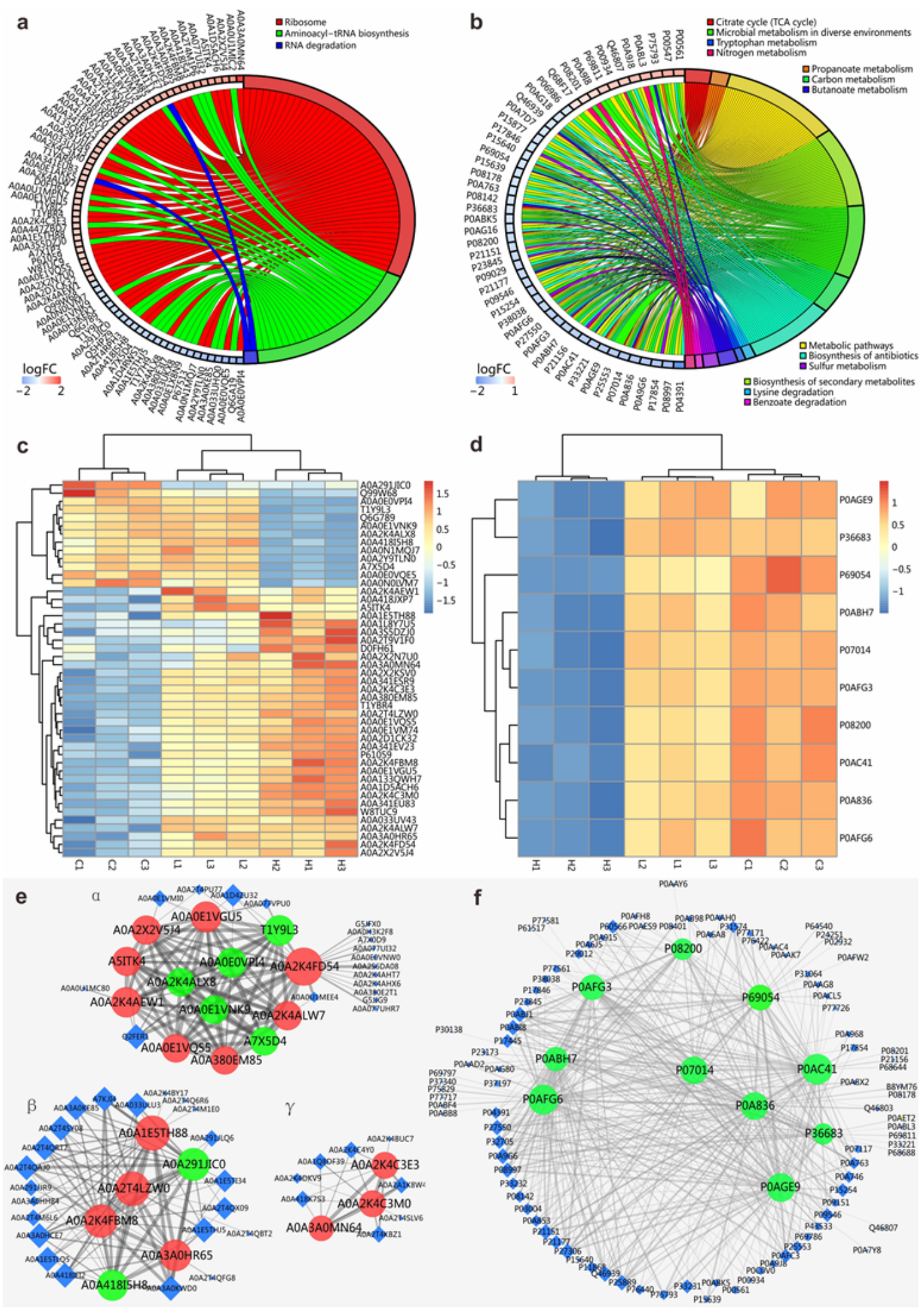

\section{Figure 5}

Differentially expressed proteins associated with ribosome and citrate cycle. KEGG chord diagram between differentially expressed proteins and enriched pathway in S. aureus (a) and E. coli (b), (more information was described in Supporting Information); Clustering heat map of differentially expressed proteins associated with ribosome in S. aureus (c) and citrate cycle in E. coli (d). Protein-protein interaction network of differentially expressed proteins associated with ribosome (e) and citrate cycle (f). 
The circles represent ribosomal proteins and citrate cycle related proteins, and the diamonds represent other proteins. Red indicates up-regulated expression, while green indicates down-regulated expression. Ribosomal proteins (c) and citrate cycle related proteins (d) in clustering heat map were detailed in Supplementary Table 2 and 4, respectively.
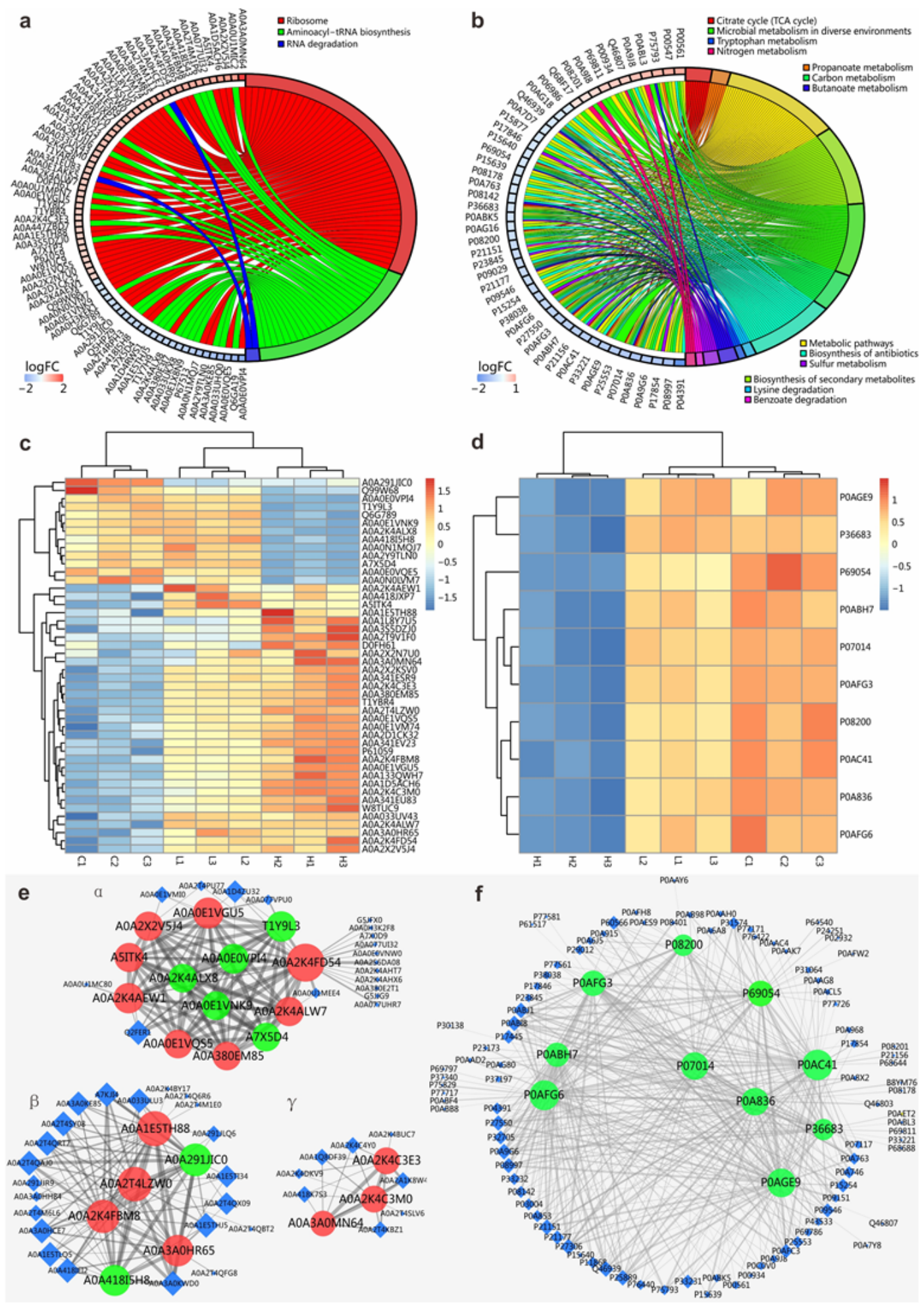

Figure 5 
Differentially expressed proteins associated with ribosome and citrate cycle. KEGG chord diagram between differentially expressed proteins and enriched pathway in S. aureus (a) and E. coli (b), (more information was described in Supporting Information); Clustering heat map of differentially expressed proteins associated with ribosome in S. aureus (c) and citrate cycle in E. coli (d). Protein-protein interaction network of differentially expressed proteins associated with ribosome (e) and citrate cycle (f). The circles represent ribosomal proteins and citrate cycle related proteins, and the diamonds represent other proteins. Red indicates up-regulated expression, while green indicates down-regulated expression. Ribosomal proteins (c) and citrate cycle related proteins (d) in clustering heat map were detailed in Supplementary Table 2 and 4, respectively. 

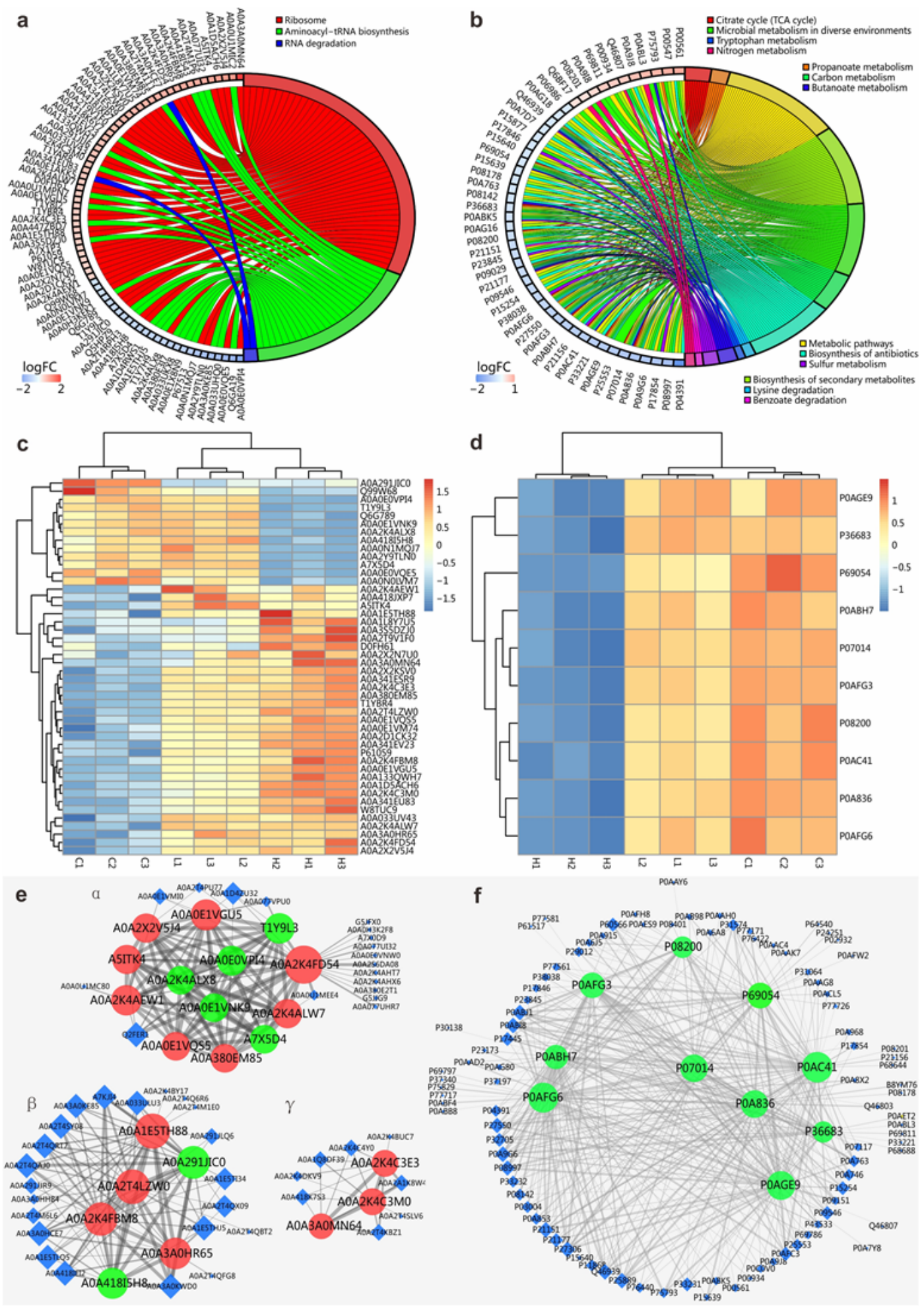

\section{Figure 5}

Differentially expressed proteins associated with ribosome and citrate cycle. KEGG chord diagram between differentially expressed proteins and enriched pathway in S. aureus (a) and E. coli (b), (more information was described in Supporting Information); Clustering heat map of differentially expressed proteins associated with ribosome in S. aureus (c) and citrate cycle in E. coli (d). Protein-protein interaction network of differentially expressed proteins associated with ribosome (e) and citrate cycle (f). 
The circles represent ribosomal proteins and citrate cycle related proteins, and the diamonds represent other proteins. Red indicates up-regulated expression, while green indicates down-regulated expression. Ribosomal proteins (c) and citrate cycle related proteins (d) in clustering heat map were detailed in Supplementary Table 2 and 4, respectively.

a

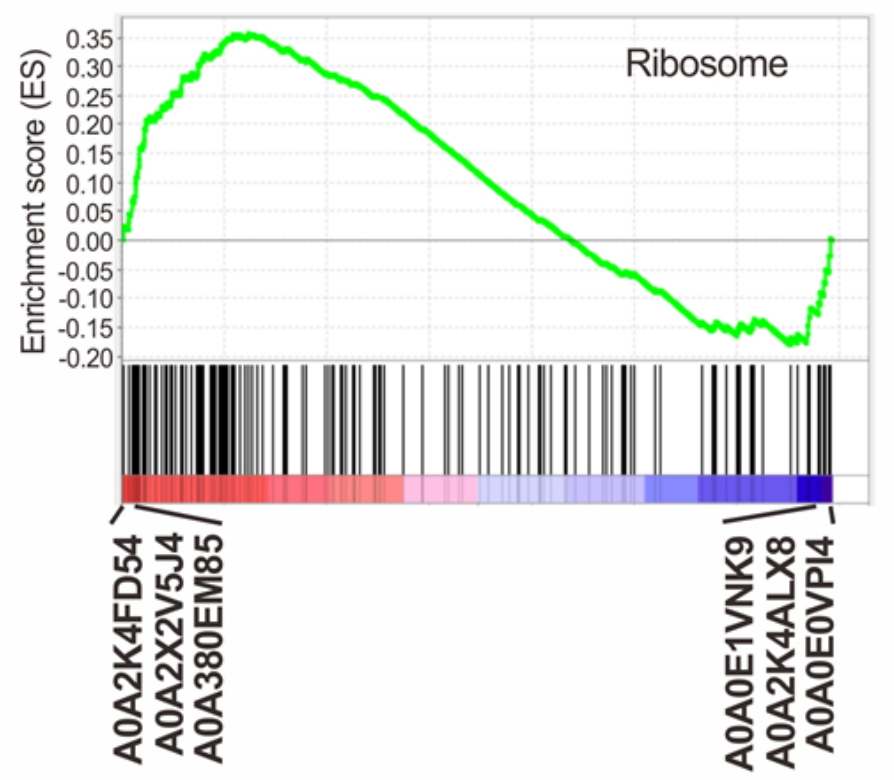

C

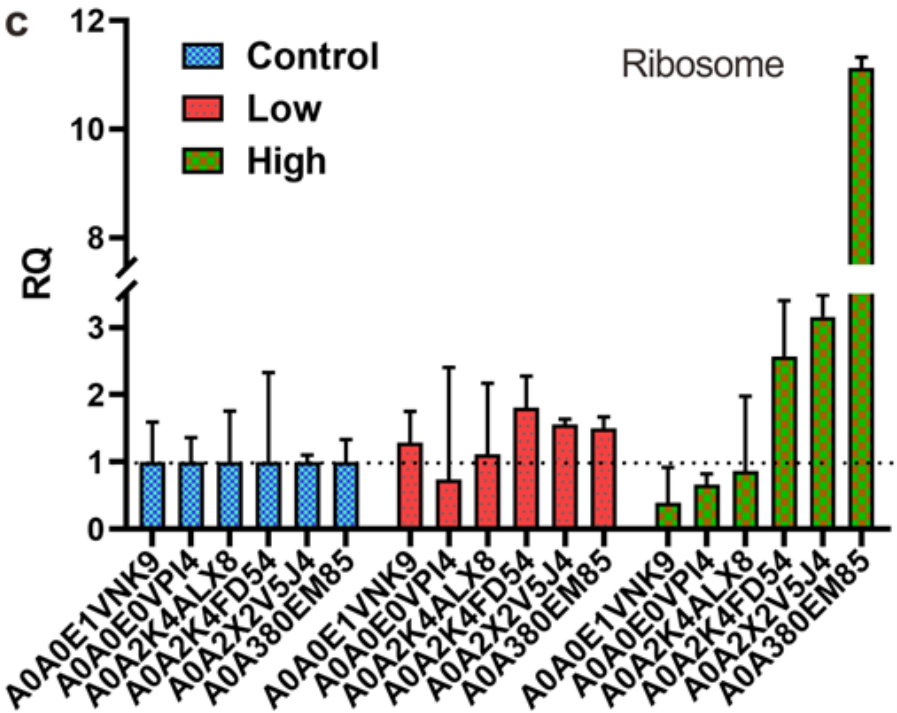

b $\quad$ Gene

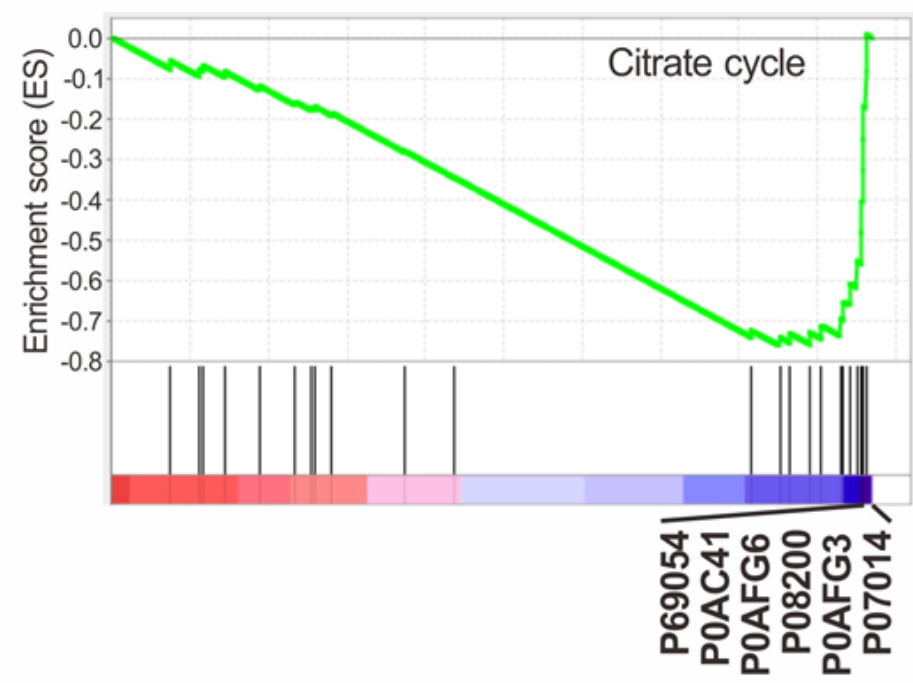

d

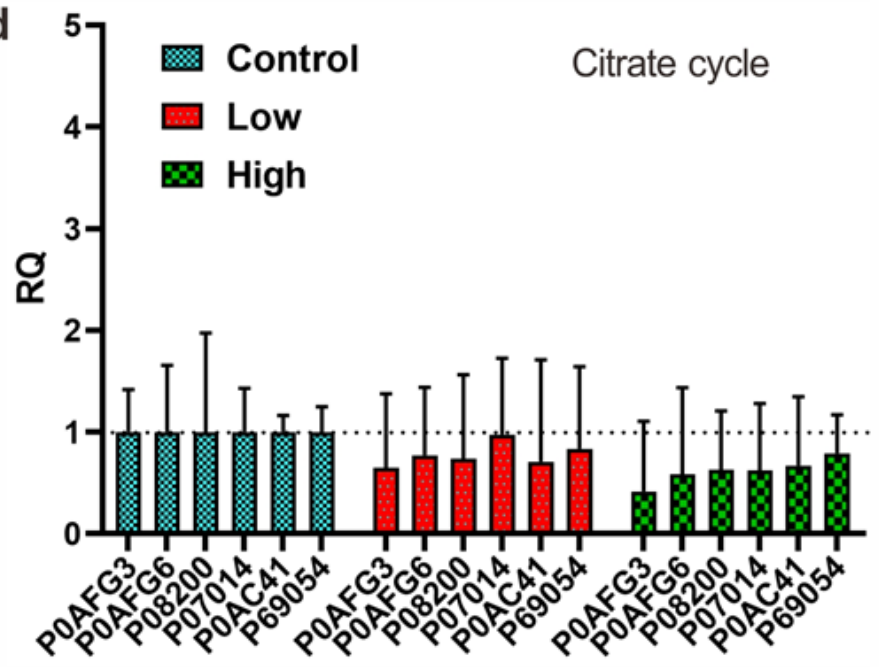

Figure 6

Six significantly different proteins in ribosome and citrate cycle. Identification of top candidate gene sets enriched in ribosome (a) and citrate cycle (b) by GSEA. Proteins in each subset of ribosome and citrate cycle were ranked by GSEA based on their differential expression level. Whether a pre-specified pathway is significantly over-represented towards the top or bottom of the ranked gene list in each subset of ribosome and citrate cycle was evaluated using the enrichment score (green line). Black vertical lines mark positions where members of a particular pathway appear in the ranked list of genes. Proteins that 
contributed most to the enrichment score were listed below the plot. RT-qPCR results of the corresponding genes in ribosome (c) and citrate cycle (d).

a

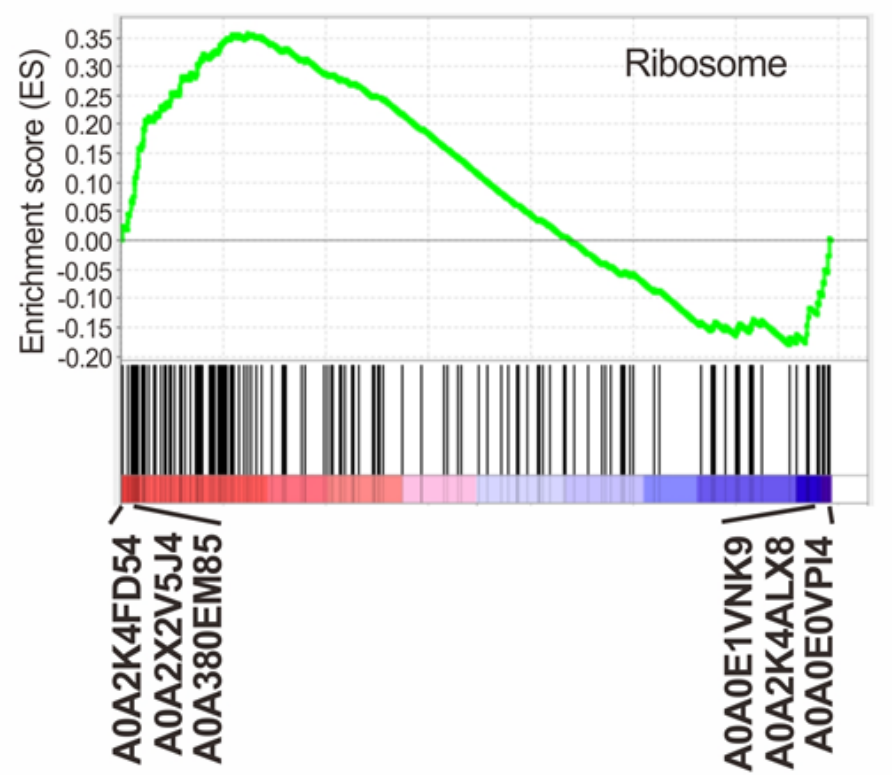

b

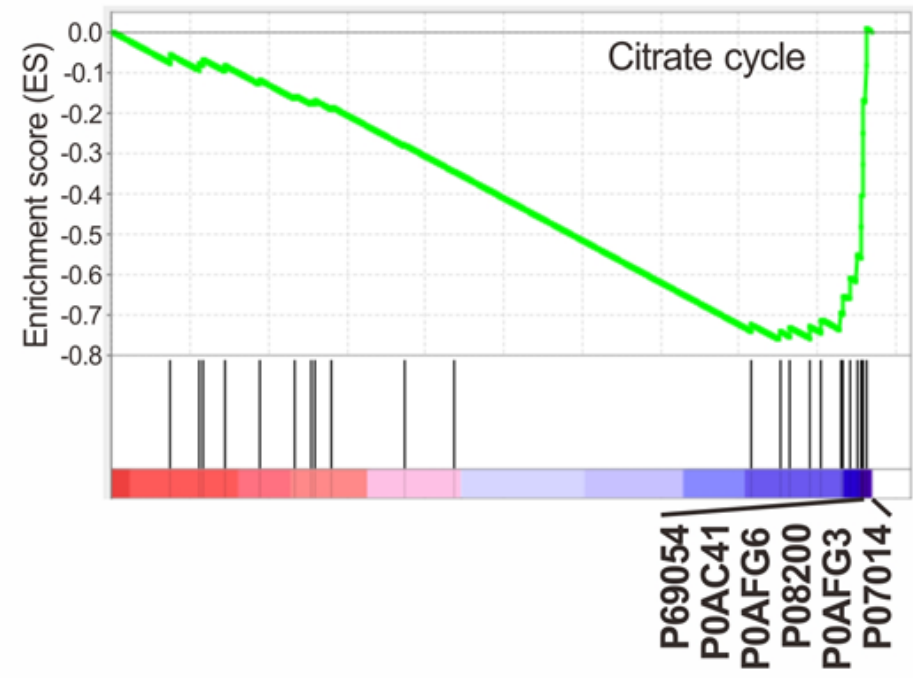

C

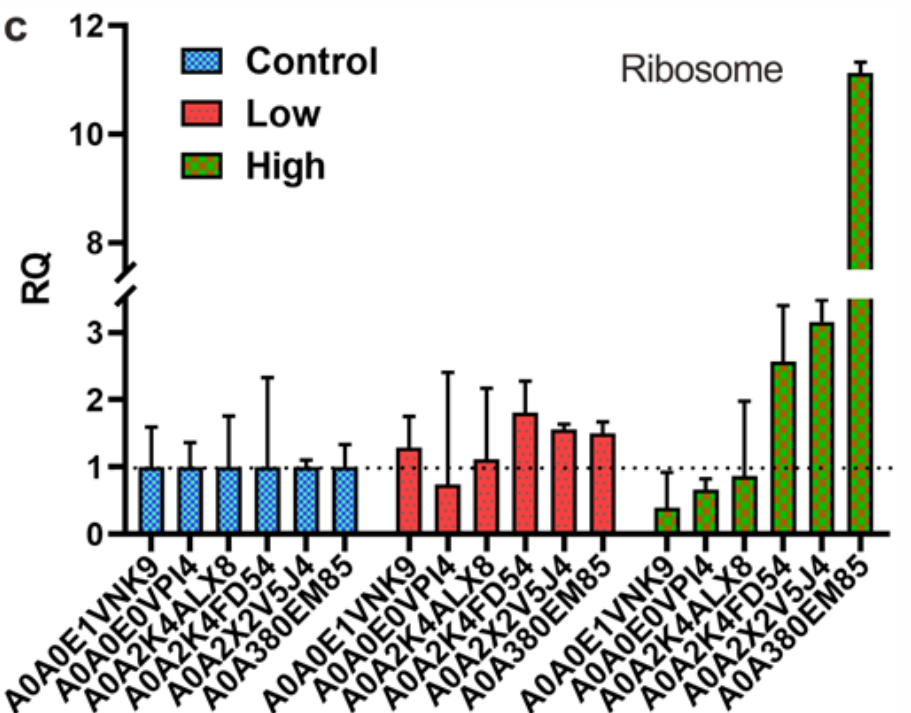

d

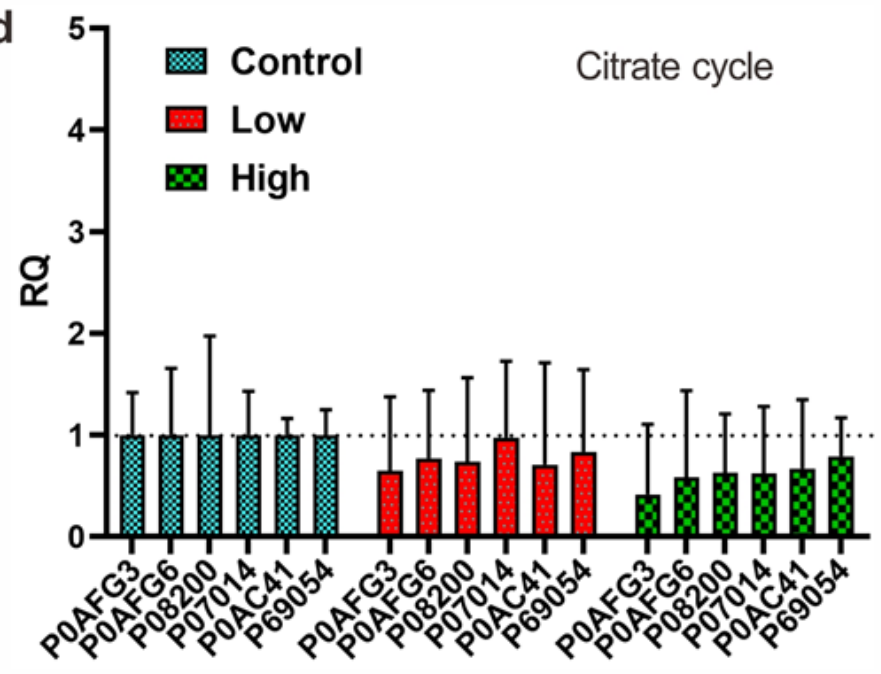

Figure 6

Six significantly different proteins in ribosome and citrate cycle. Identification of top candidate gene sets enriched in ribosome (a) and citrate cycle (b) by GSEA. Proteins in each subset of ribosome and citrate cycle were ranked by GSEA based on their differential expression level. Whether a pre-specified pathway is significantly over-represented towards the top or bottom of the ranked gene list in each subset of ribosome and citrate cycle was evaluated using the enrichment score (green line). Black vertical lines mark positions where members of a particular pathway appear in the ranked list of genes. Proteins that contributed most to the enrichment score were listed below the plot. RT-qPCR results of the corresponding genes in ribosome (c) and citrate cycle (d). 
a
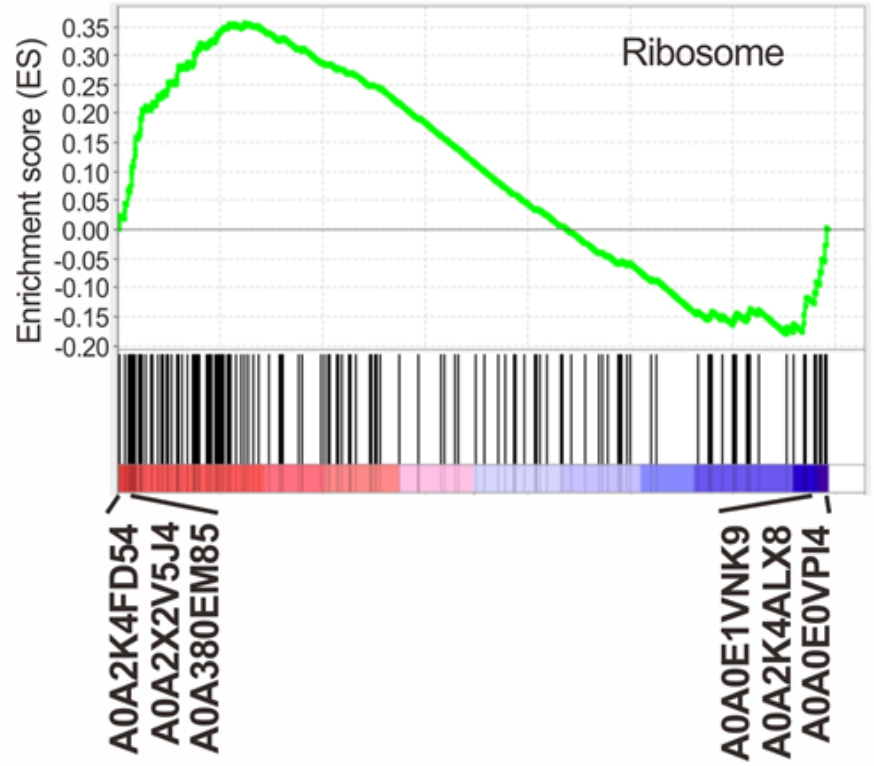

C

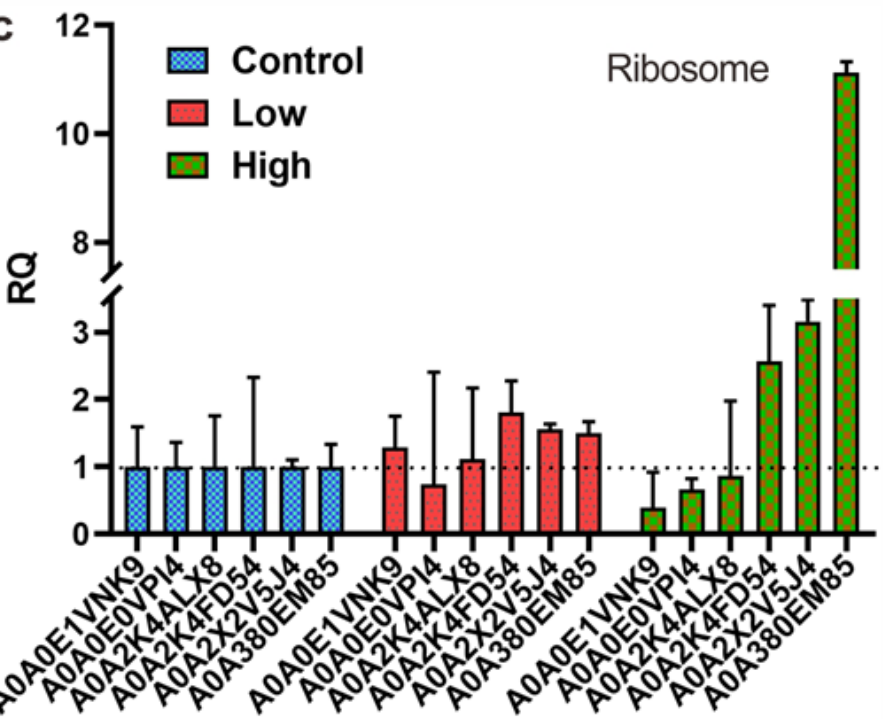

b Gene

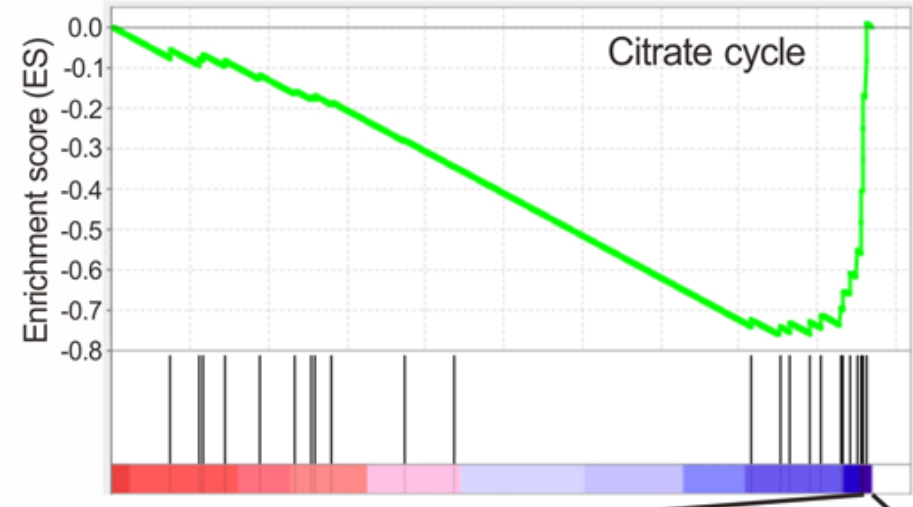

둥요뭉

넝어원

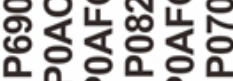

d

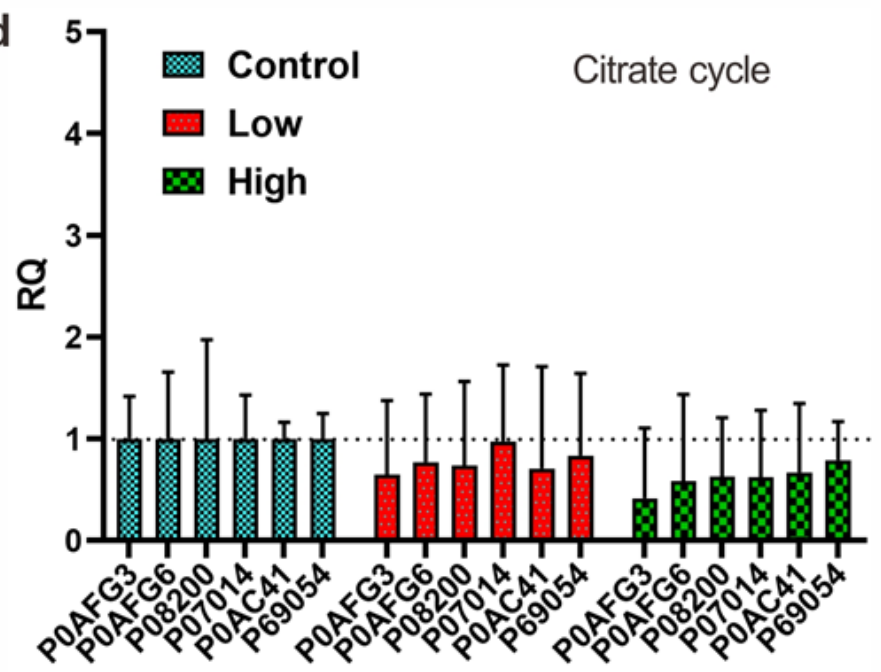

Figure 6

Six significantly different proteins in ribosome and citrate cycle. Identification of top candidate gene sets enriched in ribosome (a) and citrate cycle (b) by GSEA. Proteins in each subset of ribosome and citrate cycle were ranked by GSEA based on their differential expression level. Whether a pre-specified pathway is significantly over-represented towards the top or bottom of the ranked gene list in each subset of ribosome and citrate cycle was evaluated using the enrichment score (green line). Black vertical lines mark positions where members of a particular pathway appear in the ranked list of genes. Proteins that contributed most to the enrichment score were listed below the plot. RT-qPCR results of the corresponding genes in ribosome (c) and citrate cycle (d). 
a Mixed infection

(S. aureus and

$P$. aeruginosa)

Confirm Start infection treatment

Daily topical treatment

Wound
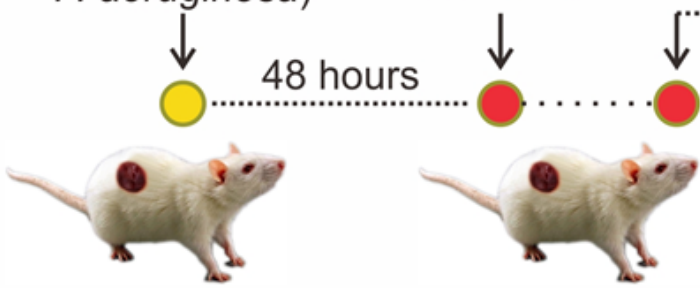

14 days

Control group: normal saline Experimental group: qCQDs Positive control group: levofloxacin healing

SD rats
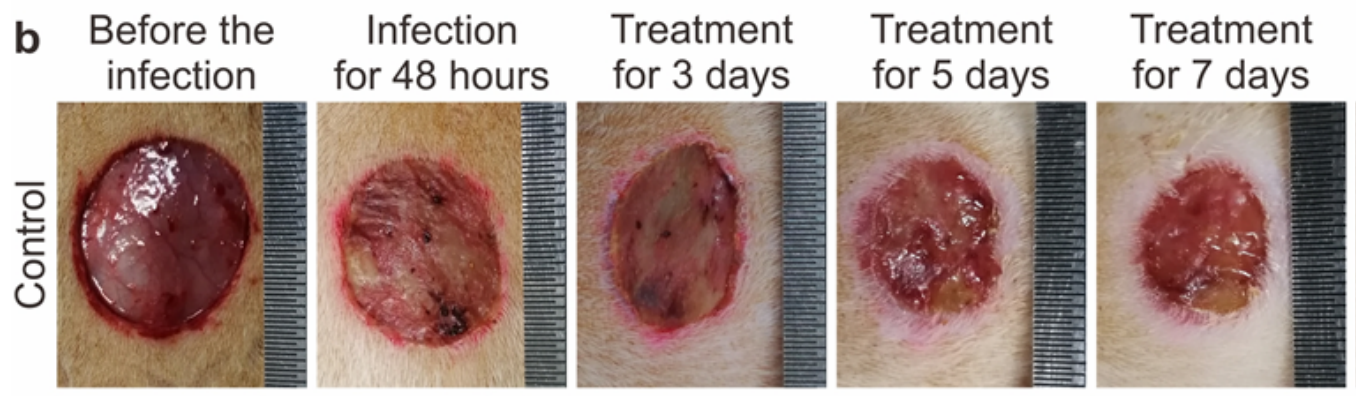

Treatment

Treatment
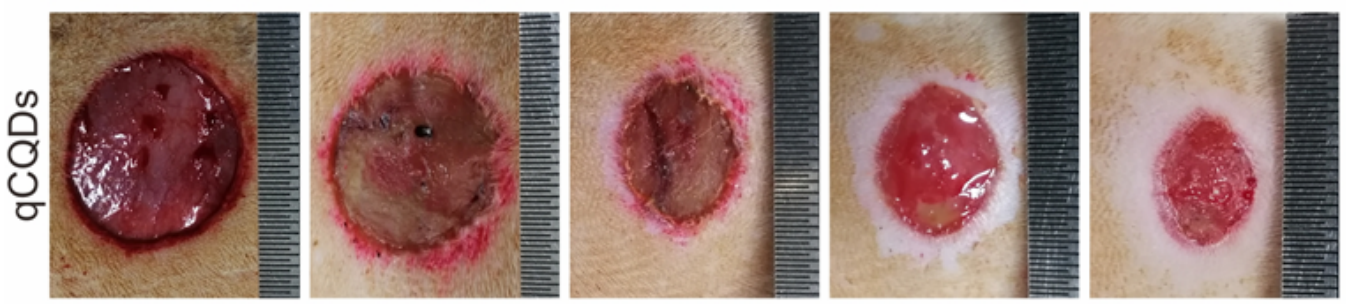
for 10 days for 14 days
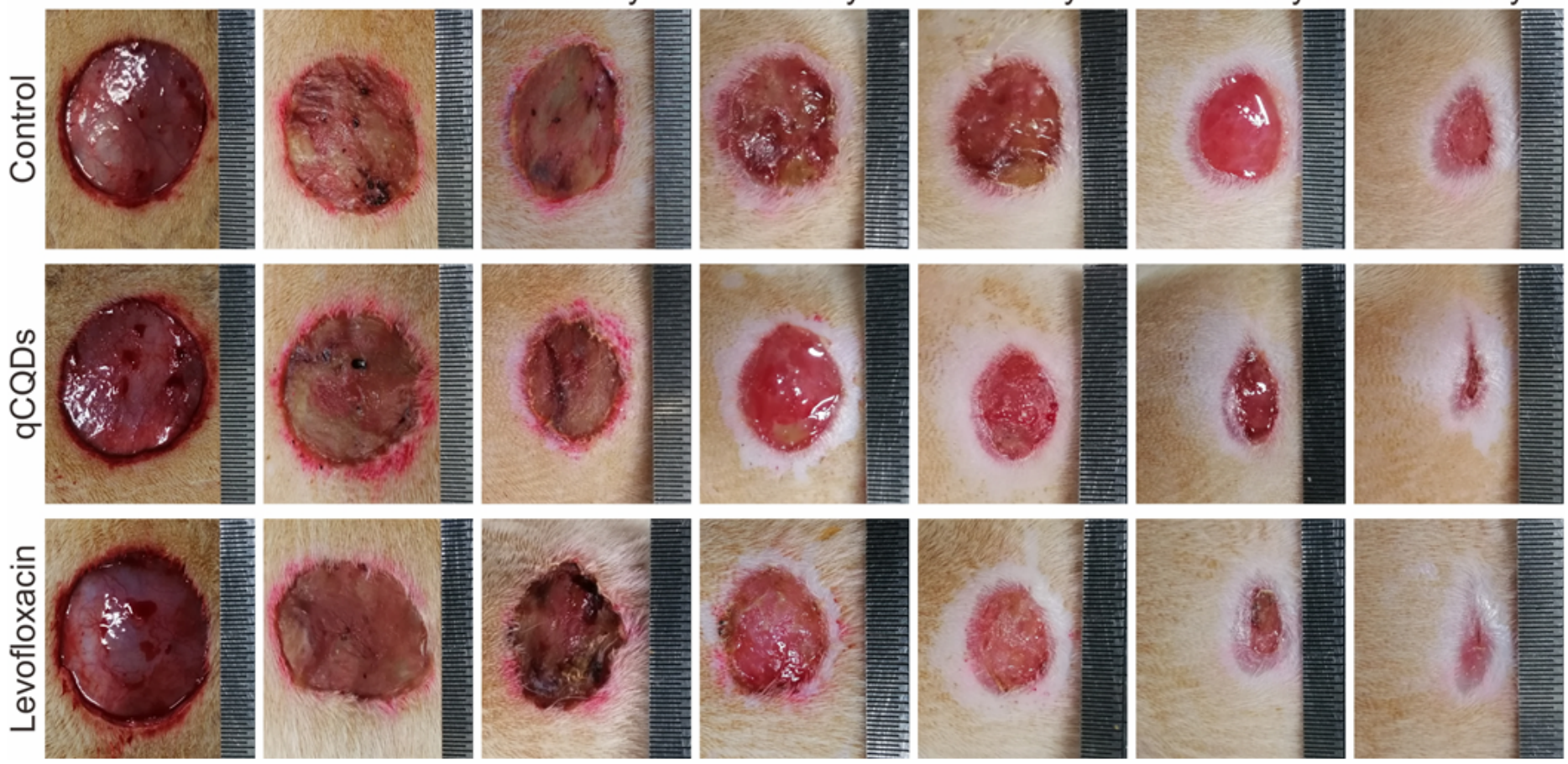

\section{Figure 7}

Treatment of qCQDs on wound infected with mixed bacteria. a Experimental process of rat trauma model with mixed infection of S. aureus and P. aeruginosa; $b$ Photographs of healing process of the infected wounds in negative control group (Conrol, normal saline), experimental group (qCQDs), and positive control group (Levofloxacin); The length of ruler is $25 \mathrm{~mm}$. 
a Mixed infection

(S. aureus and

$P$. aeruginosa)

Confirm Start infection treatment

Daily topical treatment

Wound
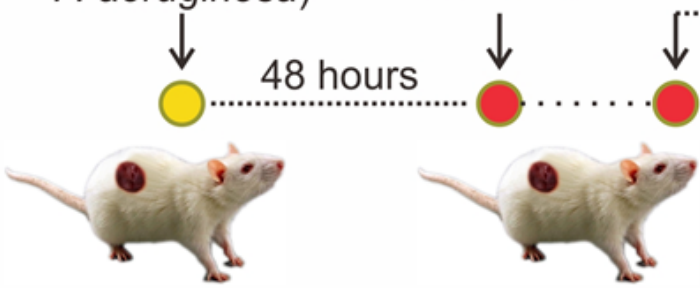

14 days

Control group: normal saline Experimental group: qCQDs Positive control group: levofloxacin healing

SD rats
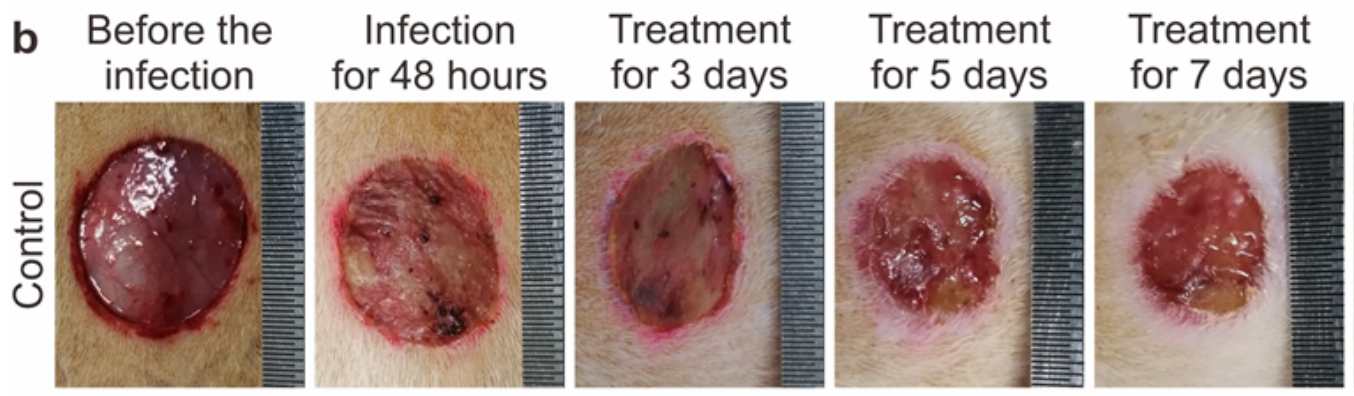

Treatment

Treatment
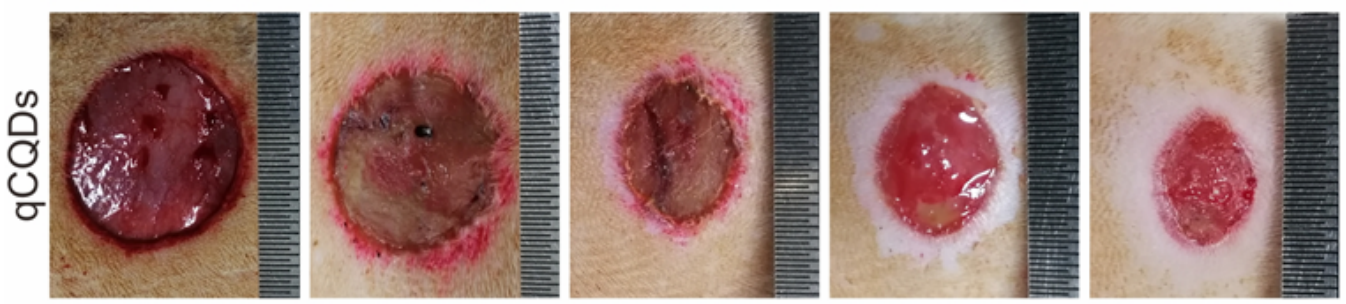
for 10 days for 14 days
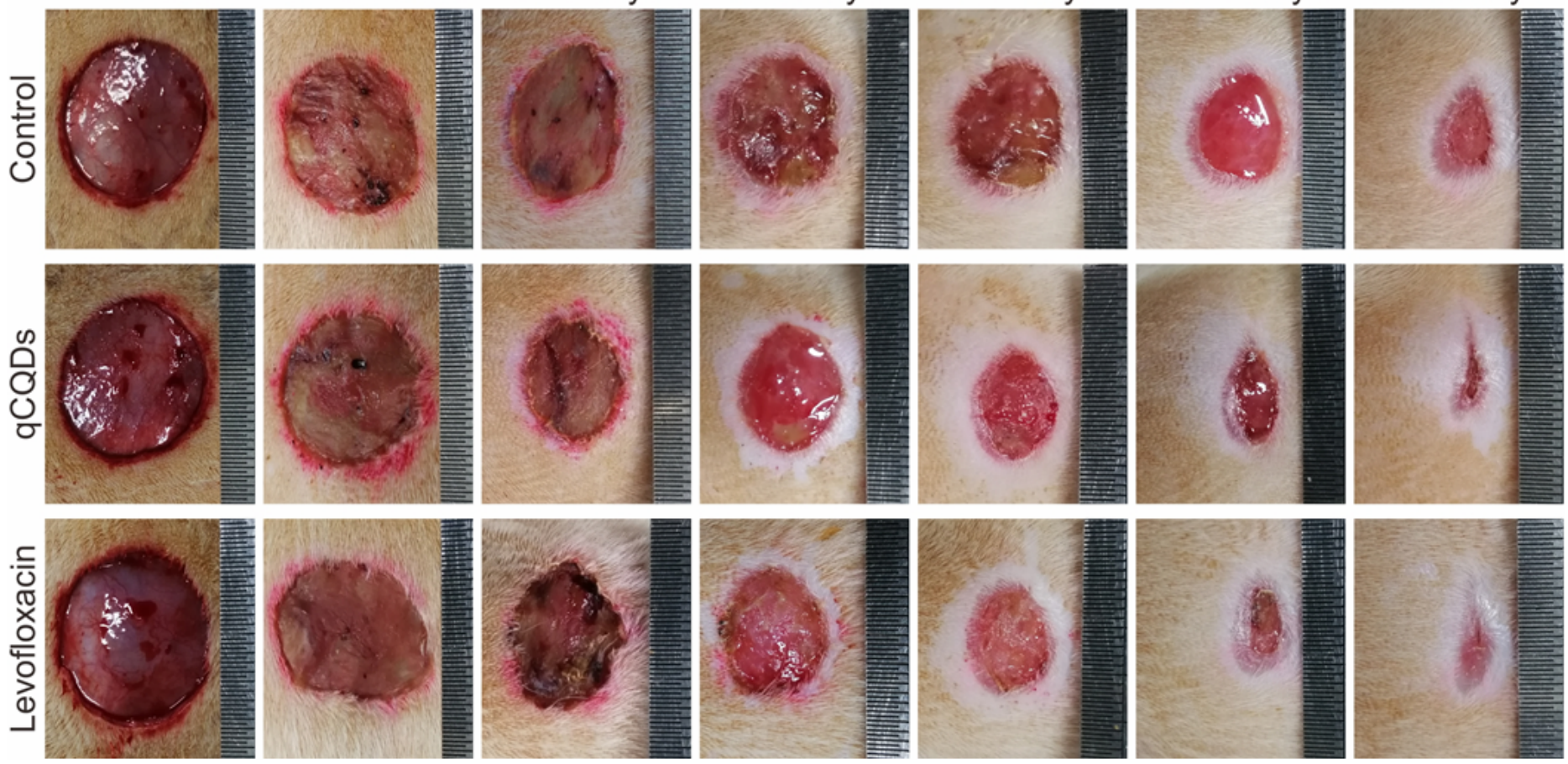

\section{Figure 7}

Treatment of qCQDs on wound infected with mixed bacteria. a Experimental process of rat trauma model with mixed infection of S. aureus and P. aeruginosa; $b$ Photographs of healing process of the infected wounds in negative control group (Conrol, normal saline), experimental group (qCQDs), and positive control group (Levofloxacin); The length of ruler is $25 \mathrm{~mm}$. 
a Mixed infection

(S. aureus and

$P$. aeruginosa)

Confirm Start infection treatment

Daily topical treatment

Wound
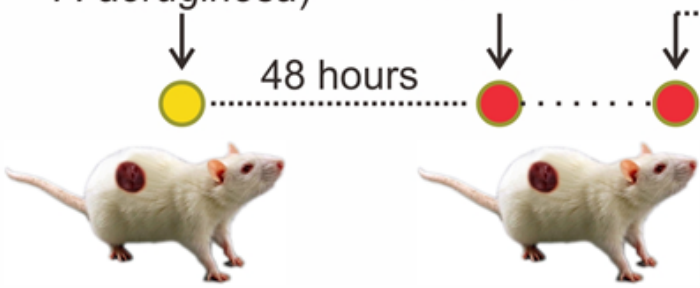

14 days

Control group: normal saline Experimental group: qCQDs Positive control group: levofloxacin healing

SD rats
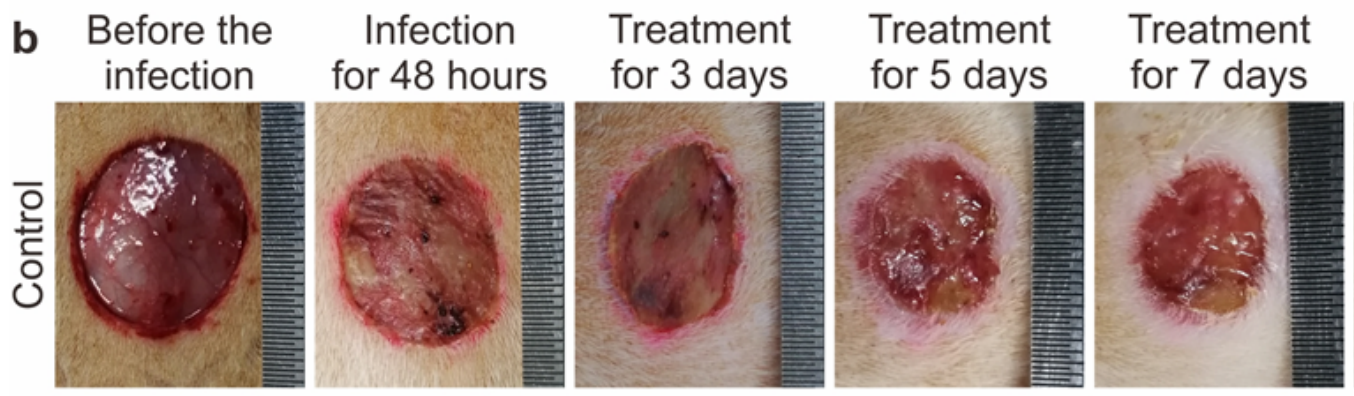

Treatment

Treatment
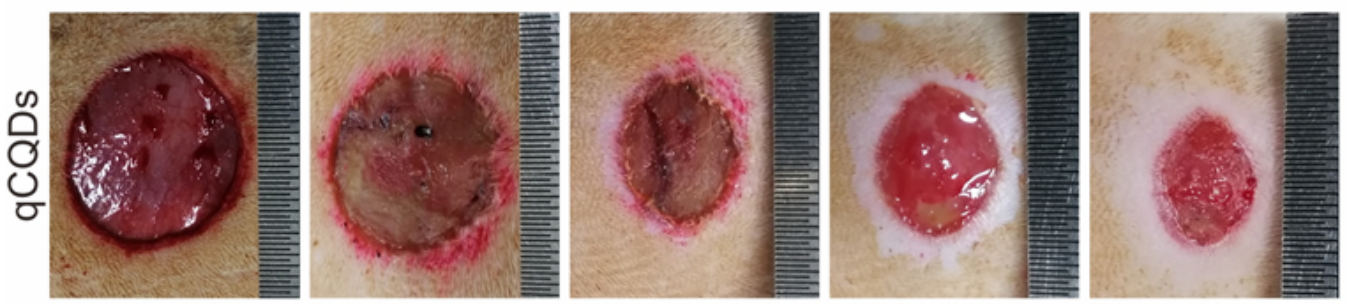
for 10 days for 14 days
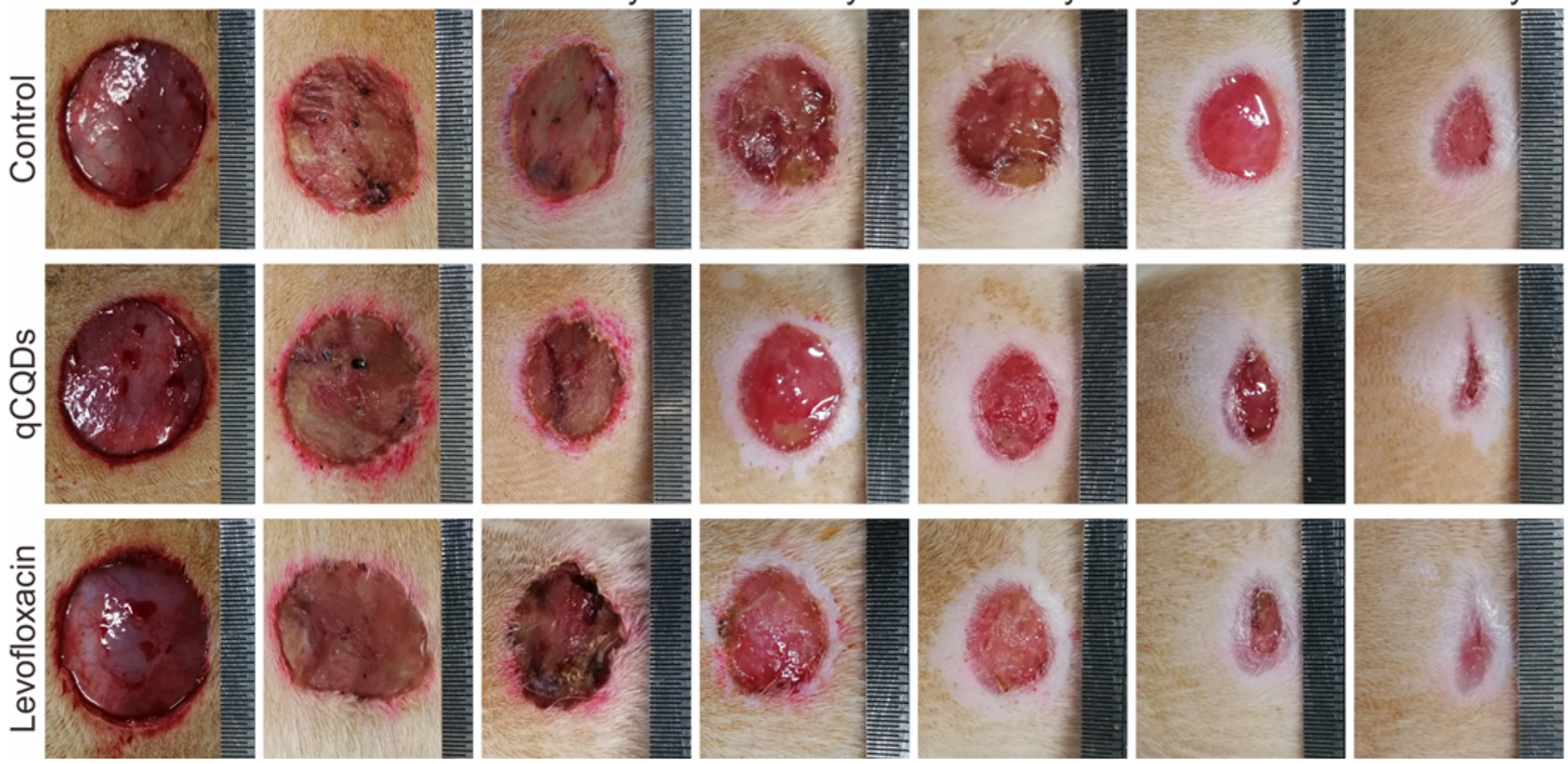

\section{Figure 7}

Treatment of qCQDs on wound infected with mixed bacteria. a Experimental process of rat trauma model with mixed infection of S. aureus and P. aeruginosa; $b$ Photographs of healing process of the infected wounds in negative control group (Conrol, normal saline), experimental group (qCQDs), and positive control group (Levofloxacin); The length of ruler is $25 \mathrm{~mm}$. 

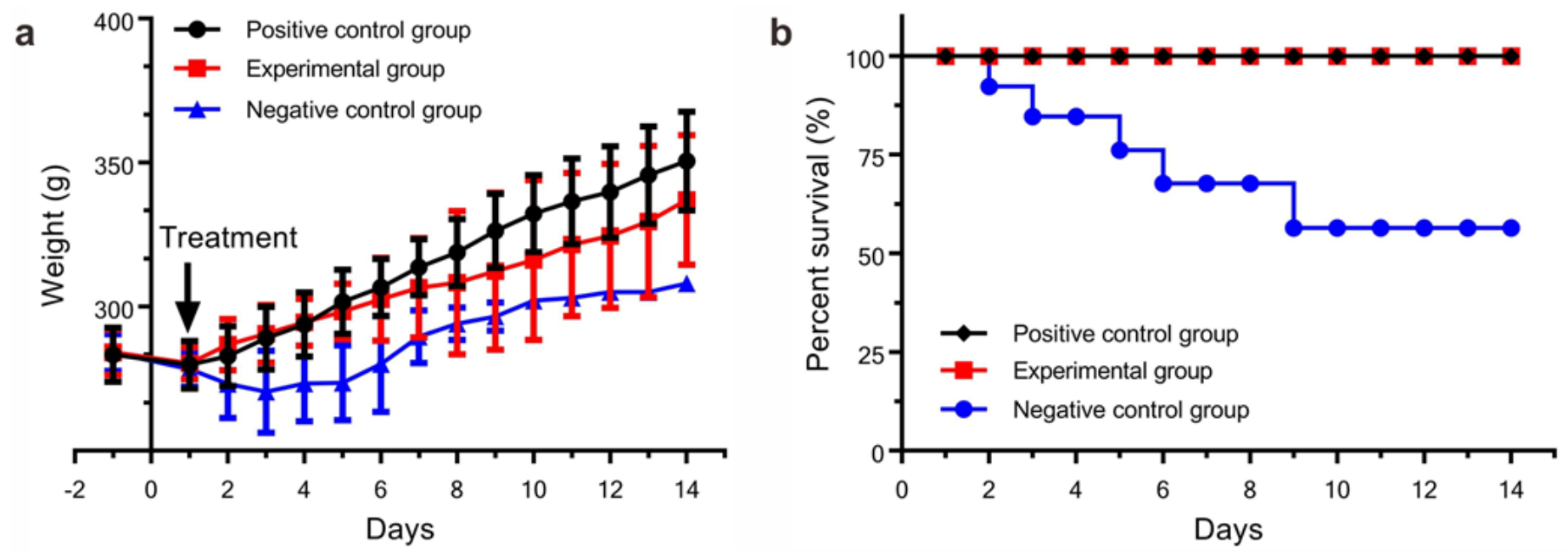

\section{c Infection for 48 hours}
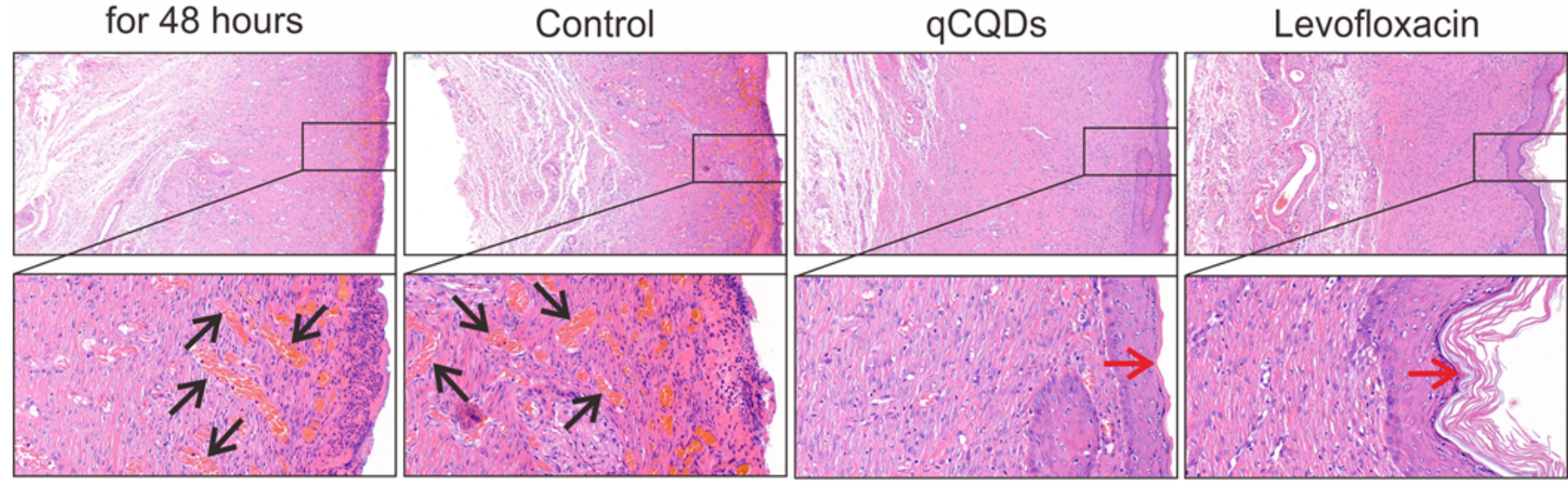

\section{Figure 8}

Antibacterial effect of qCQDs on wound infected with mixed bacteria. Weight change curve (a) and survival curve (b) of rats in negative control group (control, normal saline), experimental group (qCQDs), and positive control group (levofloxacin) during the experimental process; $\mathrm{c}$ H\&E-stained pathological sections ( $\times 100$ in first row and $\times 400$ in second row) of the middle tissue of the wounds, including infection for $48 \mathrm{~h}$ and treatment for 14 days. Black arrows and red arrows indicated blood vessels and connective tissue, respectively. Error bars represented the standard deviation of six parallel measurements. 

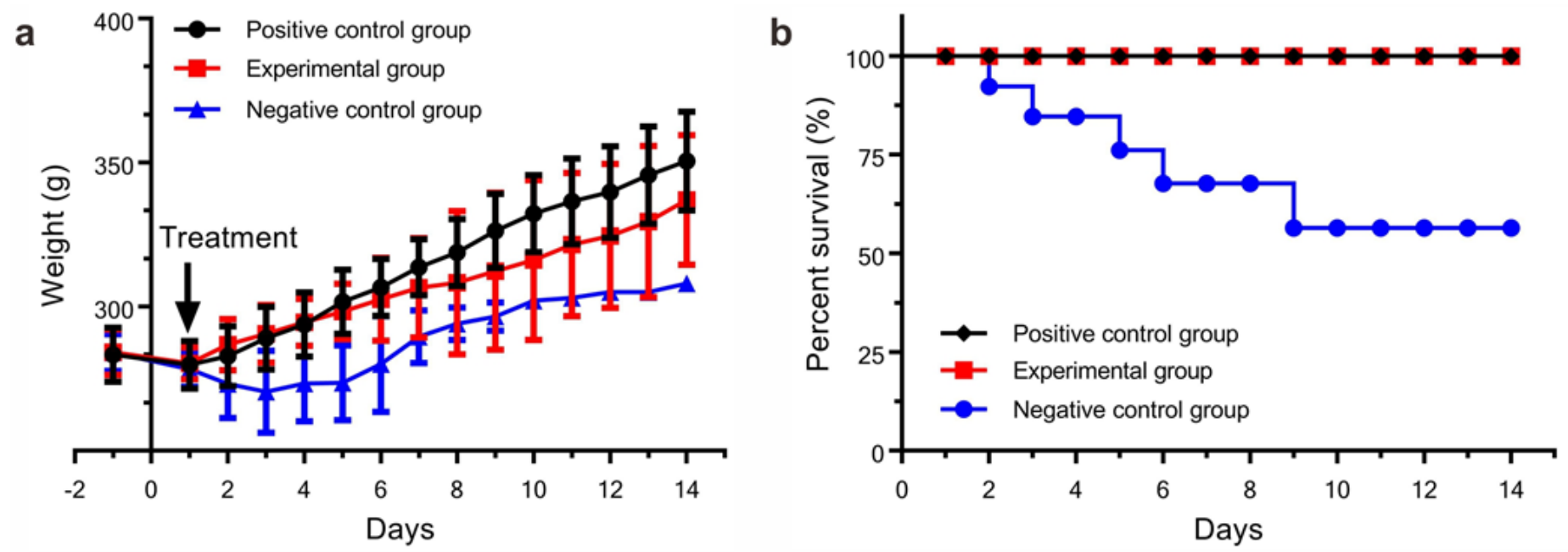

\section{c Infection for 48 hours}
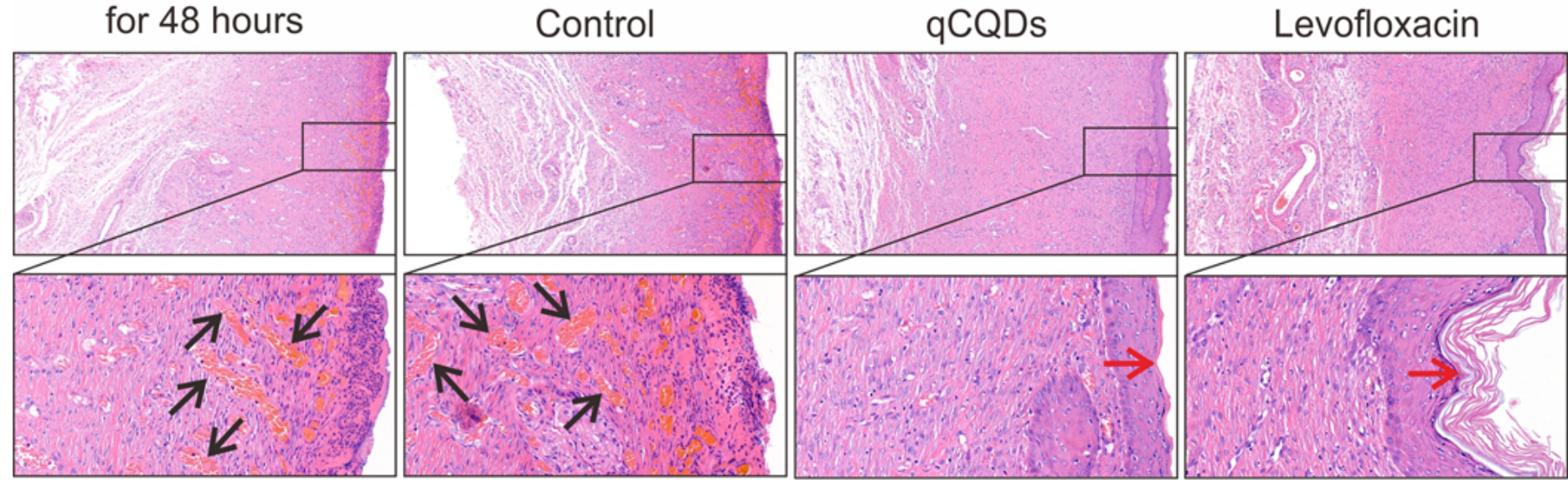

\section{Figure 8}

Antibacterial effect of qCQDs on wound infected with mixed bacteria. Weight change curve (a) and survival curve (b) of rats in negative control group (control, normal saline), experimental group (qCQDs), and positive control group (levofloxacin) during the experimental process; $\mathrm{c}$ H\&E-stained pathological sections ( $\times 100$ in first row and $\times 400$ in second row) of the middle tissue of the wounds, including infection for $48 \mathrm{~h}$ and treatment for 14 days. Black arrows and red arrows indicated blood vessels and connective tissue, respectively. Error bars represented the standard deviation of six parallel measurements. 

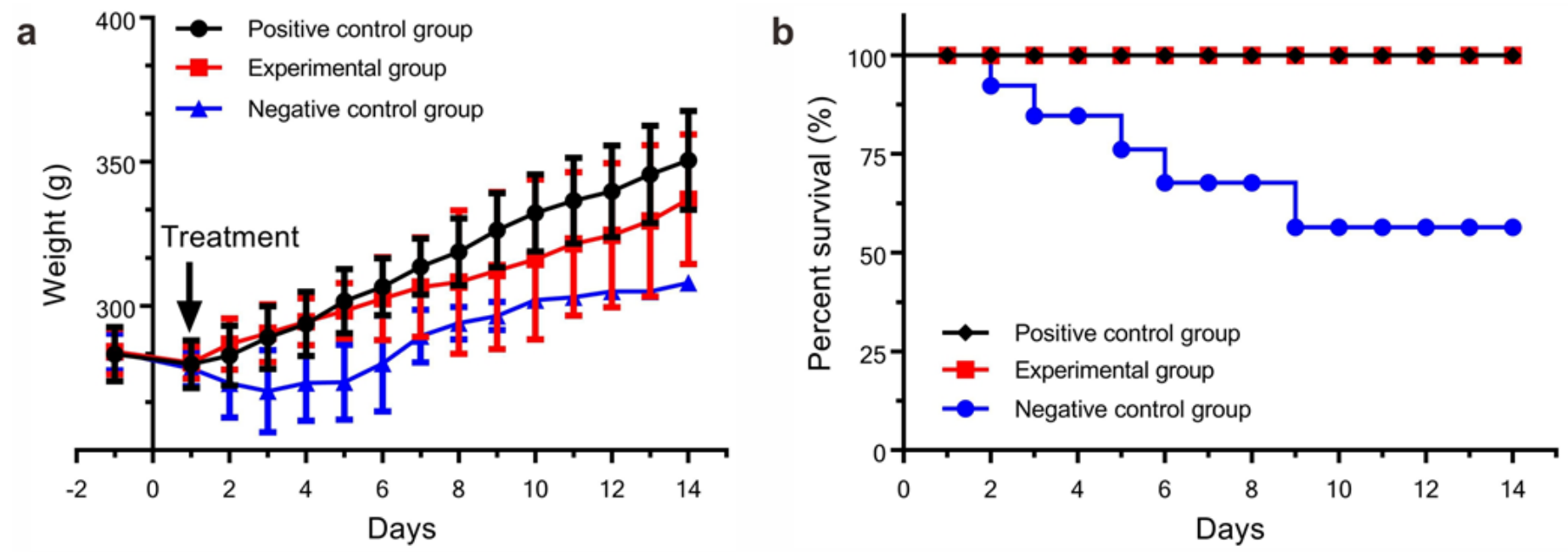

\section{c Infection for 48 hours}
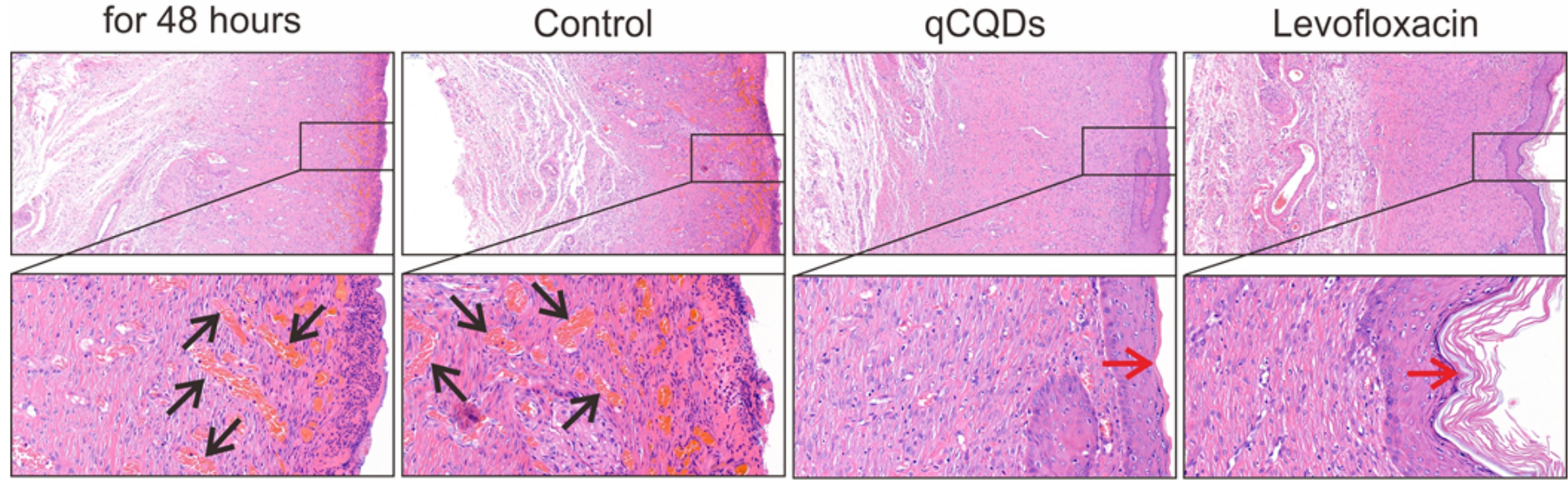

\section{Figure 8}

Antibacterial effect of qCQDs on wound infected with mixed bacteria. Weight change curve (a) and survival curve (b) of rats in negative control group (control, normal saline), experimental group (qCQDs), and positive control group (levofloxacin) during the experimental process; $\mathrm{c}$ H\&E-stained pathological sections ( $\times 100$ in first row and $\times 400$ in second row) of the middle tissue of the wounds, including infection for $48 \mathrm{~h}$ and treatment for 14 days. Black arrows and red arrows indicated blood vessels and connective tissue, respectively. Error bars represented the standard deviation of six parallel measurements. 


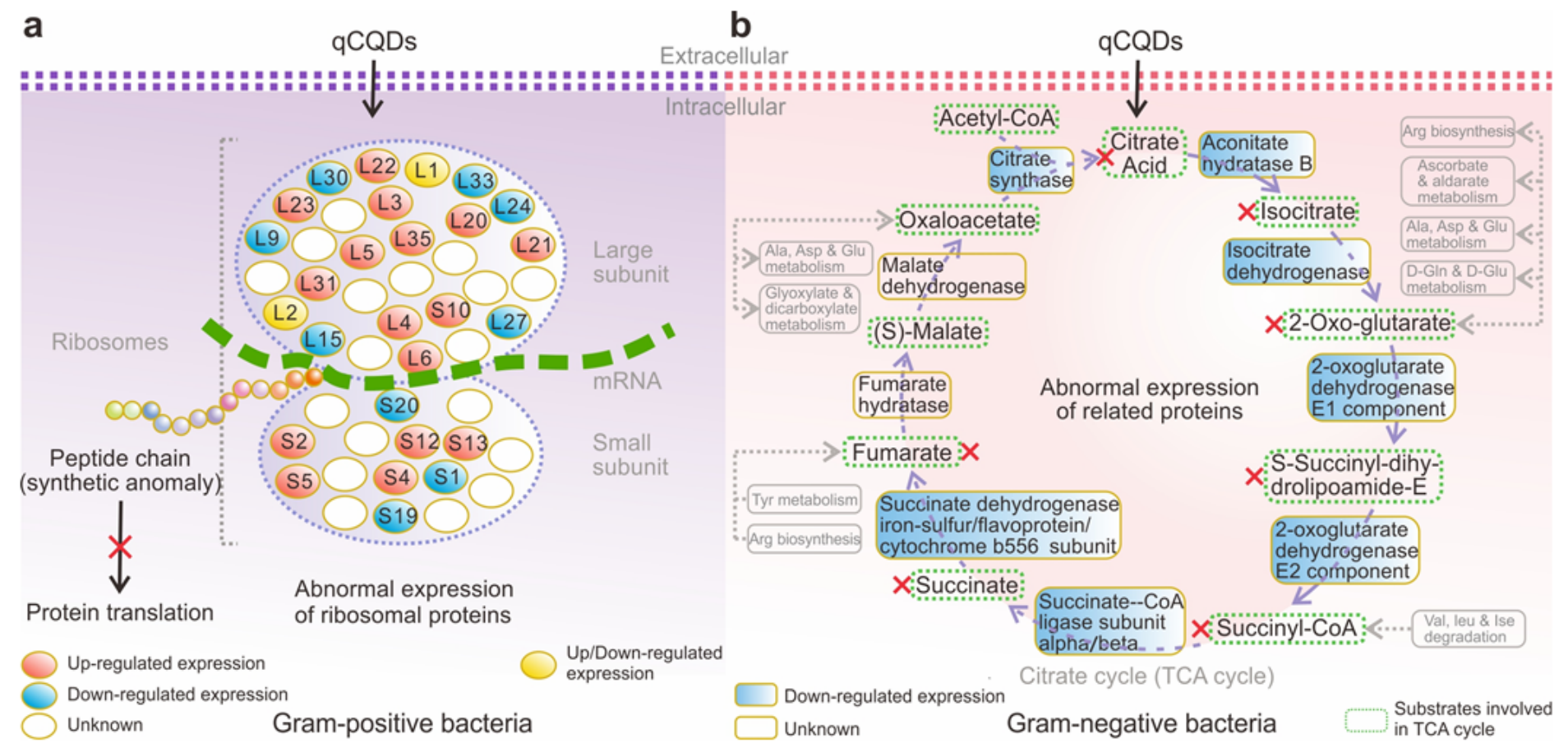

\section{Figure 9}

Schematic diagram of qCQDs against bacteria. a Ribosomes in gram-positive bacteria. b Citrate cycle in gram-negative bacteria.

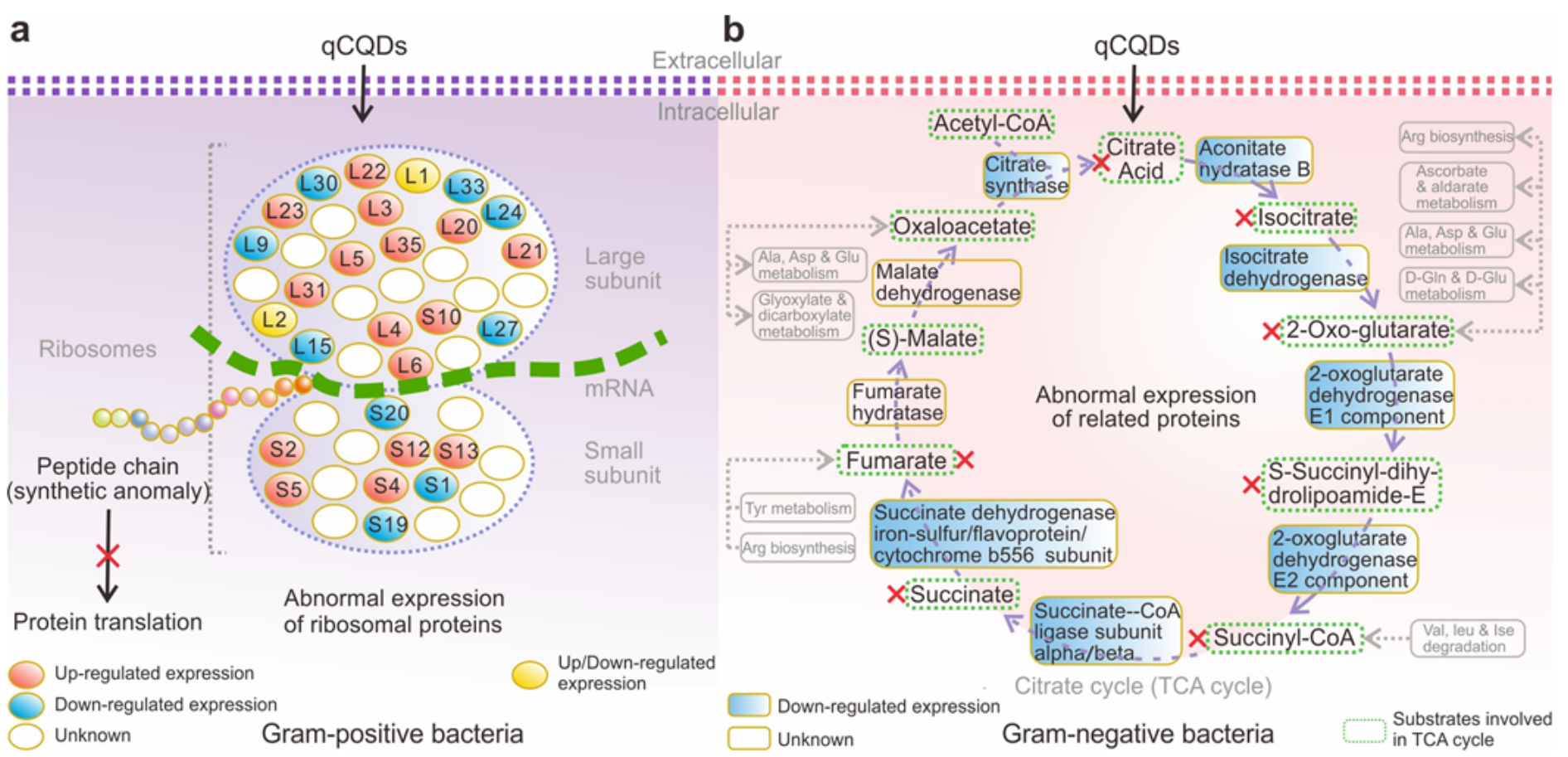

\section{Figure 9}

Schematic diagram of qCQDs against bacteria. a Ribosomes in gram-positive bacteria. b Citrate cycle in gram-negative bacteria. 


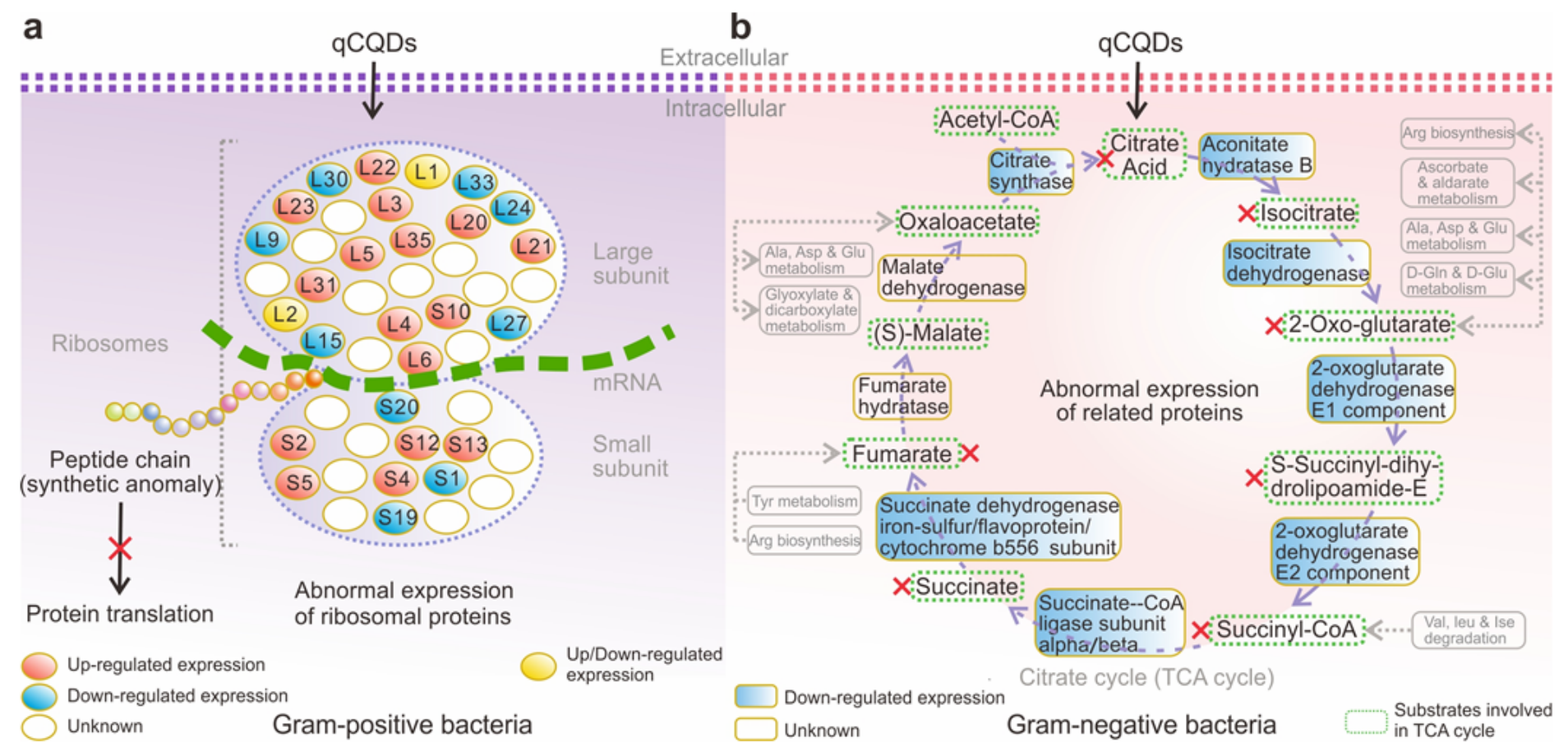

\section{Figure 9}

Schematic diagram of qCQDs against bacteria. a Ribosomes in gram-positive bacteria. b Citrate cycle in gram-negative bacteria.

\section{Supplementary Files}

This is a list of supplementary files associated with this preprint. Click to download.

- Supplementaryinformation.doc

- Supplementaryinformation.doc

- Supplementaryinformation.doc 